\title{
Análise de Comportamento de Consumidores por Agrupamento de Sessões para Avaliar o Consumo de Recursos Computacionais e de Comunicação
}

Dissertação apresentada à Escola Politécnica da Universidade de São Paulo para a obtenção do Título de Mestre em Engenharia 


\section{Análise de Comportamento de Consumidores por Agrupamento de Sessões para Avaliar o Consumo de Recursos Computacionais e de Comunicação}

Dissertação apresentada à Escola Politécnica da Universidade de São Paulo para a obtenção do Título de Mestre em Engenharia

Área de concentração: Sistemas Digitais

Orientador: Prof. Dr. Wilson Vicente Ruggiero 
Autorizo a reprodução e divulgação total ou parcial deste trabalho, por qualquer meio convencional ou eletrônico, para fins de estudo ou pesquisa, desde que citada a fonte.

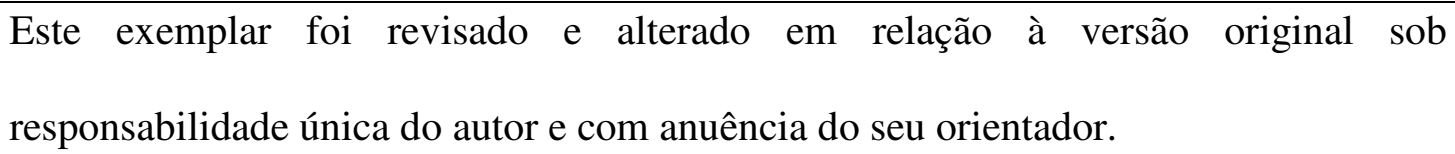

São Paulo, 22 de Outubro de 2006

Assinatura do Autor

Assinatura do Orientador

\section{FICHA CATALOGRÁFICA}

Franco, Eduardo Vidal

Análise de comportamento de consumidores por agrupamento de sessões para avaliar o consumo de recursos computacionais e de comunicação / E.V. Franco. -São Paulo 2006. Edição Revisada

$109 \mathrm{p}$.

Dissertação (Mestrado) - Escola Politécnica da Universidade de São Paulo. Departamento de Computação e Sistemas Digitais.

1. Consumidor 2. Negócio 3. World Wide Web I. Universidade de São Paulo. Escola Politécnica. Departamento de Computação e Sistemas Digitais. II. t 
Aos meus pais que sempre apoiaram a minha educação das minhas primeiras palavras à elaboração deste trabalho. 


\section{AGRADECIMENTOS}

Ao meu orientador, Prof. Dr. Wilson Ruggiero, pela constante ajuda e motivação. Pelo apoio fundamental à execução desta pesquisa, paciência em diversos momentos e orientação na organização de idéias difusas em uma dissertação de mestrado.

Á minha esposa Patrícia Caixeta da Fonseca Franco que me apoiou e assistiu mesmo tendo sido privada da minha companhia nos momentos em que desenvolvia este trabalho.

À professora Graça Bressan que me ajudou a desenvolver o trabalho que foi o embrião desta dissertação e minha principal motivação a escrever este texto.

Aos amigos Álisson Veras, Oscar Vilcachagua, Gabriel Narváez e Luis Alves Ferreira Filho que já tendo trilhado este caminho me auxiliaram e me mantiveram motivado apesar de todas as dificuldades encontradas na elaboração deste trabalho.

Finalmente gostaria de agradecer aos demais alunos, professores e funcionários da Escola Politécnica da Universidade de São Paulo que sempre contribuíram com conselhos sábios e apoios necessários na minha vida pessoal, profissional e acadêmica. 


\section{RESUMO}

O presente trabalho propõe uma nova análise de negócio para avaliar a importância de classes de consumidores para o modelo de negócio de aplicações de negócio eletrônico para a WWW. Esta avaliação é feita através do agrupamento dos consumidores em classes e da medição da receita gerada e do consumo de recursos de cada uma das classes. Este trabalho também propõe a modelagem e a implementação de uma ferramenta para a medição do consumo de recursos computacionais de cada uma das classes de consumidores.

Para medir o consumo de recursos foi criada uma nova técnica baseada na proposta por Menasce et al. (1999).que permite a medição do consumo de recursos de servidores WWW através da monitoração de uma aplicação de negócio eletrônica durante a operação ou através da extração dos dados necessários para medir o consumo de recursos de arquivos de log.

Para realizar a medição do consumo e para validar a técnica proposta foi projetada e construída uma ferramenta que, uma vez passada a forma de identificação de classes de consumidores e a navegação desses consumidores em arquivos de logs ou em banco de dados, permite contabilizar os recursos computacionais consumidos pelos mesmos.

A ferramenta e o seu correto funcionamento foram validados através da aplicação da ferramenta sobre dados de navegação simulados para grupos pré-definidos de consumidores cujo resultado obtido foi comparado ao resultado esperado. 


\section{ABSTRACT}

This work describes a new business analysis to evaluate the importance of individual customer classes to the business model of a web-based electronic business application. This can be accomplished by breaking the customer base into classes and measuring the monetary income and the resource consumption for each class. This work also proposes a software tool modeling to measure the computer resource consumption for each customer class and each individual application module.

To measure the resource consumption, a new technique based on the one proposed by Menasce et al. (1999) was created to allow the proper breakdown of the resource consumption by the customers in a WWW server through monitoring the business software application during its operation or through the extraction of the data needed to measure the resource consumption from the log files generated by the WWW servers hosting the application.

To perform the measurement and to validate the proposed technique, it was designed and built a software tool that is able to evaluate the resource consumption of a customer group when it receives the way to identify the group of a customer and the navigation of these customers in the form of a navigation database or in a log file.

This software tool was validated by applying it over some simulated customer navigating data based on the expected behavior of some predefined customer groups and comparing the data obtained with the expected result. 


\section{LISTA DE FIGURAS}

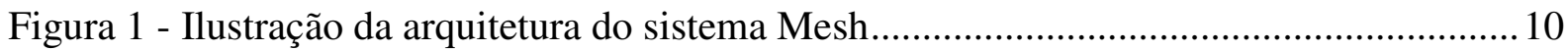

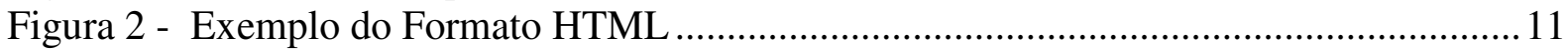

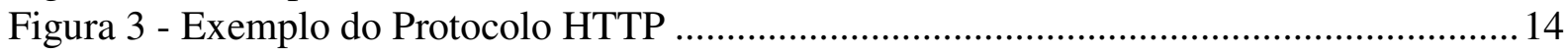

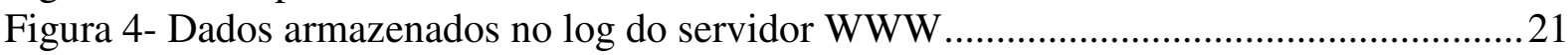

Figura 5 - Classificação de 11 Modelos de Negócio conforme públicada em Timmers(1998)28

Figura 6 - Arquitetura de Referência para uma Aplicação Ativa de Comércio Eletrônico.......38

Figura 7 - Relacionamento entre Modelo, Processo, Função e Passo de Negócio....................47

Figura 8 - Modelagem através de seqüência de requisições................................................60

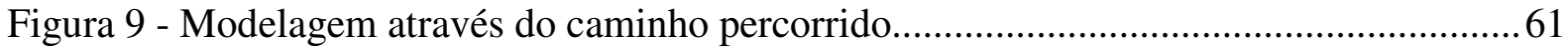

Figura 10 - Modelagem através da probabilidade de transição ..............................................61

Figura 11 - Diagrama CBMG de um site de comércio eletrônico hipotético............................63

Figura 12 - Processamento dos dados para a obtenção do CBMG .........................................66

Figura 13 - Diagrama de Classe de Implementação da Ferramenta Proposta ...........................84 


\section{LISTA DE TABELAS}

Tabela 1- Informações armazenadas em um log de servidor WWW ...................................21

Tabela 2 - Descrição dos modelos de negócio estudados por Timmers(1998)........................29

Tabela 3 - Decomposição dos modelos de negócio quanto ao valor ..........................................34

Tabela 4 - Decomposição dos modelos de negócio quanto ao faturamento ..............................34

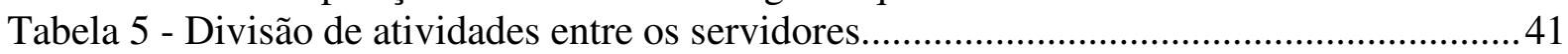

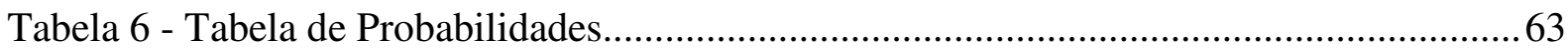

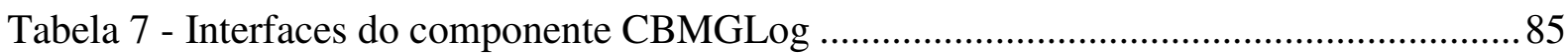

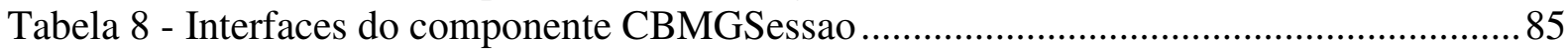

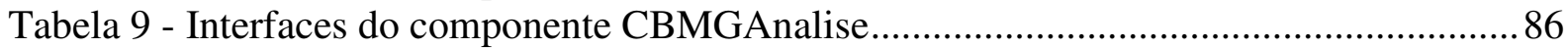

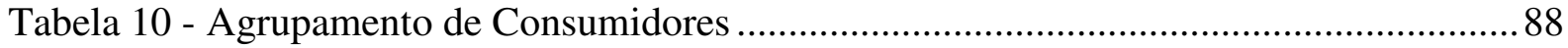

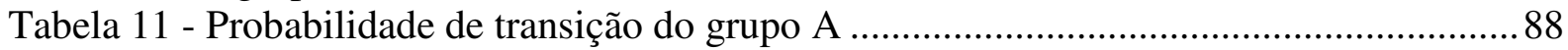

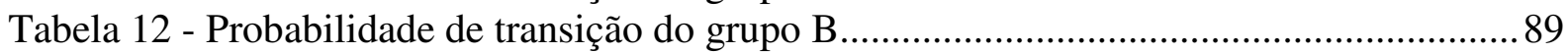

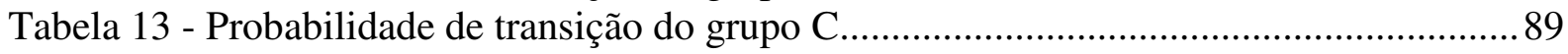

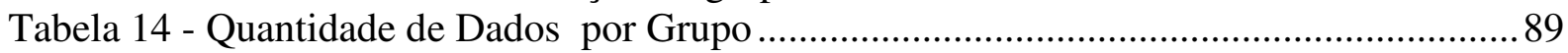

Tabela 15 - Probabilidade de transição combinada ................................................................... 91

Tabela 16 - Probabilidade de transição combinada esperada ..............................................92

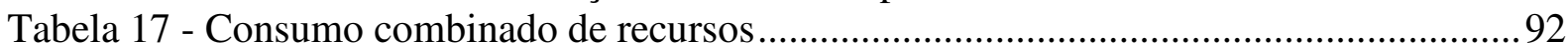

Tabela 18 - Número de médio de requisições por sessão para cada grupo NMR …….............94

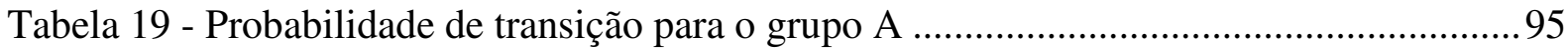

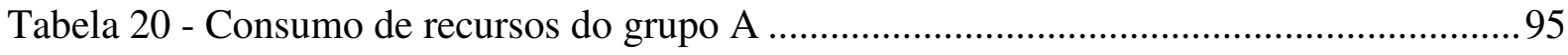

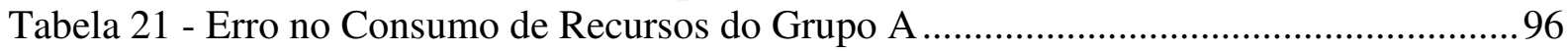

Tabela 22 - Probabilidade de transição para o grupo A ….....................................................96

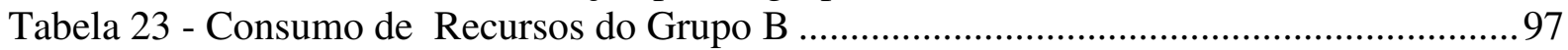

Tabela 24 - Erro no Consumo de Recursos do Grupo B ...................................................... 97

Tabela 25 - Probabilidade de transição para o grupo C..........................................................98

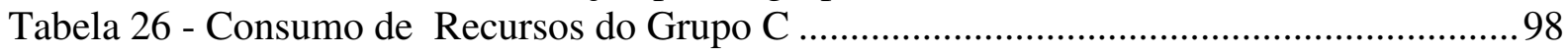

Tabela 27 - Erro no Consumo de Recursos do Grupo C ....................................................... 98

Tabela 28 - Probabilidade de Realização de Trasação por Grupo.......................................... 100

Tabela 29 - Valor Médio de Transação por Sessão do Grupo ................................................. 101

Tabela 30 - Consumo de Recursos por Requisição por Grupo.............................................. 101

Tabela 31 - Faturamento e Consumo de Rercursos por Grupo ............................................ 102

Tabela 32 - Comparação da Sessão média de cada grupo com a Sessão média.......................102 


\section{LISTA DE ABREVIATURAS E SIGLAS}

\begin{tabular}{|c|c|}
\hline AJAX & - Asynchronous JavaScript and XML \\
\hline ARPANET & - Advanced Research Program Agency Network \\
\hline ASP & - Active Server Pages \\
\hline $\mathrm{B} 2 \mathrm{~B}$ & - Business to Business \\
\hline $\mathrm{B} 2 \mathrm{C}$ & - Business to Consumer \\
\hline BBS & - Bulletin Board System \\
\hline $\mathrm{BI}$ & - Business Intelligence \\
\hline CBMG & - Customer Behavior Model Graph \\
\hline CERN & - Conseil Européen pour le Recherche Nucléaire \\
\hline CGI & - Common Gateway Interface \\
\hline CRM & - Customer Relationship Management \\
\hline CSS & - Cascading Style Sheet \\
\hline CVM & - Customer Visit Model \\
\hline DOD & - Department of Defense \\
\hline EDI & - Electronic Data Interchange \\
\hline FTP & - File Transfer Protocol \\
\hline IP & - Internet Protocol \\
\hline IIS & - Internet Information Server \\
\hline $\mathrm{J} 2 \mathrm{EE}$ & - Java 2 Enterprise Edition \\
\hline HTML & - Hypertext Markup Language \\
\hline HTTP & - Hypertext Transfer Protocol \\
\hline MODEM & - Modulator / Demodulator \\
\hline NCSA & - National Center for Supercomputer Application \\
\hline
\end{tabular}




\begin{tabular}{|c|c|c|}
\hline PHP & - & $\begin{array}{l}\text { Personal Home Page Tools, posteriormente alterado para: } \\
\text { PHP: Hypertext Pre-processor }\end{array}$ \\
\hline PERL & - & Practical Extraction \& Report Language \\
\hline P3P & - & Platform for Privacy Preferences Project \\
\hline QoS & - & Quality of Service \\
\hline SGML & - & Standard Generalized Markup Language \\
\hline TCP & - & Transmission Control Protocol \\
\hline RFC & - & Request For Comments \\
\hline UCLA & - & University of California in Los Angeles \\
\hline UCSB & - & University of California in Santa Barbara \\
\hline UUTAH & - & University of Utah \\
\hline URI & - & Universal Resource Identifier \\
\hline URL & - & Uniform Resource Locators \\
\hline VPN & - & Virtual Private Network \\
\hline SGML & - & Standard Generalized Markup Language \\
\hline SQL & - & Structured Query Language \\
\hline SRI & - & Stanford Research Institute \\
\hline SSL & - & Secure Sockets Layer \\
\hline TLS & - & Transport Layer Security \\
\hline WWW & - & World Wide Web \\
\hline W3C & - & World Wide Web Consortium \\
\hline XML & - & Extensible Markup Language \\
\hline
\end{tabular}




\section{SUMÁRIO}

1 INTRODUÇÃO.

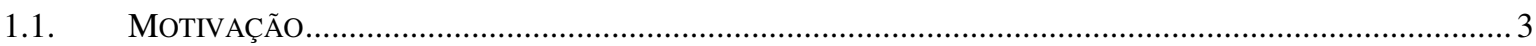

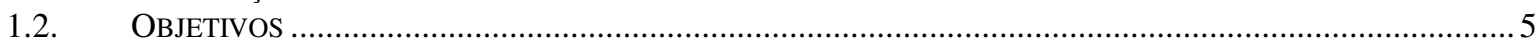

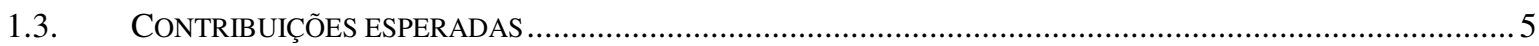

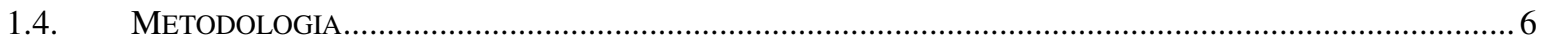

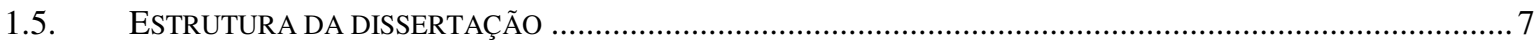

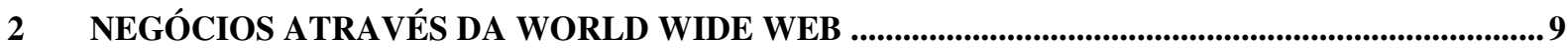

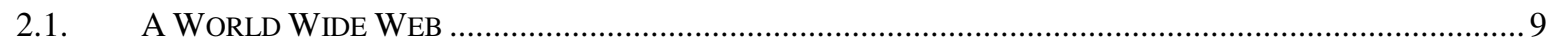

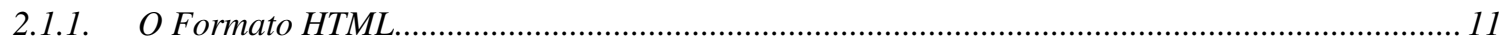

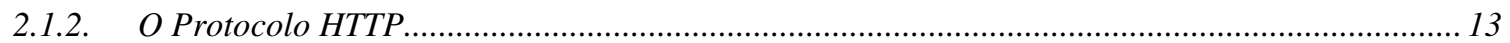

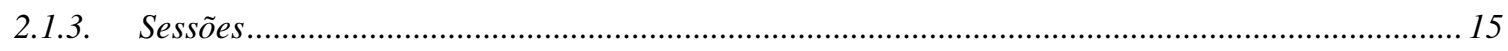

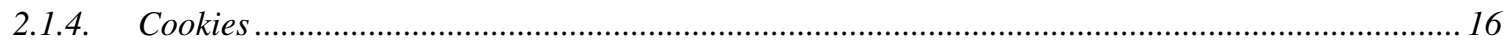

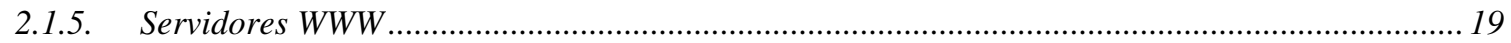

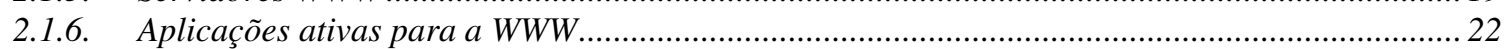

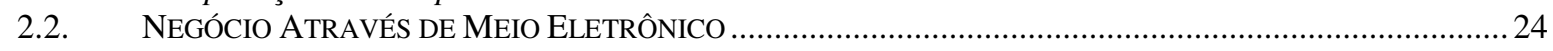

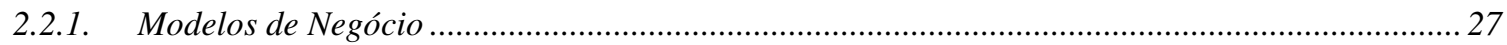

2.2.2. Decomposição e comparação de modelos de negócio...................................................................... 30

2.2.3. Decomposição dos modelos de negócio propostos por Timmers ………………………….............. 33

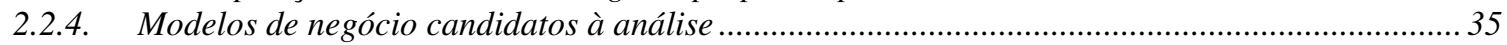

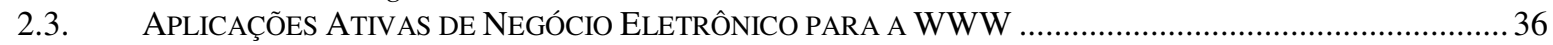

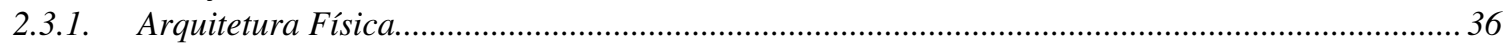

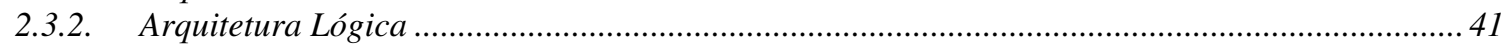

2.3.3. Estudo de caso: Funçães de Negócio de uma aplicação de comércio eletrônico ............................ 43

2.3.4. Mapeamento de funções de negócio em uma aplicação de comércio eletrônico ............................. 46

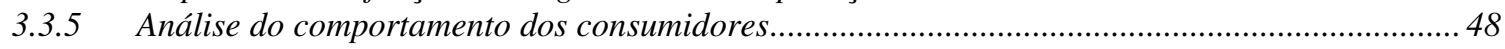

3 MODELAGEM DO COMPORTAMENTO DE CONSUMIDORES ....................................................50

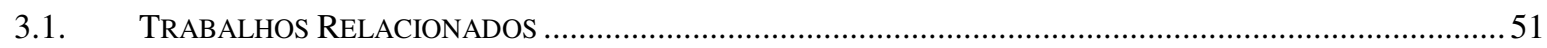

3.1.1. Uma metodologia para Caracterização de Carga para Sites de Comércio Eletrônico .................. 51

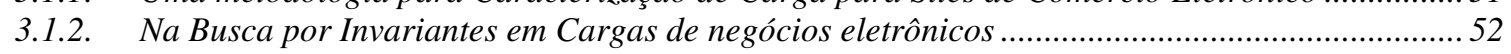

3.1.3. Controle de Sobrecarga Baseado em Sessões para Servidores com Suporte à qualidade de

serviço. 52

3.1.4. Caracterização Fractal de Cargas em Aplicações para a Web .......................................................5

3.1.5. Descoberta e Análise Inteligente da Composição do Tráfego de Usuários Web ..............................53

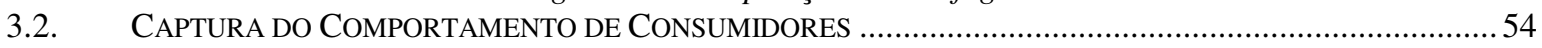

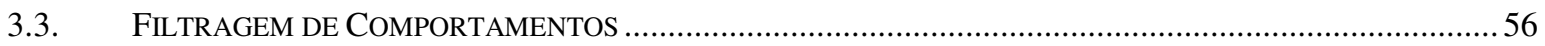

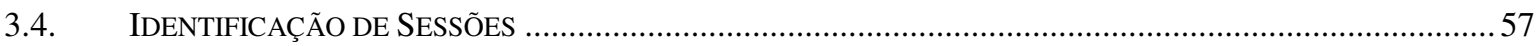

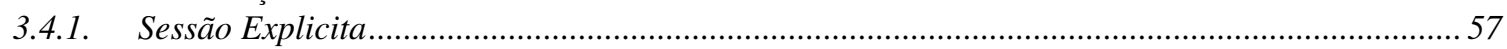

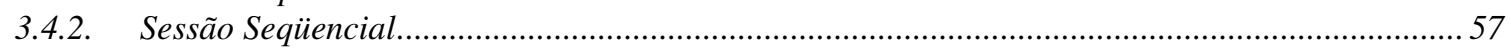

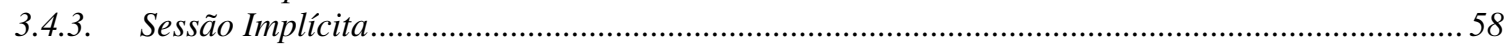

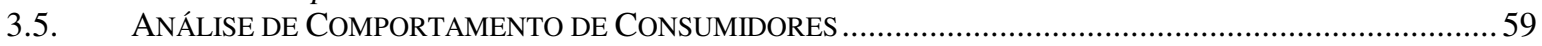

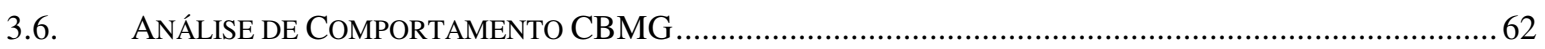

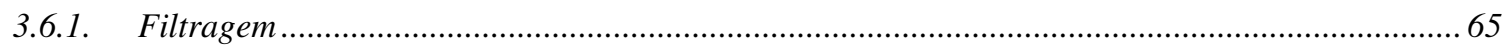

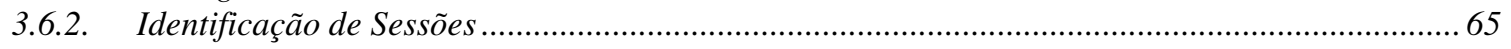

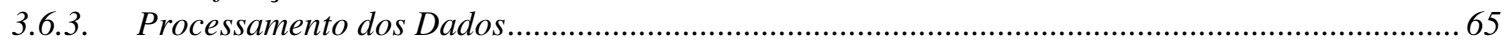

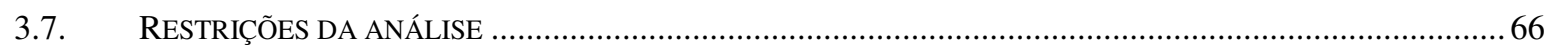

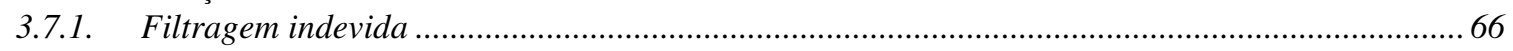

3.7.2. Identificação de sessão sujeita a erros devido a proxies..............................................................67 67

3.7.3. Sessões irregulares geradas por crawlers e robôs de vendas .......................................................67 67

3.7.4. Identificação errada devido a estruturas complexas de web-sites ................................................. 68

4 EXTRAÇÃO DE INFORMAÇÕES DE NEGÓCIO ATRAVÉS DA MODELAGEM DE COMPORTAMENTO DE CONSUMIDORES..........................................................................................70

4.1. METODOlOGIA PARA ANÁliSE DE NEGÓcio ATRAVÉS DA MODELAGEM DE COMPORTAMENTO DE

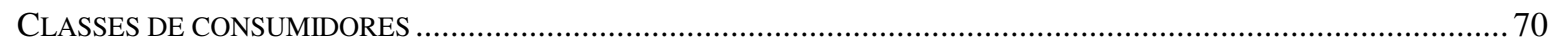


4.1.1. Cálculo do Custo não Operacional de um Negócio Eletrônico.................................................... 74

4.1.2. Agrupamento de consumidores em classes.............................................................................. 74

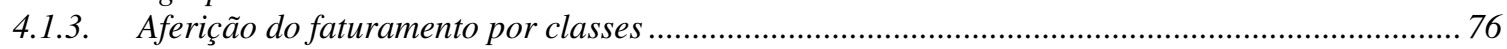

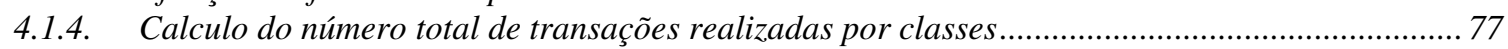

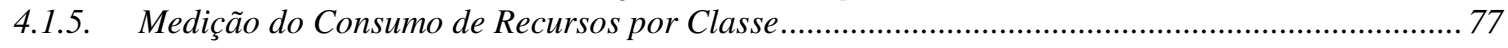

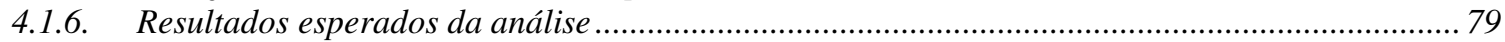

4.2. FERRAMENTA PARA ANÁLISE DO CONSUMO DE RECURSOS DE CLASSES DE CONSUMIDORES .............80

4.2.1. Análise de requisitos para implementação da ferramenta ......................................................... 81

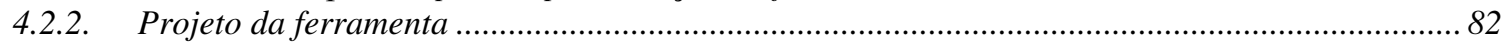

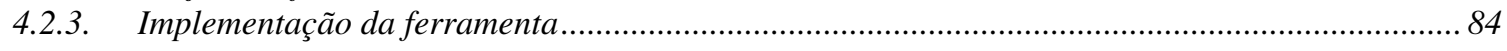

5 APLICAÇÃO DA ANÁLISE E DA FERRAMENTA PROPOSTAS ..................................................8 87

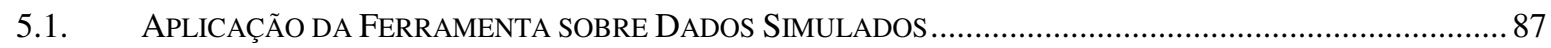

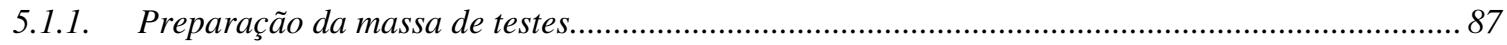

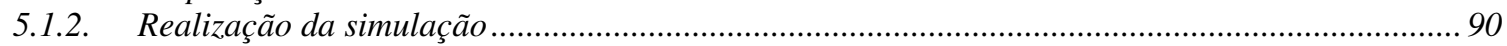

5.1.3. Aplicação da ferramenta sobre os dados simulados .................................................................. 91

5.1.4. Aplicação da metodologia de análise sobre os dados simulados ...............................................99

5.1.5. Exemplo de interpretação do resultado da análise de negócios............................................... 103

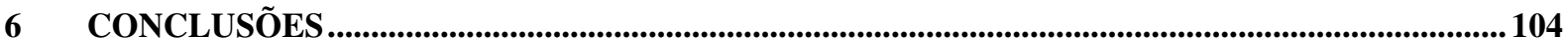

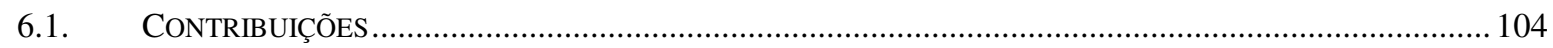

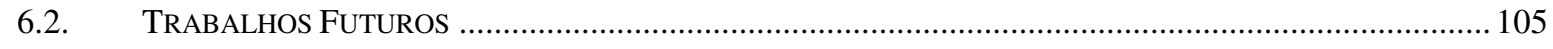

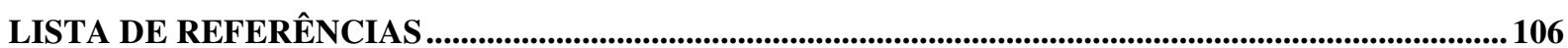




\section{Introdução}

O comércio eletrônico atual, o comportamento das empresas que vendem produtos ou prestam serviços pela WWW (World Wide Web) e o comportamento dos consumidores, só podem ser entendidos se estudados em conjunto com a evolução das tecnologias que permitiram a existência da Internet e do processo de adoção destas tecnologias por empresas e consumidores.

Em 1969 o Departamento Norte-Americano de defesa DOD (Department of Defense), com o propósito de compartilhar recursos computacionais, criou a ARPANET (Advanced Research Program Agency Network), uma rede de transmissão de pacotes entre três universidades americanas: UCLA (University of California in Los Angeles), UCSB (University of California in Santa Barbara), UUTAH (University of Utah) e um instituto de pesquisa: o SRI (Stanford Research Institute). No ano de 1969 também foi publicada a primeira RFC (Request For Comments) onde era descrito o Software necessário para conectar um dispositivo à Internet (IETF RFC 1).

Em 1971 foram criados os primeiros protocolos: FTP (File Transfer Protocol) (IETF RFC 114) e Telnet proposto na (IETF RFC 97) e especificado na (IETF RFC 137). A primeira Killer Application, ou seja, forma de utilização que popularizou a Internet além dos círculos de pesquisa voltados a seu estudo foi o E-Mail (IETF RFC 196) que foi publicado em 1972. Em 1973 a Internet se tornou internacional com a interligação de dois países: A Inglaterra e a Suécia. Os protocolos de rede e transporte utilizados até hoje só surgiram em 1980: O IP (Internet Protocol) (IETF RFC 760) e o TCP (Transmission Control Protocol) (IETF RFC 761).

Passados 20 anos de sua criação, em 1989, a Internet atingiu 100.000 dispositivos conectados em diversos países tornando-se uma rede de escala global, porém 
predominantemente acadêmica, até que neste ano a WWW (World Wide Web) foi criada por Tim Berners-Lee, um pesquisador inglês lotado no laboratório europeu de física de partículas em Genebra na Suíça CERN, através da especificação do formato HTML (Hypertext Markup Language) (IETF RFC 1886) e do protocolo HTTP (Hypertext Transfer Protocol) (IETF RFC 1945) que foram criados para facilitar a organização das informações neste laboratório. A partir desta invenção, a Internet que era apenas timidamente adotada fora dos círculos acadêmicos por empresas e usuários de e-mail (Correio Eletrônico) através de BBS (Bulletin Board System) passou a se popularizar com o público em geral em todo o mundo a partir do lançamento em 1994 do primeiro web browser (Navegador Web) comercial: o MOSAIC da NCSA.

Percebendo a adoção cada vez maior do uso da Internet pela população em geral, diversos empreendedores passaram a utilizar a Internet como canal de venda de produtos e meio de prestação de serviços, criando desta forma, o negócio eletrônico e as empresas pontocom.

Os negócios eletrônicos pela WWW foram baseados na premissa que a interação do consumidor com o negócio deveria acontecer de forma análoga à interação que o consumidor já possuía com a WWW. Por isso, as aplicações de negócio eletrônico foram projetadas tendo os servidores WWW como responsáveis pela apresentação das informações e a única parte do sistema acessível ao consumidor.

Devido à adoção tardia do negócio pela Internet por empresas tradicionais, durante um certo tempo, estas empresas concorreram em pé de igualdade com os primeiros empreendedores de Internet. Esta concorrência acirrada e o efeito rede que pregava que para as empresas ponto-com era justificável perder dinheiro para construir sua participação de mercado levou a uma especulação crescente que culminou na acentuada desvalorização das ações das empresas ponto-com em Março de 2001 que ficou conhecida como "O Estouro da 
Bolha Ponto Com" (Dot Com Bubble Burst) e causou a falência da maioria das empresas ponto-com da época.

Depois de passada a empolgação inicial, o mercado de comércio eletrônico se estabilizou e acabou divido entre as empresas tradicionais, que adotaram a Internet como mais um canal para atuação e empresas as surgidas na Internet como a Amazon, o E-bay, o Google e o Yahoo. Esta nova era de comércio eletrônico passou a ser pautada pela inovação tecnológica somada a estratégias de negócios tradicionais.

\subsection{Motivação}

Devido à abundância de financiamento e recursos nas fases que precederam a bolha, diversos modelos de negócio foram baseados em premissas que se tornaram inviáveis após o colapso do mercado de negócio eletrônico. Esta nova realidade exigiu que as empresas adotassem infra-estruturas tecnológicas mais enxutas e forçou que as empresas obtivessem lucro através do corte de financiamento para as empresas que insistiam na ampliação da sua fatia de mercado mesmo sem apresentar resultados positivos.

A maior competição entre os negócios eletrônicos também causou a diminuição da margem de lucro nas operações e levou muitas empresas a utilizar técnicas de Business Intelligence (BI) e Customer Relationship Management (CRM) para aumentar o faturamento e o lucro através da identificação do perfil dos consumidores e atração de potenciais consumidores com o mesmo perfil através de estratégias de marketing.

A pressão por infra-estruturas tecnológicas menores não foi igual para todos os modelos de negócio. Os modelos onde o lucro sobre uma transação é ordens de grandeza maior que o custo dos recursos computacionais consumidos pela mesma, como a venda de livros através da WWW, sofrem menores pressões que os modelos onde o lucro por transação é da mesma ordem de grandeza que o custo dos recursos computacionais consumidos, como por exemplo, a exibição de noticias, vídeos ou áudio financiados através de propagandas. 
O consumo de recursos computacionais é produto do número de visitas a um negócio eletrônico e da quantidade de informação consumida a cada visita. Para os modelos de negócio onde a diminuição do consumo de recursos computacionais é necessária, reduzir de forma indiscriminada o número de visitas ao negócio não é recomendado, pois, acarreta a redução do número de potenciais consumidores. A redução indiscriminada da quantidade de informação consumida a cada visita também é arriscada, pois, pode causar a diminuição da qualidade da informação transmitida e desta forma, reduzir o número de visitas e por conseqüência o faturamento.

Para que a diminuição do consumo de recursos computacionais seja possível sem que o faturamento seja afetado, é necessário equilibrar a quantidade da informação passada a cada consumidor com o potencial de retorno deste consumidor para o negócio. Tal equilíbrio só é atingível quando é possível avaliar corretamente o consumo de recursos dos consumidores e o potencial de retorno dos consumidores para o negócio.

A avaliação do potencial de retorno dos consumidores para um negócio faz parte da disciplina de marketing e é feita através da classificação dos consumidores em classes através de um ou mais critérios sócio-econômicos e comportamentais. Para avaliar o potencial de retorno de cada grupo de consumidores, as empresas tradicionais valem-se da observação do comportamento dos consumidores nos pontos de venda, de pesquisas qualitativas e quantitativas, e de aplicação de técnicas de data-mining no seu repositório de informação sobre vendas. Já as empresas de negócio eletrônico não podem observar diretamente os consumidores e por isso precisam de métodos e ferramentas para avaliar o comportamento dos consumidores em seu web-site.

A análise de comportamento de consumidores em web-sites tem sido estudada desde a popularização da WWW para melhorar a eficiência dos servidores WWW e para a automação da elaboração de mapas de navegação para web-sites. A maioria das análises baseia-se no 
levantamento da navegação do consumidor através da análise das informações contidas nos logs dos servidores WWW visitados já que nesses logs é armazenada, direta ou indiretamente, a informação sobre quem visitou, o que foi visitado e a que horas ocorreu a visita.

A partir das mesmas informações armazenadas nos logs de servidores WWW que permitem conhecer o comportamento dos consumidores, também é possível calcular o consumo de recursos neste servidor e, quando conhecido o comportamento da aplicação, estimar o consumo de recursos dos outros servidores que dão suporte à aplicação.

\subsection{Objetivos}

Para tornar um modelo de negócio eletrônico mais rentável é necessário equilibrar o faturamento e o consumo de recursos através da diminuição do consumo sem que isto afete o faturamento. Para que isto seja possível, é necessário dividir os consumidores em diversas classes, aferir o consumo e o faturamento de cada uma das classes e adotar estratégia de marketing e de priorização de serviços diferenciada para cada uma das classes dos consumidores do negócio eletrônico.

O objetivo deste trabalho é elaborar e verificar a eficácia de uma técnica de análise do consumo de recursos de um web-site através da contabilização do consumo de recursos por módulo do web-site e por classe de consumidor. A técnica proposta é baseada na que foi proposta por Menasce et al. (1999) alterada de forma a contabilizar diversas informações que são filtradas e descartadas na análise original.

\subsection{Contribuiçõos esperadas}

Deste trabalho espera-se duas contribuições: Uma metodologia de análise de comportamento baseado no consumo de recursos de classes de consumidores e uma ferramenta para a medição do consumo de recursos. 
A metodologia de análise será baseada na comparação dos dados de consumo de cada uma das classes de consumidores como os dados de faturamento estimados ou obtidos através de outras análises. Tornando possível identificar quais classes de consumidores são mais rentáveis e quais classes de consumidores são menos rentáveis e assim alterar o modelo de negócio, estratégias de marketing ou até o próprio web-site para garantir o maior equilíbrio possível entre o faturamento e o consumo de recursos das diversas classes de consumidores.

O grande diferencial da técnica proposta é permitir diferenciar custos que hoje são tratados como custos fixos e rateados entre todos os consumidores em custos transacionais e calculá-los por transação e por grupo. Os custos referentes à hospedagem e operação de um web-site de negócio eletrônico são categorizados como custos fixos assim como também são considerados custos fixos os custos referentes a aluguéis e condomínios de empresas tradicionais. Porém, devido à natureza da interação de uma empresa de negócio eletrônico ser realizada através de um web-site e outros meios eletrônicos, torna-se possível medir quantos recursos foram consumidos na venda de cada produto ou na prestação de cada serviço e desta forma contabilizar os custos de hospedagem e operação por transação.

A ferramenta, a base técnica para a aplicação da metodologia, funcionará através da análise de evidências de navegação de consumidores em web-sites e contabilização do consumo de recursos computacionais.

\subsection{Metodologia}

Para se iniciar a pesquisa estudamos as metodologias aplicadas atualmente para análise, classificação e agrupamento de consumidores através de web-log mining para classificar e analisar os pontos fortes e fracos de cada metodologia e eventualmente adaptar métodos e técnicas de outras metodologias, para melhorar a eficiência e a eficácia da metodologia proposta por Menasce et al. (1999). 
Também foram estudadas técnicas de segmentação de consumidores de web-sites de comércio eletrônico, utilizadas em marketing e estratégia, para poder criar as classes de consumidores utilizadas nos testes de validação da técnica e para poder interpretar os resultados da metodologia e propor alterações nos web-sites que por sua vez podem ser avaliadas pela aplicação da mesma metodologia a posteriori. Também foram estudados diversos modelos de negócio para verificar quais desses modelos seriam candidatos à aplicação da análise e da ferramenta proposta.

Após esse estudo inicial a técnica de análise foi proposta e o processo de desenvolvimento voltou-se para a ferramenta de análise e sua arquitetura foi definida com base nos estudos iniciais sendo também adequada para a aplicação de teste e suas peculiaridades.

Os testes, seguindo a técnica proposta e utilizando a ferramenta de análise criada, foram feitos utilizando-se massa simulada, porém, contendo informação suficiente para uma análise profunda e dessa forma permitir validar a ferramenta.

\subsection{Estrutura da dissertação}

Este trabalho está organizado em 6 capítulos. O primeiro deles, esta introdução, apresenta o cenário atual onde se posiciona o trabalho, identificando fatores que sustentam as motivações que levaram ao seu desenvolvimento.

O capítulo 2 apresenta uma introdução sobre a arquitetura da WWW, sobre o funcionamento de aplicações ativas, conceitos importantes de negócio eletrônico, conceitos sobre caracterização das classes de consumidores e por último, apresenta uma arquitetura de referência para soluções de negócio eletrônico.

O capítulo 3 apresenta alguns trabalhos relacionados que descrevem algumas metodologias de análise de comportamento de consumidores. Neste capitulo são comparados os pontos fortes e fracos de cada uma das metodologias para em seguida focar na metodologia 
proposta por Menasce et al. (1999) que é usada como referência para a proposição de uma nova metodologia.

O capítulo 4 propõe uma metodologia para a medição do consumo de recursos e apresenta a modelagem de uma ferramenta para realizar a análise.

O capítulo 5 apresenta os resultados obtidos com a execução da ferramenta sobre dados simulados.

O capítulo 6 apresenta as conclusões e considerações finais do trabalho e sugere novas pesquisas na área. 


\section{Negócios através da World Wide Web}

Os negócios através da WWW surgiram quando alguns empreendedores notaram que a WWW e a Internet podiam ser utilizadas para outras atividades além das atividades acadêmicas e de comunicação eletrônica. Estes empreendedores perceberam que a WWW poderia ser mais um canal de interação com o consumidor para modelos de negócio tradicionais e que também poderia servir como suporte para diversos novos modelos de negócio, baseados na facilidade de comunicação provida pela WWW.

\subsection{A World Wide Web}

As tecnologias que permitiram o surgimento da WWW, apesar de publicadas somente entre 1995 e 1996, foram propostas por Berners-Lee (1989) para resolver o problema de gerenciamento de informações enfrentado pelo CERN.

O CERN enfrentava dois principais problemas no gerenciamento de informação: Uma quantidade muito grande de informações era perdida e o tempo gasto na busca de informações era muito alto, pois, as informações produzidas pelos milhares de pesquisadores em centenas de projetos ficavam espalhadas em diversos sistemas e codificadas em diversos formatos. Estes problemas eram agravados pelo fato do tempo médio de estadia de cada pesquisador no CERN ser de apenas dois anos. 


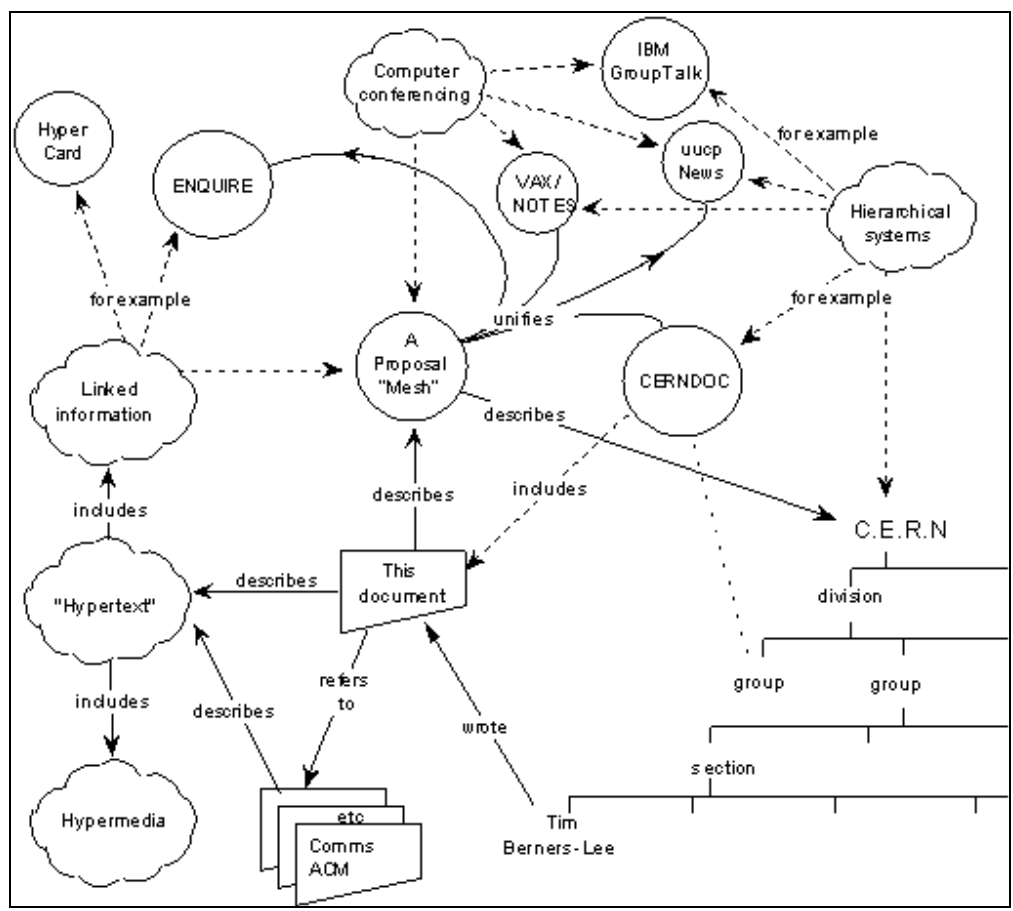

Figura 1 - Ilustração da arquitetura do sistema Mesh

Conforme proposto por Berners-Lee (1989), os problemas de gerenciamento de informação poderiam ser resolvidos através da utilização de Hipertexto e da criação de uma infra-estrutura de publicação de hipertexto inicialmente chamada de Mesh que possuísse as seguintes características:

1. Heterogeneidade,

2. Descentralização,

3. Acesso a dados já existentes,

4. Possibilidade de inclusão de links por qualquer usuário e

5. Possibilidade de se adicionar gráficos

A solução proposta era constituída de dois componentes: as aplicações clientes chamadas browsers implementadas através de um software utilizado para a exibição do hipertexto, os 
hypertext servers que seriam os servidores de banco de dados onde os hipertextos seriam armazenados, e de uma interface bem definida entre ambos os componentes.

\subsubsection{O Formato HTML}

O formato HTML foi criado inicialmente como uma especialização do formato SGML (Standard Generalized Markup Language) para permitir a criação de textos onde fossem possíveis a inclusão de elementos de formatação no texto e a inclusão de elementos que possibilitem a ligação de informações no documento a outras informações armazenadas no próprio documento ou em outros documentos (Hyperlinks).

O HTML combina na forma de texto, o próprio texto e informações adicionais sobre o mesmo. Estas informações adicionais são expressas na forma de marcações também conhecidas como etiquetas (tags) no caso do HTML. Desta forma, o documento HTML apesar de conter texto e marcações, continua sendo composto apenas de texto e por isso pode ser processado e armazenado por dispositivos de tratamento de texto sem necessitar de softwares adicionais.

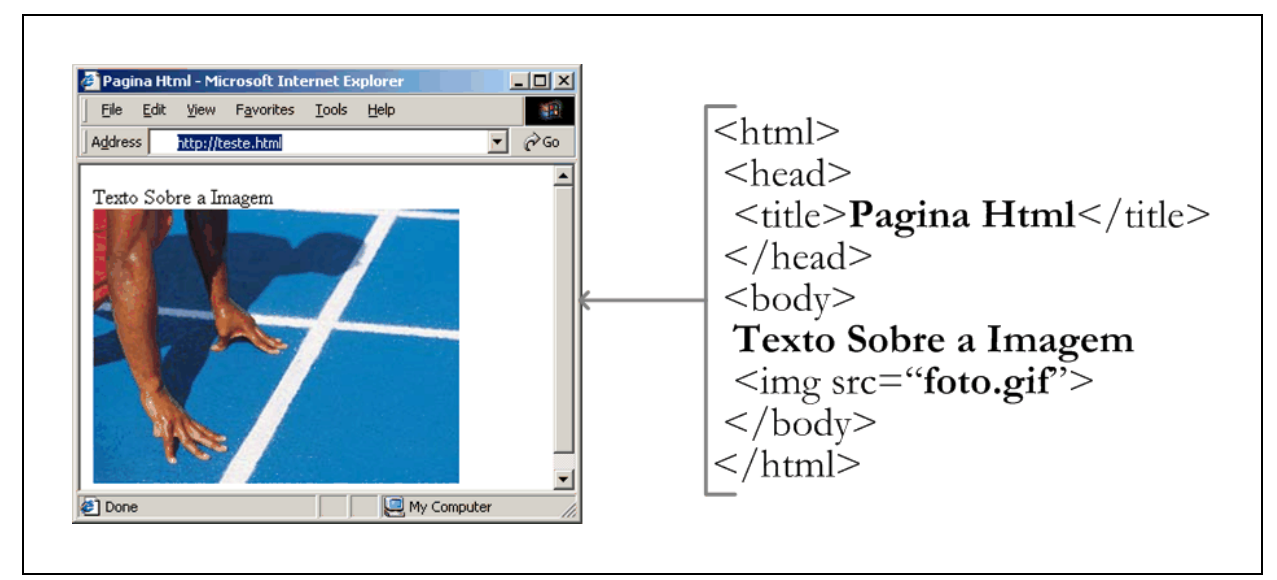

Figura 2 - Exemplo do Formato HTML 
O HTML foi proposto em 1989 por Berners-Lee e, mais tarde, padronizado através da RFC 1886 - Hypertext Markup Language (IETF RFC 1886) em 1995. A partir deste mesmo ano foi criado o W3C (World Wide Web Consortium): entidade responsável por pesquisar, discutir e padronizar alterações no formato HTML.

\subsubsection{A Técnica DHTML}

Devido ao fato do HTML ser um formato estático onde a única interação possível com o usuário é através da navegação, não era possível criar interfaces com o usuário além de formulários e links. Tal limitação restringia a capacidade da WWW para o comércio eletrônico, devido a dificuldade imposta ao usuário através da constante espera pelo carregamento de um novo documento HTML a cada ação do usuário.

Esta limitação foi ultrapassada através da criação da técnica DHTML, que permite a criação de web-sites interativos através da combinação de HTML e linguagens de programação, como por exemplo, Javascript. Utilizando a técnica DHTML é possível construir web-sites onde a responsabilidade sobre a interação com o consumidor fica divida entre a aplicação dinâmica que roda no cliente (Browser) e a aplicação ativa que roda no servidor WWW, diminuindo desta forma o numero de acessos que o cliente faz ao servidor e conseqüentemente diminuindo o tempo que o consumidor passa esperando pelo carregamento de páginas HTML pelo cliente.

Levada ao extremo, a técnica DHTML permite a criação de web-sites onde o carregamento da página HTML ocorre uma única vez e toda a ação subseqüente do usuário é tratada através do acionamento de funções da aplicação que são executadas no cliente. Estas funções utilizam o formato XML (Extensible Markup Language) e protocolo HTTP para obter do servidor apenas o conteúdo que deve ser alterado no documento HTML. A tal técnica convencionou chamar AJAX (Asynchronous Javascript and XML). 


\subsubsection{O Protocolo HTTP}

Conforme descrito por Berners-Lee et al. (1996) o HTTP é um protocolo de aplicação com a agilidade e a velocidade necessária para um sistema de informação de hipermídia colaborativo e distribuído. É um protocolo genérico, sem estado e orientado a objeto.

A grande vantagem do HTTP é a habilidade de requisitar e transmitir objetos independentemente do conteúdo e da formatação dos dados transmitidos e por isso pode ser utilizado para diversas aplicações, sendo que sua principal aplicação é o transporte de arquivos HTML e quaisquer outros arquivos e objetos necessários para a exibição completa de um documento HTML.

O protocolo HTTP é um protocolo extremamente simples onde o cliente inicia uma comunicação através do estabelecimento de uma conexão com o servidor, requisita um objeto e fecha a conexão assim que o objeto é transmitido pelo servidor. Desta forma, o HTTP não implementa e nem é dependente de nenhum mecanismo de controle de estado. Para a realização de uma comunicação HTTP são necessárias somente duas mensagens: a Requisição e a Resposta, sendo que a Requisição é sempre enviada do cliente para o servidor e a Resposta é sempre devolvida do servidor ao cliente quando recebida uma requisição.

Outra característica do HTTP é sua adaptabilidade, já que tanto na Requisição quanto na Resposta não existe nenhum campo de tamanho fixo, existem poucos campos obrigatórios, todas as informações são formatadas como texto e todas as separações de campos são feitas através de espaços ou através de quebra de linhas. Quando o servidor ou o cliente recebe um campo para o qual não estão preparados, este campo é simplesmente ignorado. A simplicidade do protocolo foi um dos principais fatores que permitiu sua adoção por virtualmente todos os usuários da Internet. 


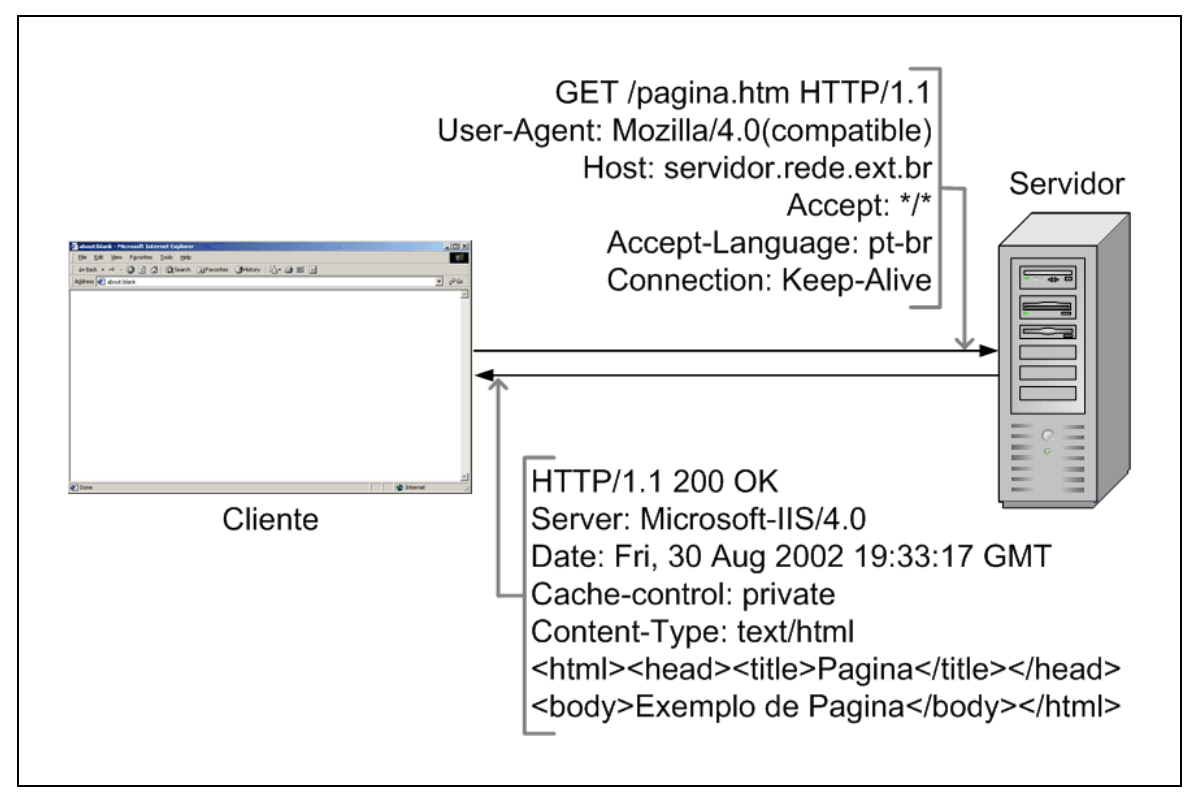

Figura 3 - Exemplo do Protocolo HTTP

Desde sua criação, o protocolo HTTP sofreu uma única alteração em 1999 através da RFC 2616 (IETF RFC 2616) que definiu a versão 1.1 do protocolo, sendo que as principais alterações foram:

- Um mecanismo para permitir que diversas requisições sejam executadas em uma única requisição tornando desta forma o protocolo mais eficiente.

- A inclusão de um campo obrigatório no cabeçalho para permitir que diversos servidores WWW lógicos compartilhem um único servidor WWW físico utilizando apenas uma porta em apenas um endereço IP.

\subsubsection{O Protocolo HTTPS}

O Protocolo HTTPS estabelece um canal de comunicação seguro entre o cliente e o servidor utilizando o protocolo SSL (Secure Sockets Layer) ou o protocolo TLS (Transport Layer Security) e posteriormente trafega as mensagens do protocolo HTTP através desta conexão criada. Ambos os protocolos utilizam protocolo TCP para transmitir os dados. 
O protocolo HTTPS é considerado uma versão segura do protocolo HTTP, pois no protocolo HTTP as mensagens são trafegadas de forma aberta pela utilização direta do protocolo TCP.

O fato de o protocolo HTTPS ser apenas um encapsulamento do protocolo HTTP garante a simplicidade de implementação e mantém a maleabilidade do protocolo HTTP. O Comércio eletrônico foi o principal fator que levou a criação do protocolo HTTPS devido à necessidade de autenticação e criptografia de informações sensíveis como senhas, números de cartões de crédito e outras informações que por algum motivo só devem ser conhecidas pelo transmissor e pelo receptor.

\subsubsection{Sessões}

Devido à natureza atômica e dispersa da WWW a obtenção de informações pelos usuários é feita através da requisição de diversas páginas associadas entre si por ligações “links". Para ir de uma página à outra, um usuário necessita clicar em um link ou preencher um formulário com informações. A essa requisição de uma nova página de informação a partir de uma outra página se convencionou chamar de navegação.

Geralmente, quando um usuário procura uma informação especifica, ou quando realiza um serviço através da WWW, são necessárias diversas navegações para se chegara ao objetivo. A essa seqüência de navegações dentro de um espaço de tempo se convencionou chamar sessão.

A grande dificuldade da identificação de sessões em servidores WWW advém do fato de os servidores WWW não fazerem controle de estado e por isso, o conceito de sessão não é intrínseco ao protocolo de comunicação.

Depois de um conjunto de navegações realizadas por diversos usuários em um servidor WWW, toda informação restante sobre essas navegações é armazenada na forma de logs. Para ser possível extrair uma sessão de um log deve-se utilizar o máximo de informações possíveis 
para identificar os diferentes usuários que geraram as informações no log e a seqüência correta das navegações de cada um dos usuários.

\subsubsection{Cookies}

Outro fator limitante que dificultava a implementação do comércio eletrônico era o fato do protocolo HTTP não possuir nenhum mecanismo de controle de estado e por isso, qualquer forma de autorização ou identificação de usuários precisava ser provida externamente ao protocolo.

Para criar um mecanismo de controle de estado sem efetuar grandes alterações no funcionamento do protocolo HTTP, foi proposto, em 1997, através da RFC 2109 (IETF RFC 2109) o aproveitamento de um conceito já amplamente utilizado no desenvolvimento de aplicações cliente-servidor chamado magic-cookie.

Um magic-cookie ou apenas cookie, como ficou posteriormente conhecido, consiste no envio de uma informação do servidor ao cliente, sendo que a informação transmitida não possui nenhum significado para o cliente e dessa forma não é interpretado até que o cliente transmita esta informação de volta ao servidor na comunicação seguinte. Ao receber a informação novamente, o servidor pode identificar o cliente e o estado da comunicação com o cliente.

A simplicidade da solução adotada permitiu que as alterações no protocolo HTTP se limitassem à criação de dois novos valores a serem transmitidos no cabeçalho do protocolo.

\subsubsection{Persistência de cookies e privacidade}

A RFC 2109 (IETF RFC 2109) que definiu o mecanismo de controle de sessão através de magic-cookies prevê que uma das informações que podem ser carregadas por um cookie é o prazo de validade (Max-Age). O prazo de validade é utilizado pelo servidor para indicar ao cliente que o cookie deve ser enviado ao servidor em todas as comunicações entre ambos até a 
data especificada. Quando este valor não é enviado, a RFC expressa que o cookie deve ser enviado ao servidor em todas as comunicações até que a aplicação cliente seja encerrada. Um cookie com prazo de validade é conhecido como persistente.

O grande problema criado por essa solução, é que o mecanismo de controle de sessão é tão transparente, que combinado com a ausência de limites no prazo de validade de um cookie, cria uma forma para um web-site identificar qualquer usuário que ao menos uma vez tenha se identificado, sem que este usuário tenha que se identificar novamente e sem saber que foi identificado pelo web-site.

O problema de privacidade se agrava, pois, além dos arquivos HTML, todos os outros objetos que forem requisitados pelo cliente para a montagem completa de um documento HTML podem também enviar cookies para o cliente. Dessa forma é possível, e comum, que empresas envolvidas em marketing pela WWW paguem a muitos web-site pelo direito de exibir imagens, muitas vezes imagens transparentes, em páginas chaves do web-site e dessa forma conseguir monitorar o acesso de muitos usuários por vários web-sites sem o conhecimento dos mesmos.

Devido à crescente preocupação dos usuários com a privacidade, a maioria dos clientes WWW, como por exemplo, o Microsoft Internet Explorer e o Mozilla Firefox permitem que o usuário configure quais tipos de cookies podem ser criados. Por exemplo, os clientes WWW atuais possibilitam ao usuário, configurar a permissão de existência de cookies persistentes ou configurar se objetos requisitados de sites terceiros, ou seja, armazenados em servidores diferentes do servidor onde o arquivo HTML está armazenado, possam criar cookies.

Outra tecnologia criada para possibilitar um melhor gerenciamento da privacidade do usuário é o padrão P3P (Platform for Privacy Preferences Project) (W3C P3P) que define um formato padrão para que web-sites publiquem a sua política de privacidade de forma interpretável pelo cliente WWW. Desta forma, alguns clientes WWW permitem que o usuário 
configure as opções de privacidade com base na política de privacidade publicada pelo website.

A grande desvantagem da tecnologia P3P, é que não existe uma forma viável de se verificar se os web-sites realmente seguem a política publicada nem uma forma confiável de se publicar e distribuir listas de sites que seguem ou não seguem as políticas publicadas. Devido a este motivo, as últimas versões de alguns clientes WWW, como por exemplo, o Mozilla Firefox descontinuaram o suporte a esta tecnologia.

\subsubsection{Outros mecanismos de controle de estado para a WWW}

Além do controle de estado através de cookies, existem dois outros mecanismos comumente utilizados: A sessão explicita e as extensões de clientes WWW.

A sessão explicita é caracterizada pela utilização de um código de autorização que deve ser passado como parâmetro pelo browser para cada requisição feita para uma aplicação WWW. Inicialmente, após a autenticação do usuário, a aplicação WWW deve gerar um código único de autorização e associá-lo ao usuário. Após a geração do código de autorização, a aplicação deve estar preparada para receber a cada requisição o código de autorização, e validá-lo antes de processar a requisição do usuário.

A validação da sessão explicita é geralmente feita através da comparação do endereço IP da requisição com o endereço IP para o qual foi feita a autenticação que gerou o código de autorização enviado. A aplicação também precisa garantir que todos os links e formulários gerados contenham o código de autorização. Desta forma, quando a requisição é feita utilizando o método GET do protocolo HTTP, o código de autorização deve ser um dos parâmetros passados no URI (Universal Resource Identifier) e quando a requisição é feita utilizando o método POST do protocolo HTTP, o código de autorização deve ser um dos campos do formulário enviado. 
A grande limitação do uso de sessão explicita é que as aplicações WWW precisam ser construídas de forma especial para tratar a sessão explicita. Outra limitação é que o código de autorização pode ser visível no URI exibido pelo browser quando a requisição é feita através do método GET do protocolo HTTP, ao contrário dos cookies, que ficam armazenados em memória ou em disco e, apesar de serem enviados, não ficam visíveis no URI.

As extensões de clientes WWW são programas, executados pelos browsers, para o controle de estado através do armazenamento de informações no cliente e da transmissão destas informações para o servidor WWW quando necessário. A vantagem de se utilizar extensões é a possibilidade de se utilizar métodos de autenticação mais sofisticados já que as extensões, por serem programas, podem aplicar algoritmos de segurança sobre os dados, além de armazená-los.

A desvantagem na utilização de extensões de clientes WWW é o fato de as extensões de clientes WWW serem limitadas devido a questões de segurança dos browsers. Por exemplo, as extensões podem ser divididas em dois grupos: as extensões simples que não precisam ter sua instalação nem sua execução autorizadas pelo usuário, porém não podem armazenar ou acessar dados na estação do usuário e desta forma limitam a segurança do processo de autenticação; as extensões complexas, que para poder armazenar ou acessar dados na estação do usuário, precisam ter sua instalação ou execução autorizada pelo usuário e por isso cria uma barreira para a sua utilização.

\subsubsection{Servidores WWW}

Servidor WWW é o nome coloquial para todos os programas que disponibilizam informações através do protocolo HTTP. As informações disponibilizadas podem estar no formato de arquivos, e neste caso, os servidores são classificados como servidores estáticos, ou as informações podem ser geradas dinamicamente, e neste caso, os servidores são classificados como servidores dinâmicos. 


\subsubsection{Armazenamento de Logs Servidores WWW}

Quando os primeiros servidores WWW foram implementados, foi definido que as requisições recebidas pelo servidor e os seus resultados deveriam ser armazenados para possibilitar a detecção de problemas no servidor e também para permitir a realização de auditorias. O armazenamento destas informações passou a ser feito na forma de texto em arquivos chamados de arquivos de logs.

Para cada requisição feita, o servidor WWW gera uma resposta e transmite através da mesma conexão em que foi feita a requisição. Dados sobre a conexão, requisição e reposta são então armazenadas no log do servidor WWW.

A forma de armazenar os logs varia entre os diversos tipos de servidores WWW. Além disso, a maioria dos servidores WWW permite que o administrador do servidor configure quais informações são armazenadas nos logs e quais informações devem ser descartadas. Esta configuração é necessária, pois, os arquivos de log podem atingir tamanhos muito grande devido à quantidade de requisições atendidas, à quantidade de informação armazenadas ou ambos. Na figura abaixo, está descrita a origem dos dados armazenados através do padrão "W3C Extended Log Format" (IETF Extended Log File Format W3C) utilizado pelos servidores WWW IIS da Microsoft e Apache da Apache Foundation. 
Na tabela e na figura abaixo, estão as descrições dos campos e a relação eentre campo do protocolo http e informação armazenada no log:

\begin{tabular}{|c|l|l|}
\hline$\#$ & \multicolumn{1}{l|}{ Nome } & \multicolumn{1}{l|}{ Descrição } \\
\hline 1 & date & Data da resposta da requisição. \\
\hline 2 & time & Hora da resposta da requisção. \\
\hline 3 & c-ip & IP da origem da requisição \\
\hline 4 & cs-username & Nome do usuário que fez a requisição \\
\hline 5 & s-ip & IP do servidor que atendeu a requisição \\
\hline 6 & cs-method & Método utilizado na requisição \\
\hline 7 & cs-uri-stem & URI do objeto requisitado \\
\hline 8 & cs-uri-query & Parâmetros passados ao objeto requisitado \\
\hline 9 & sc-status & Status da resposta \\
\hline 10 & sc-bytes & Tamanho em bytes da resposta \\
\hline 11 & cs-bytes & Tamanho em bytes da requisição \\
\hline 12 & time-taken & Tempo gasto para processar a requisição \\
\hline 13 & cs-version & Versão do protocolo \\
\hline 14 & cs(User-Agent) & User-Agent da origem da requisição \\
\hline 15 & cs(Cookie) & Cookies enviados com a requisição \\
\hline 16 & cs(Referrer) & Objeto que originou a requisição \\
\hline
\end{tabular}

Tabela 1- Informações armazenadas em um log de servidor WWW

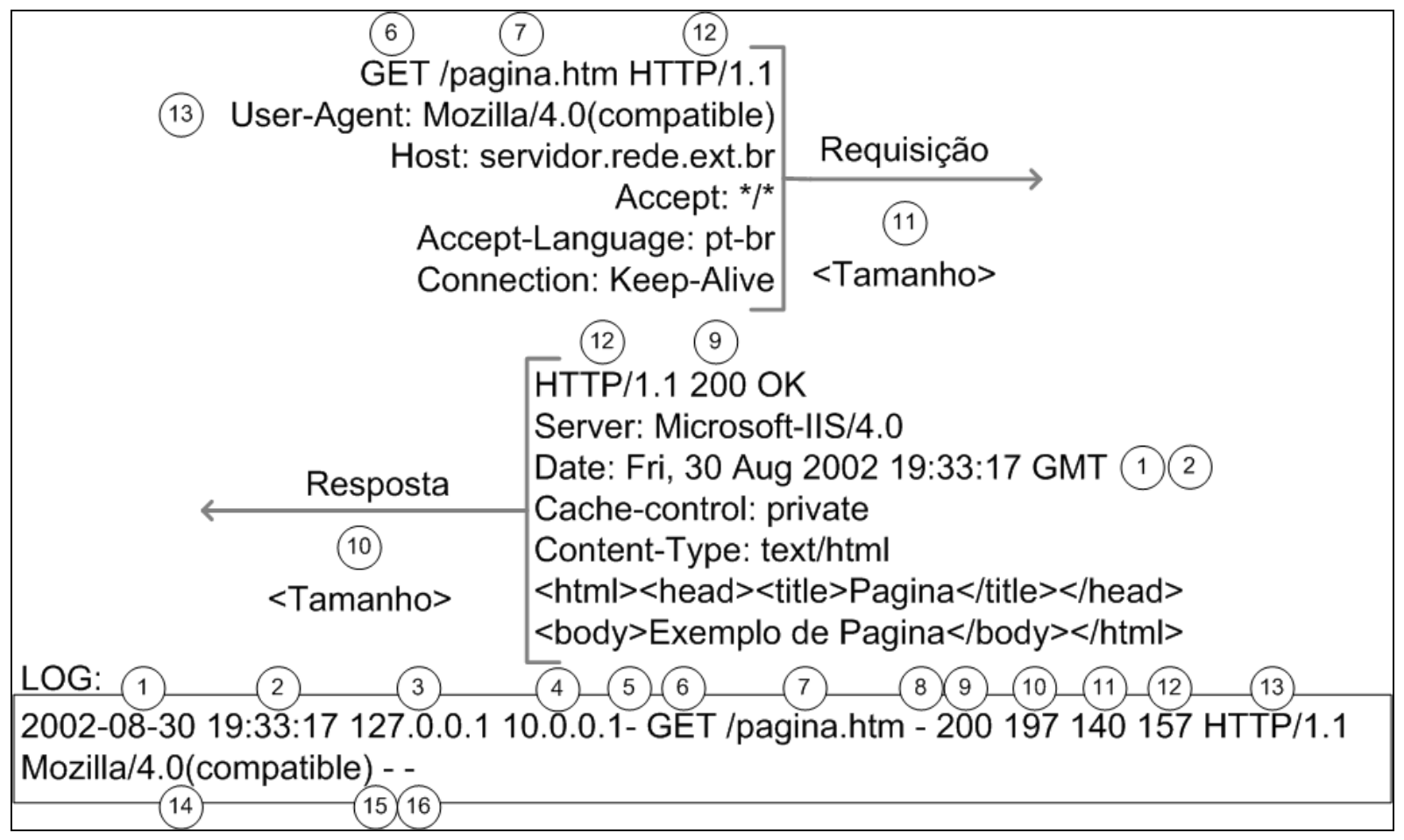

Figura 4- Dados armazenados no log do servidor WWW 


\subsubsection{Aplicações ativas para a WWW}

No mesmo documento em que propôs a WWW, Berners-Lee (1989) também propõe que seja criada uma classe de programas chamados hypertext gateways, que permitiriam que informações armazenadas em diversos formatos em diversos servidores pudessem ser exibidas no formato HTML e obtidas através do protocolo HTTP. Tal proposta visava que as informações que já existiam espalhadas por diversos sistemas já existentes pudessem ser aproveitadas sem a necessidade de conversão das informações ou dos sistemas.

A interface através de gateways proposta por Berners-Lee foi implementada somente em 1993, com a criação do ORAPERL um script na linguagem Perl que permitia que o banco de dados relacional Oracle pudesse gerar páginas HTML a partir de pesquisas SQL (Structured Query Language). No mesmo ano, a NCSA criou uma extensão para que o servidor HTTP mosaic pudesse acessar servidores SQL dando origem à primeira geração de gateways: as extensões de servidores. A grande limitação da primeira geração de gateways era que a página HTML gerada pelos servidores era limitada aos dados armazenados no banco de dados relacional, sendo assim, não era possível incluir mais nenhuma operação lógica adicional para montagem do resultado final.

Como resposta às limitações conhecidas da primeira geração de gateways, no próprio ano de 1993, a NCSA propôs uma interface padrão para comunicação entre os servidores HTTP e os softwares gateways e a batizou de CGI (Common Gateway Interface). Tal interface foi amplamente adotada tornando-se um padrão de fato e dessa forma deu origem à segunda geração de aplicações ativas: os CGI. A segunda geração de gateways possuía duas limitações: a primeira era o desempenho baixo das aplicações CGI já que um novo processo precisava ser disparado pelo gateway a cada requisição recebida e a segunda era que os aplicativos CGI eram de difícil manutenção já que toda vez que eram necessárias alterações 
em textos gerados pelo CGI, o programa precisava ser novamente compilado, testado e instalado no servidor WWW.

A terceira geração de aplicações ativas, as linguagens de script, surgiu como resposta às limitações da geração anterior. O problema da dificuldade de manutenção do gateway foi resolvido através da criação do conceito de páginas ativas, onde cada arquivo de script era responsável pela geração de um único tipo de página HTML e o script, por ser interpretado pelo servidor HTTP, não necessitava da fase de compilação para ser utilizado. O problema do desempenho foi resolvido através do uso de threads pelo servidor HTTP para a interpretação das páginas ativas e assim tornou possível economizar o tempo gasto pelo sistema operacional para o disparo de novos processos para atender as requisições CGI. As linguagens de script surgiram em 1995 com a criação da linguagem Cold Fusion pela empresa Allaire. Entre as soluções que se destacaram na terceira geração de aplicações estão o ASP (Active Server Pages) do servidor IIS (Internet Information Server) da Microsoft e as linguagens PHP (Personal Home Page Tool), Perl (Practical Extraction \& Report Language) e Python, que são integráveis tanto ao servidor IIS quanto ao servidor Apache da Apache Foundation.

Apesar de resolver muito dos problemas das gerações anteriores, a terceira geração de aplicações, baseadas em linguagens de scripts, introduziu um novo problema: o gerenciamento de código. O fato de cada página HTML ser gerada por um script diferente, complicou o reaproveitamento de funcionalidades e a gestão de qualidade do software produzido já que uma mesma funcionalidade poderia estar presente em mais de uma página e desta forma, qualquer correção ou melhoria de uma funcionalidade implicava no esforço extra de localizar todas as páginas que utilizavam a funcionalidade e depois corrigi-las uma a uma. Um problema secundário também introduzido pela terceira geração era que, devido ao fato de os scripts serem interpretados ao invés de serem executados, scripts muito complexos 
demoravam mais tempo para serem interpretados do que o tempo gasto para o disparo de um novo processo e a execução da mesma funcionalidade implementada na tecnologia CGI.

Novamente, uma nova geração de aplicações ativas foi criada para resolver os problemas da geração anterior, a nova geração de aplicações ativas são baseadas em frameworks de desenvolvimento de software já existentes no mercado, como o framework "Net" da Microsoft e o framework J2EE da Sun Microsystems. Frameworks são estrutras de apoio para a construção de web-sites. Nas gerações anteriores, cada módulo da aplicação era desenvolvido isoladamente e a integração entre os módulos era parte do trabalho de desenvolvimento dos mesmos. Com a utilização de Frameworks como, por exemplo, o ".Net" e o J2EE, a integração entre os módulos é garantida por construção e desta forma, menos tempo é gasto no desenvolvimento da aplicação e na correção de erros.

Devido ao fato de tanto as aplicações ativas quanto as aplicações estáticas serem acessadas através do protocolo HTTP e dos logs dos servidores WWW serem baseados neste protocolo as mesmas informações armazenadas nos logs dos servidores estático são armazenadas pelos servidores dinâmicos.

\subsection{Negócio Através de Meio Eletrônico}

Negócio através de meios eletrônicos (electronic commerce ou e-commerce) consiste na realização de um negócio entre duas partes onde parte ou toda a transação é realizada atravéa de meio eletrônico. Conforme notado por Timmers (1998), o conceito de negócio eletrônico surgiu durante o final da década de 70 com a adoção do EDI (Electronic Data Interchange), que permitiu às empresas facilitar a realização de transações comerciais através do envio de documentos como ordens de compra e faturas através de meios eletrônicos.

A grande vantagem em se utilizar o EDI era o ganho de eficácia, através da garantia que os dados recebidos não poderiam ser alterados pelas pessoas responsáveis pela alimentação das transações comercias no sistema corporativo da empresa, e de eficiência, através do tempo 
economizado ao não ser mais necessária a alimentação manual das informações na forma de digitação das transações no sistema coorporativo. A grande limitação do EDI era o fato da troca eletrônica de informações só ser possível entre empresas, principalmente para empresas de médio e grande porte que podiam arcar com a infra-estrutura humana e tecnológica necessárias para o funcionamento dos sistemas EDI.

O grande crescimento da quantidade de processos de negócio e do volume de negócios através de meio eletrônico ocorreu devido à criação da Internet, que permitiu que a troca eletrônica de informações pudesse ser feita a um custo baixo sem depender de uma conexão direta (física ou lógica) entre os participantes da troca, e com o surgimento de aplicações ativas para a WWW, que permitiu o surgimento de processos de negócios baseados na relação Negócio-Consumidor (B2C - Business to Consumer), já que os únicos requisitos que um consumidor precisa cumprir para participar de uma transação B2C são:

- Possuir um meio de comunicação para acesso a Internet: Geralmente através da utilização de um dispositivo modem ligado a uma linha telefônica discada ou através de dispositivos especializados como modems ADSL, cable modems ou por telefones celulares com capacidade para transmissão de dados.

- Possuir um dispositivo eletrônico para executar um software cliente HTTP: Geralmente um computador pessoal, mas também é possível realizar transações B2C através de dispositivos específicos interligáveis a televisão (set top boxes) ou telefones celulares.

A grande maioria das transações $\mathrm{B} 2 \mathrm{C}$ é realizada através de computadores pessoais nos ambientes de trabalho e doméstico. Dessa forma, outro fator importante que contribuiu para a grande expansão dos processos de negócio B2C foi a grande penetração da utilização de computadores pessoais nos ambientes listados anteriormente. 
Dois fatores contribuíram imensamente para a popularização da utilização dos computadores pessoais e apesar de ambos os fatores terem se influenciado de forma cruzada podem ser caracterizados separadamente.

O primeiro fator que contribuiu para a popularização da utilização dos computadores pessoais no ambiente de trabalho foi a tendência observada a partir da metade da década de 80 onde grandes empresas passaram a substituir a utilização de terminais "burros" para o acesso a softwares que eram executados em mainframes pela utilização de computadores pessoais conectados a redes locais. O aumento da demanda por computadores pessoais causou a redução dos preços no inicio da década de 80 nos Estados Unidos e na Europa ocidental e no final da década de 80 no Brasil e possibilitou que pequenas e médias empresas também pudessem utilizar computadores pessoais e redes locais para substituir os processos manuais de controle e gestão. Com a popularização da Internet ocorrida no final da década de 90 em todo mundo, as redes locais que já existiam em pequenas e médias empresas passaram a ser interligada à Internet principalmente para a utilização de correio eletrônico para melhorar o processo de comunicação entre as empresas, seus fornecedores e consumidores.

O segundo fator foi a larga adoção do uso de computadores pessoais no ambiente doméstico principalmente para o lazer. A utilização de computadores pessoais surgiu como hobby de entusiastas de tecnologia no final da década de 1970 que montavam computadores pessoais a partir dos recém-criados microprocessadores. A partir desta primeira fase, várias empresas, entre elas a Apple Computers, passou a produzir microcomputadores para uso doméstico. O mercado ficou segmentado em diversos padrões de microcomputadores até a introdução do Personal Computer em 1981 pela empresa IBM que através do licenciamento de sua arquitetura de microcomputador acabou por criar um padrão de-facto que até hoje domina uma grande parcela do mercado. Após o estabelecimento do padrão de-facto, uma segunda expansão na utilização de computadores pessoais foi devida ao aumento da 
usabilidade dos computadores pessoais graças ao surgimento de sistemas operacionais como Microsoft Windows e o Apple Mac OS.

Paralelamente à popularização dos computadores pessoais, no final da década de 1980 surgiram os Bulletin Board Systems (BBS). Estas empresas prestavam serviços de correio eletrônico, comunicação instantânea (chat) e distribuição de arquivos para usuários de computadores pessoais através de linhas telefônicas. Com o surgimento da WWW as empresas passaram a oferecer conexão a Internet como um serviço adicional e passaram também a integrar seus serviços de correio eletrônico, que até então eram locais, a serviços de e-mail. Pouco a pouco a WWW tornou os serviços prestados pelas BBS obsoletos e as empresas passaram a prestar apenas serviços de conexão a Internet.

Quando foi popularizada a WWW em 1996 já havia um grande parque instalado de computadores pessoais em empresas e domicílios e uma pequena parte desses domicílios já utilizavam serviços interativos limitados através das BBS.

\subsubsection{Modelos de Negócio}

Devido a grande expansão dos negócios eletrônicos causado pela WWW, diversos estudos foram feitos e diversos modelos foram propostos para tentar encontrar quais processos de negócio eram possíveis através da WWW e qual o impacto desses novos processos nos modelos de negócio já existentes anteriormente e nos novos modelos de negócio que viriam a surgir.

Logo após o surgimento do comércio eletrônico, foi proposta por Timmers (1998) uma lista não exaustiva de 11 modelos de negócio baseados nas formas de negócio eletrônico utilizadas por algumas empresas que existiam na época do estudo. Os modelos encontrados foram classificados de acordo com o grau de integração e o grau de inovação de cada deles. 


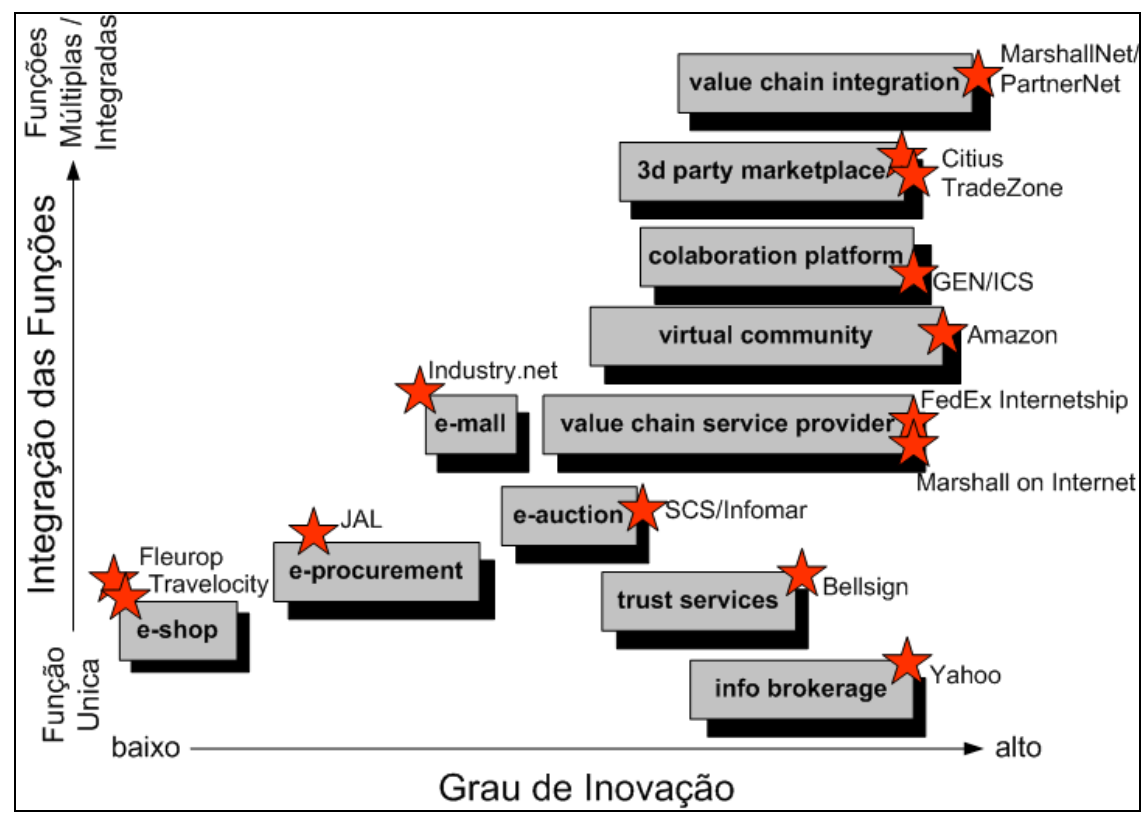

Figura 5 - Classificação de 11 Modelos de Negócio conforme públicada em Timmers(1998)

A classificação proposta por Timmers (1998) conforme a figura acima, leva em conta o grau da integração funcional do negócio eletrônico com seus fornecedores e consumidores e o grau de inovação de cada um dos modelos de negócio listados. A tabela na página seguinte ajuda a entender o que como operam cada um dos modelos propostos por Timmers. 


\begin{tabular}{|c|c|}
\hline Modelo & ção \\
\hline e-shop & $\begin{array}{l}\text { Loja virtual: vende produtos, serviços ou informações através da } \\
\text { WWW }\end{array}$ \\
\hline 11 & $\begin{array}{l}\text { Portal de Informação: Disponibiliza diversas formas de } \\
\text { informação como noticias, catálogos e outros serviços de } \\
\text { informação. }\end{array}$ \\
\hline trust : & $\begin{array}{l}\text { Serviços de garantia de identificação como, por exemplo, a } \\
\text { venda de certificados seguros SSL. }\end{array}$ \\
\hline e-pro & $\begin{array}{l}\text { Compra de produtos ou serviço de fornecedores através de } \\
\text { requisições de proposta dos fornecedores através da WWW }\end{array}$ \\
\hline e-auction & $\begin{array}{l}\text { Leilão virtual: prove infra-estrutura de venda produtos, serviços } \\
\text { ou informações através de leilões pela WWW. }\end{array}$ \\
\hline e-mall & $\begin{array}{l}\text { Shopping Virtual: Agrega diversos serviços de e-shop e promove } \\
\text { os mesmos para os consumidores. }\end{array}$ \\
\hline $\begin{array}{l}\text { value chain } \\
\text { service } \\
\text { provider }\end{array}$ & $\begin{array}{l}\text { Negócios específicos dentro da cadeia de valor como, por } \\
\text { exemplo, logística ou meios de pagamento. }\end{array}$ \\
\hline $\begin{array}{l}\text { virtual } \\
\text { commu }\end{array}$ & $\begin{array}{l}\text { Realização de negócios através de comunidades virtuais onde os } \\
\text { próprios participantes alimentam as informações. }\end{array}$ \\
\hline $\begin{array}{l}\text { collaborat } \\
\text { platform }\end{array}$ & $\begin{array}{l}\text { Provisão de ferramentas e ambiente para colaboração entre } \\
\text { potenciais parceiros de negócio. }\end{array}$ \\
\hline $\begin{array}{l}\text { 3rd Party } \\
\text { Marketplace }\end{array}$ & $\begin{array}{l}\text { Terceirização de canais de venda ou de relacionamento com o } \\
\text { consumidor }\end{array}$ \\
\hline $\begin{array}{l}\text { Value Chain } \\
\text { Integration }\end{array}$ & $\begin{array}{l}\text { Foca na integração dos diversos elos da cadeia de valor e explora } \\
\text { o fluxo de informação entre os passos. }\end{array}$ \\
\hline
\end{tabular}

Tabela 2 - Descrição dos modelos de negócio estudados por Timmers(1998) 


\subsubsection{Decomposição e comparação de modelos de negócio}

Para comparar os diversos modelos de negócio propostos, foi proposto por Peterovic et al. (2001) uma técnica de decomposição de modelos de negócio. A técnica proposta por Peterovic parte do seguinte pressuposto: “um modelo de negócio não é a descrição de um sistema social complexo com seus atores, relações e processos. $\mathrm{Na}$ verdade, um modelo de negócio descreve a lógica utilizada para criar o valor que se encontra atrás dos processos reais de um sistema de negócio. O modelo de negócio dá sentido aos diversos processos de negócio ao explicar porque alguns processos de negócio são organizados da forma que são" e prega a decomposição do modelo de negócios em 7 sub modelos:

1. Modelo de Valor,

2. Modelo de Recursos,

3. Modelo de Produção,

4. Modelo de Relação com os Consumidores,

5. Modelo de Faturamento (Revenue),

6. Modelo de Capital,

7. Modelo de Mercado.

\subsubsection{Sub modelo de valor}

O sub modelo de valor descreve qual é o principal produto ou serviço vendido ou prestado por um negócio eletrônico, este sub modelo também descreve quais outros serviços agregados são prestados para o consumidor.

Exemplo de modelo de valor:

- Produto: Livros vendidos por lojas virtuais,

- Serviço: Recolocação profissional prestada através da WWW, 
- Experiência: Filmes exibidos por empresas de video on demand através de streaming na WWW.

\subsubsection{Sub modelo de recursos}

O sub modelo de recursos descreve quais elementos são utilizados para produzir o "Valor" do negócio, e a forma como estes elementos são adquiridos.

\subsubsection{Sub modelo de produção}

O sub modelo de produção descreve como os recursos adquiridos são combinados para produzir o "Valor" do negócio.

\subsubsection{Sub modelo de relação com os consumidores}

O sub modelo de relação com os consumidores descreve a lógica de como alcançar, atender e manter o consumidor. Este submodelo pode ser dividido sucessivamente em:

\subsection{Distribuição}

O sub modelo de distribuição descreve a lógica por trás do processo de entrega do valor ao consumidor. Normalmente o processo de entrega pode ser feito através de meios físicos ou eletrônicos. Por exemplo:

- Meio Físicos: A utilização de uma operadora logística para entregar um livro comprado através de uma loja virtual,

- Meios Eletrônicos: O download de um software adquirido em uma empresa de comércio eletrônico.

\subsection{Marketing}

O sub modelo de marketing descreve a lógica de como alcançar e manter os consumidores. Os processos de marketing pode ser divididos em processos mistos e processos 
puramente eletrônicos de acordo com a pré-existência do processo antes da criação do conceito de negócio eletrônico. Por exemplo:

- Mistos: Envio de divulgação em massa (mala direta / e-mail) e descontos no preço para consumidores regulares,

- Puramente eletrônicos: Personalização.

\subsection{Atendimento}

O sub modelo de atendimento descreve como um consumidor é atendido e as tecnologias utilizadas para o atendimento. Por exemplo:

- O web-site de uma loja de comércio eletrônico,

- O envio de toques de celular via MMS para os consumidores de uma operadora de telefonia celular,

- A utilização de streaming de vídeo pela Internet para a exibição de vídeos sob demanda.

\subsubsection{Sub modelo de faturamento}

Descreve como, quando, o quê, e por quê a empresa recebe compensação em retorno à relação com o consumidor.

Exemplo de modelos de faturamento:

- O preço que as lojas virtuais cobram pelos produtos vendidos antes da entrega do mesmo,

- As taxas fixas, ou proporcionais ao valor da transação, cobradas pelas empresas de leilões on-line após a realização de uma venda,

- O valor pago pelos anunciantes a cada exibição de uma determinada propagandas em web-sites de noticias, lazer ou mesmo nos de compra. 


\subsubsection{Sub modelo de capital}

O sub modelo de capital descreve a estrutura financeira do negócio.

\subsubsection{Sub modelo de mercado}

O sub modelo de mercado descreve o tipo de mercado escolhido e a estratégia de posicionamento no mesmo. O sub modelo de mercado também descreve qual a relação entre os participantes do negócio. A relação de negócio pode ser Negócio-Consumidor (Businessto-consumer) (B2C) ou Negócio-Negócio (Business-to-business) (B2B).

\subsubsection{Decomposição dos modelos de negócio propostos por Timmers}

Para entender quais modelos de negócio são candidatos à aplicação da técnica proposta por este trabalho, os modelos propostos por timmers devem ser decompostos quanto aos sub modelos de valor, faturamento e relação com os consumidores nas páginas seguintes. 


\begin{tabular}{|l|l|}
\hline Modelo & Sub Modelo de Valor \\
\hline e-shop & Produtos \\
\hline info brokerage & Informação \\
\hline trust service & Serviços. \\
\hline e-procurement & Produtos, Serviços ou Informação. \\
\hline e-auction & Produtos, Serviços ou Informação. \\
\hline e-mall & Serviços. \\
\hline value chain service provider & Serviços \\
\hline virtual community & Serviços e Informação. \\
\hline collaboration platform & Serviços. \\
\hline 3rd Party Marketplace & Serviços. \\
\hline Value Chain Integration & Serviços e Informação. \\
\hline
\end{tabular}

Tabela 3 - Decomposição dos modelos de negócio quanto ao valor

\begin{tabular}{|l|l|}
\hline Modelo & Faturamento \\
\hline e-shop & Preço Fixo \\
\hline info brokerage & Anúncios \\
& Mais raramente Taxas de assinatura e Preço Fixo \\
\hline trust service & Preço Fixo \\
\hline e-procurement & Taxas sobre o valor da transação. \\
& Mais raramente Taxas de assinatura \\
\hline e-auction & Taxas sobre o valor da transação \\
\hline e-mall & Assinatura \\
\hline value chain service provider & Pagúncios \\
\hline virtual community & Anúncios \\
\hline Collaboration platform & Mais raramente Taxas de assinatura \\
\hline 3rd Party Marketplace & Preço fixo por transação \\
\hline & Taxas sobre o valor da transação \\
\hline
\end{tabular}

Tabela 4 - Decomposição dos modelos de negócio quanto ao faturamento 


\begin{tabular}{|l|l|}
\hline Modelo & Relação com os consumidores \\
\hline e-shop & Negócio-Consumidor \\
\hline info brokerage & Negócio-Consumidor \\
\hline trust service & Negócio-Consumidor \\
\hline e-procurement & Negócio-Negócio \\
\hline e-auction & Negócio-Consumidor \\
\hline e-mall & Negócio-Negócio \\
\hline value chain service provider & Negócio-Negócio \\
\hline virtual community & Negócio-Consumidor \\
\hline collaboration platform & Negócio-Negócio \\
\hline 3rd Party Marketplace & Negócio-Negócio \\
\hline Value Chain Integration & Negócio-Negócio \\
\hline
\end{tabular}

Tabela 5 - Decomposição dos modelos de negócio quanto à relação com os consumidores

\subsubsection{Modelos de negócio candidatos à análise}

Nem todos os modelos de negócio existentes são candidatos a analise devido ao fato que em muitos modelos de negócio, o lucro por transação é ordens de grandeza maior que o custo dos recursos consumidos pela mesma.

Para que um modelo de negócio seja candidato à análise, duas condições devem ser satisfeitas:

1. Custo dos recursos consumidos com mesma ordem de grandeza do lucro da transação

2. Alto número de transações de negócio, ou seja, na maioria das vezes, relações negócio-consumidor.

Desta forma, os modelos de negócio candidatos à análise são os modelos "info brokerage", "e-auction", "e-mall" e "virtual community".

Exemplos de modelos de negócio que não são candidatos à análise são as lojas virtuais (e-shop), onde o lucro por transação é proporcional ao valor do faturamento que por sua vez é proporcional ao valor do produto vendido e o custo de cada transação envolve apenas os custos de exibição das informações para a realização das vendas, e o "collaboration platform", 
que apesar do custo dos recursos consumidos ser da mesma ordem de grandeza do lucro da transação, possui um baixo número de transações por se tratar de um serviço B2C

\subsection{Aplicações Ativas de Negócio Eletrônico para a WWW}

A construção de aplicações ativas de negócio eletrônico consiste na utilização de tecnologias para implementar e viabilizar os processos de negócio criados a partir do modelo de negócio. A utilização de uma arquitetura modular para as aplicações de comércio eletrônico é recomendada devido ao fato do comportamento da chegada dos consumidores ser em rajadas e do imenso número de consumidores potenciais que podem ser atendidos através da WWW. Do ponto de vista de negócios, problemas de desempenho nas aplicações implicam em um tempo elevado para a realização das transações e conforme descrito por Menasce (2000), após oito segundos de espera, de 8 a 35\% dos consumidores desistem de realizar o negócio para cada segundo a mais que ficam esperando pela realização da transação.

\subsubsection{Arquitetura Física}

A arquitetura física de uma aplicação de negócio através de meio eletrônico, além de implementar os processos de negócio deve levar em conta os seguintes fatores técnicos:

- Segurança,

- Escalabilidade,

- Carga esperada,

- Tecnologias utilizadas.

A segurança de uma aplicação de negócio eletrônico é dada pelo cumprimento dos requisitos: confidencialidade, integridade e disponibilidade. A confidencialidade é garantida através da utilização do protocolo HTTPS para a transmissão de dados críticos, pela utilização de ferramentas criptográficas no armazenamento de informações críticas e pela correta 
implementação da aplicação para que um usuário possa acessar somente as informações estritamente necessárias para a realização de um negócio. A integridade é garantida pelo armazenamento de todas as informações necessárias para se reconstruir cada passo de um processo de negócio e pela correta proteção dos dados e dos recursos dos sistemas contra ataques. Por último a disponibilidade é garantida, principalmente, através da correta definição da arquitetura e através do funcionamento da aplicação de forma que ataques contra o sistema não prejudiquem a realizações de negócios.

A escalabilidade é importante, já que a carga de uma aplicação de negócio eletrônico é dependente da quantidade de informação passada a cada consumidor, da qualidade da informação passada a cada consumidor e do número de consumidores simultaneamente atendidos. Desta forma, um sistema escalável permite que mudanças nos fatores descritos anteriormente possam ser compensadas pelo aumento da quantidade ou pelo aumento do desempenho de um ou mais módulos do sistema sem que o desempenho da aplicação seja afetado.

A carga esperada para um sistema de negócio eletrônico é um fator crítico, pois quanto maior o sucesso de uma aplicação, maior é o número de usuários que a utilizam. Somando-se este fator ao fato do número de consumidores atendidos simultaneamente apresentar picos em determinados períodos e ao fato do comportamento da chegada de consumidores ser em rajadas a aplicação deve estar preparada para suportar picos de utilização com cargas muito maiores que a média histórica sem que esta carga influencie no desempenho da aplicação.

Por último, as tecnologias escolhidas para a implementação da aplicação influenciam diretamente no desempenho, na segurança e na carga esperada por consumidor.

Devido aos fatores descritos anteriormente, convencionou-se que cada atividade distinta de uma aplicação de negócio eletrônico deve ser realizada por um conjunto de servidores específicos e escaláveis. Juntando-se todas as atividades necessárias para uma aplicação de 
negócio eletrônico, chega-se em uma arquitetura de referência descrita na figura abaixo. Tal arquitetura é baseada na combinação de característica de diversas arquiteturas físicas de sistemas comércio eletrônico estudadas pelo autor.

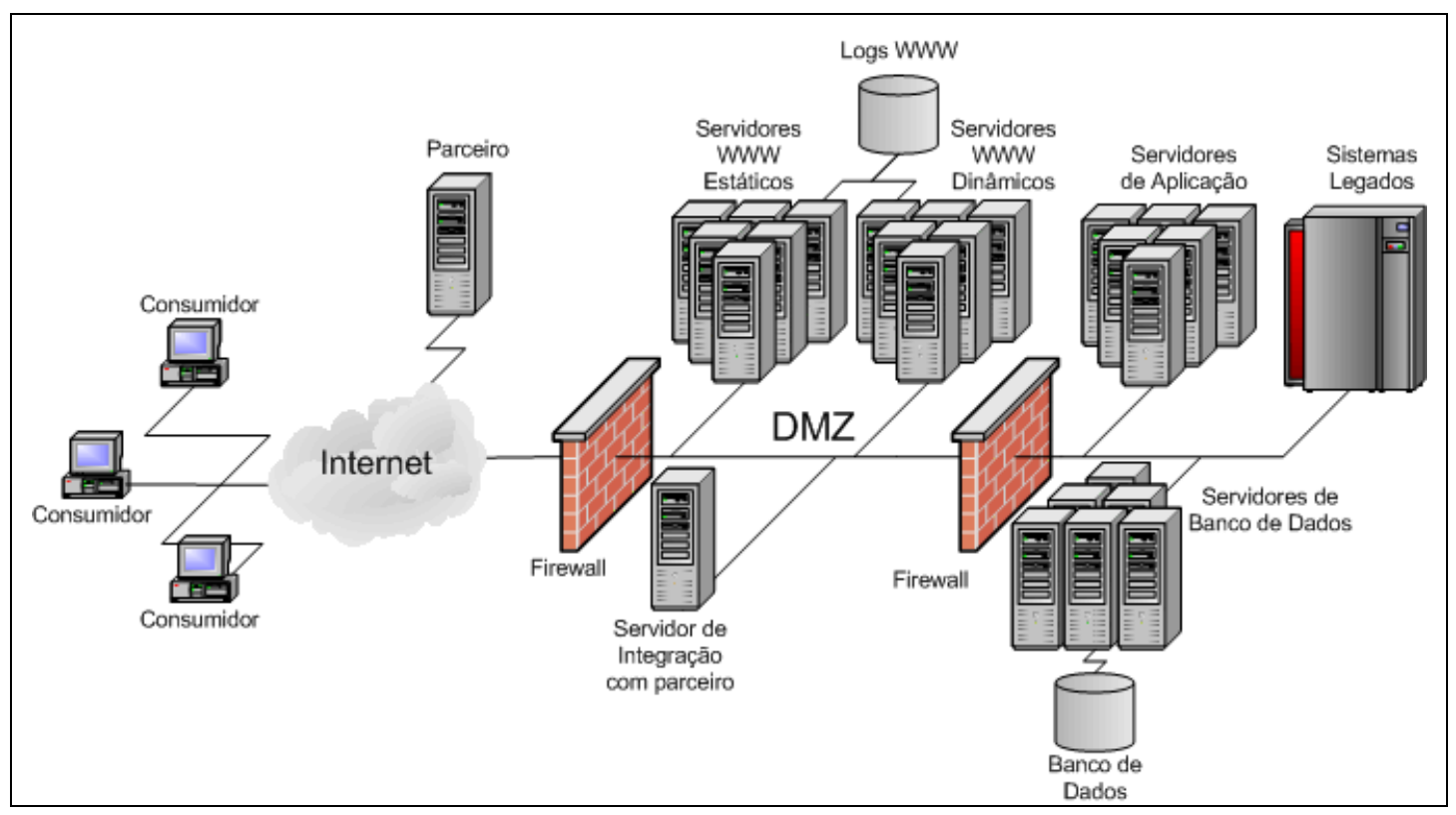

Figura 6 - Arquitetura de Referência para uma Aplicação Ativa de Comércio Eletrônico

A arquitetura de referência é composta de três zonas de segurança delimitadas através de dois equipamentos firewall. Na zona externa de segurança, ficam localizados os clientes e os parceiros. Na zona desmilitarizada (DMZ) ficam apenas os servidores que precisam ser acessados pelos consumidores e parceiros para a realização dos negócios. Por último, na zona interna ficam localizados todos os servidores que não devem ser acessados por nenhum elemento que não faça parte de aplicação de negócio. As zonas de segurança são formadas através da garantia que nenhuma comunicação que passe por um dos equipamentos de firewall, consiga passar através do segundo equipamento. Firewalls são dispositivos de rede que permite ou nega a passagem de um pacote de dados através do mesmo de acordo com um conjunto de regras pré-estabelecidas 
Os servidores se localizados na DMZ e na zona interna podem ser descritos da seguinte forma:

\subsubsection{Servidor WWW Estático}

A função do servidor WWW estático é armazenar todo o conteúdo não ativo de uma aplicação de comércio eletrônico, como por exemplo:

- Imagens,

- Arquivos de Estilo (CSS),

- Arquivos dinâmicos para execução pelo cliente WWW com arquivos Javascript e Applets Java.

\subsubsection{Servidor WWW Ativo}

O servidor WWW ativo possui funções distintas dependendo da arquitetura de software adotada. Caso seja adotada uma arquitetura baseada na tecnologia J2EE, a função do servidor WWW ativo é fazer apenas o tratamento da requisição HTTP e a criptografia quando for utilizado o protocolo HTTPS, já que o tratamento da requisição e a geração da página HTML são feitos pelo servidor de aplicação.

Caso a solução adotada seja baseada em outras tecnologias, além do tratamento da requisição e da criptografia, o servidor WWW ativo também deve interpretar um script ou executar o programa CGI para gerar a página HTML. A utilização de arquiteturas de gerações mais antigas não exclui a possibilidade de uso de servidores de aplicação já que podem ser utilizadas soluções onde parte do processamento é feita pelo servidor ativo e parte do processamento é feita pelo servidor de aplicação através da utilização de objetos distribuídos ou da utilização de soluções proprietária para divisão de tarefas entre programas rodando no servidor ativo e no servidor de aplicação. 


\subsubsection{Servidor de Aplicação}

A função do servidor de aplicação é dividir a carga de processamento de requisições a conteúdo ativo com o servidor WWW ativo. A grande vantagem da utilização de servidores de aplicação é a segurança extra criada pelo fato de o servidor de aplicação ficar na região segura após a zona desmilitarizada (DMZ) e dessa forma não ser possível um atacante que esteja na Internet conseguir acessar o servidor e desta forma executar as aplicações que rodam no servidor ou mesmo obtê-las.

\subsubsection{Banco de Dados}

A função do servidor de banco de dados é armazenar os dados utilizados pelas aplicações dinâmicas executadas pelos servidores WWW ativos e pelos servidores de aplicação. Por segurança, o servidor de banco de dados também deve ficar na região segura.

\subsubsection{Sistemas Legados}

Em muitas situações, uma aplicação ativa de negócio eletrônico precisa acessar sistemas legados pré-existentes para poder funcionar corretamente. Os sistemas legados existem devido à realização de negócios semelhantes pela empresa através de outros canais e meios de comunicação e precisam ser integrados às aplicações de comércio eletrônico para garantir a correta geração e contabilização de informações necessárias para o suporte às estratégias e objetivos da empresa.

\subsubsection{Sistemas Parceiros}

Em muitas situações, uma aplicação ativa de negócio eletrônico precisa acessar sistemas parceiros como, por exemplo, quando um web-site de comércio eletrônico precisa acessar um 
sistema bancário para verificar a autorização de transações bancárias para meios de pagamento.

Caso o sistema parceiro seja acessível através de caminhos seguros como linhas de dados privativas ou redes virtuais privativas (VPN), os servidores de acesso a sistemas parceiros devem ficar na região segura, caso o acesso aos sistemas parceiros só possa ser feito através da Internet, os servidores de sistemas parceiros devem ficar na DMZ.

\subsubsection{Outros Sistemas}

Em muitas situações, uma aplicação ativa de negócio eletrônico precisa acessar outros sistemas para poder implementar corretamente o processo de negócio. Como, por exemplo, a utilização de servidores de envio de correio eletrônico por uma aplicação de comércio eletrônico para poder informar ao consumidor a aprovação da transação bancária e a entrega do produto comprado ao operador de logística.

\subsubsection{Arquitetura Lógica}

Além da arquitetura física de uma aplicação de negócio eletrônico, também faz parte da definição da arquitetura da aplicação a arquitetura lógica da aplicação. A arquitetura lógica de uma aplicação de negócio eletrônico pode ser dividida em 3 atividades principais: Atendimento ao consumidor, tratamento de requisições e armazenamento de dados. A divisão de atividades entre os servidores pode ser vista na tabela abaixo:

\begin{tabular}{|l|c|c|c|}
\multicolumn{1}{c|}{$\begin{array}{c}\text { Servidor } \\
\text { Atividade }\end{array}$} & Apresentação & Negócio & $\begin{array}{c}\text { Armazenamento } \\
\text { de dados }\end{array}$ \\
\hline WWW Estático & $\mathrm{X}$ & & \\
\hline WWW Ativo & $\mathrm{X}$ & $\mathrm{X}$ & \\
\hline Aplicação & & $\mathrm{X}$ & \\
\hline Banco de Dados & & & $\mathrm{X}$ \\
\hline Sistemas Legados & & $\mathrm{X}$ & $\mathrm{X}$ \\
\hline Sistemas Parceiros & & $\mathrm{X}$ & \\
\hline Outros Sistemas & $\mathrm{X}$ & & \\
\hline
\end{tabular}

Tabela 5 - Divisão de atividades entre os servidores 


\subsubsection{Apresentação}

A apresentação consiste no atendimento ao consumidor através da interação direta, como por exemplo, a exibição da lista de produtos, a exibição de detalhe de um determinado produto ou o envio de um e-mail notificando o comprador do envio de um produto para o operador logístico.

Os servidores envolvidos na apresentação são principalmente os servidores WWW estáticos e os servidores WWW ativos. Normalmente para atender um consumidor também é necessário o tratamento da requisição do consumidor.

\subsubsection{Negócio}

O Negócio consiste no tratamento das requisições através da transformação do desejo do consumidor em um conjunto de operações cujo resultado são as informações a serem exibidas como resultado. Por exemplo, quando um consumidor clica no nome de uma das seções de uma loja virtual é entendido que devem ser exibidas informações sobre a seção da loja, uma lista com alguns produtos da seção e uma forma de se acessar os outros produtos da seção. Muitas vezes, para fazer corretamente o tratamento da requisição deve-se armazenar informações sobre o estado da navegação do consumidor e por isso, normalmente são utilizados cookies.

Os principais servidores envolvidos na camada de negócio são os servidores WWW ativos e os servidores de aplicação, pois estes servidores são responsáveis por entender o desejo do consumidor, através do estado atual e dos parâmetros enviados pelo consumidor, e fazer o tratamento da requisição através do armazenamento e obtenção de informações do banco de dados e através da interação com sistemas legados e sites parceiros. 


\subsubsection{Armazenamento de Dados}

O armazenamento de dados consiste em armazenar três tipos de dados que são utilizados por negócios eletrônicos:

- Dados de domínio discreto: utilizados para gestão e configuração de um web-site de negócio eletrônico.

- Dados operacionais: utilizados para o tratamento das requisições dos consumidores e para manter um histórico das operações realizadas pelos mesmos.

- Dados de consumidores: utilizados para a identificação dos consumidores recorrentes e para a personalização da interação com web-site de negócio eletrônico.

Os dados podem ser armazenados em servidores de banco de dados do web-site de negócio eletrônico ou em servidores legados principalmente quando o web-site de negócio eletrônico é apenas um dos canais de atendimento ao consumidor presentes no modelo de negócio.

\subsubsection{Estudo de caso: Funções de Negócio de uma aplicação de comércio eletrônico}

Cada um dos processos de negócio baseado no modelo de negócio pode ser dividido em uma ou mais funções de negócio sendo que cada função de negócio é responsável para atingir um determinado estado dentro de um processo de negócio.

Para entender melhor a relação entre modelo de negócio, processo de negócio, função de negócio e implementação, deve-se estudar um modelo hipotético de um negócio de venda de livros pela WWW. 


\subsubsection{Caracterização do Modelo de Negócios}

Primeiro, é necessário caracterizar o modelo de negócio escolhido. O modelo de negócio de uma loja virtual que vende livros através da WWW pode ser caracterizado da seguinte forma:

1. Submodelo de valor: A loja trabalhará com produtos, mais especificamente, livros.

2. Submodelo de relação com o consumidor: Distribuição dos produtos através dos correios para o mundo inteiro; Marketing através de faixas (Banners) em sites de noticias, cultura e entretenimento; Personalização baseada na identificação das compras potenciais de um consumidor baseado no seu histórico de consumo; E por último, atendimento através de um web-site de venda de livros e a utilização de correio eletrônico para informar o sucesso das operações de autorização de crédito e entrega do produto.

3. Submodelo de faturamento: Os livros terão preços fixo, ou seja, a venda não será por leilão, e os livros terão que ser pagos antes da entrega.

A partir desta caracterização, é possível exemplificar a classificação do modelo de negócio como uma loja virtual (e-shop)

\subsubsection{Processos de negócio}

A loja deve possuir um processo de negócio principal baseado no modelo de negócios: a venda de livros, e dois processos de negócio secundários:

- A indicação de sites onde o consumidor pode encontrar produtos complementares aos livros vendidos como, por exemplo, panelas no caso da venda de livros de receita. 
- A venda de livros devolvidos ou queima de estoques através de leilões realizados através de um parceiro de negócio, porém, acessíveis através de links existentes na loja.

\subsubsection{Funções de Negócio do Processo de negócio de venda de livros}

A partir da caracterização do modelo de negócio, é possível prever a existência das seguintes funções de negócio para o processo de negócio de venda de livros:

\subsection{Divulgação}

A função "Divulgação" deve ser a porta de entrada do consumidor e conter elementos de divulgação institucional, a relação das seções da loja, um elemento que permita a busca por livros e uma lista sugerida de livros para o consumidor baseado no histórico de compras do consumidor com links para acesso a detalhes de cada um dos livros da lista. A lista de livros deve ser baseada nos livros mais vendidos caso não seja possível identificar o consumidor ou nos livros mais indicados para o consumidor caso contrário.

\subsection{Navegação}

A função "Navegação" deve exibir ao consumidor uma lista com diversos títulos contendo a imagem da capa, o título, o autor e um resumo curto. Esta função deve ser utilizada para se exibir os livros de uma seção ou a lista de livros mais vendidos.

\subsection{Detalhes}

A função "Detalhes" deve exibir todos os detalhes sobre um determinado livro.

\subsection{Inserir no Carrinho}

A função "Inserir no Carrinho" deve reservar um determinado livro para que o consumidor possa comprá-lo posteriormente. 


\subsection{Pagamento}

A função "Pagamento" deve informar o consumidor sobre o valor total da compra, permitir a seleção de um meio de pagamento e direcionar o consumidor para o meio de pagamento escolhido.

\subsection{Busca}

A função "Busca" deve permitir a procura de um livro pelo seu titulo, autor, assunto, categoria, ISBN, descrição ou outras formas de categorização dos produtos.

\subsection{Personalização}

A função "Personalização" deve permitir que o usuário informe ou altere seus dados pessoais.

\subsubsection{Mapeamento de funções de negócio em uma aplicação de comércio eletrônico}

Para cada função de negócio levantada para um web-site de comércio eletrônico, é necessário levantar quais são os passos de negócio necessários para a sua implementação. Todo passo de negócio é implementado através de um módulo dentro da aplicação de negócio eletrônico e para cada passo também pode haver acessos ao banco de dados e a aplicações legadas.

Do ponto de vista de modelagem, cada passo de negócio possui um estado inicial, um conjunto de parâmetros esperados e um conjunto de estados finais que podem ser atingidos. $\mathrm{O}$ estado final atingido depende dos parâmetros recebidos, e do resultado do acionamento de um módulo de negócio. 


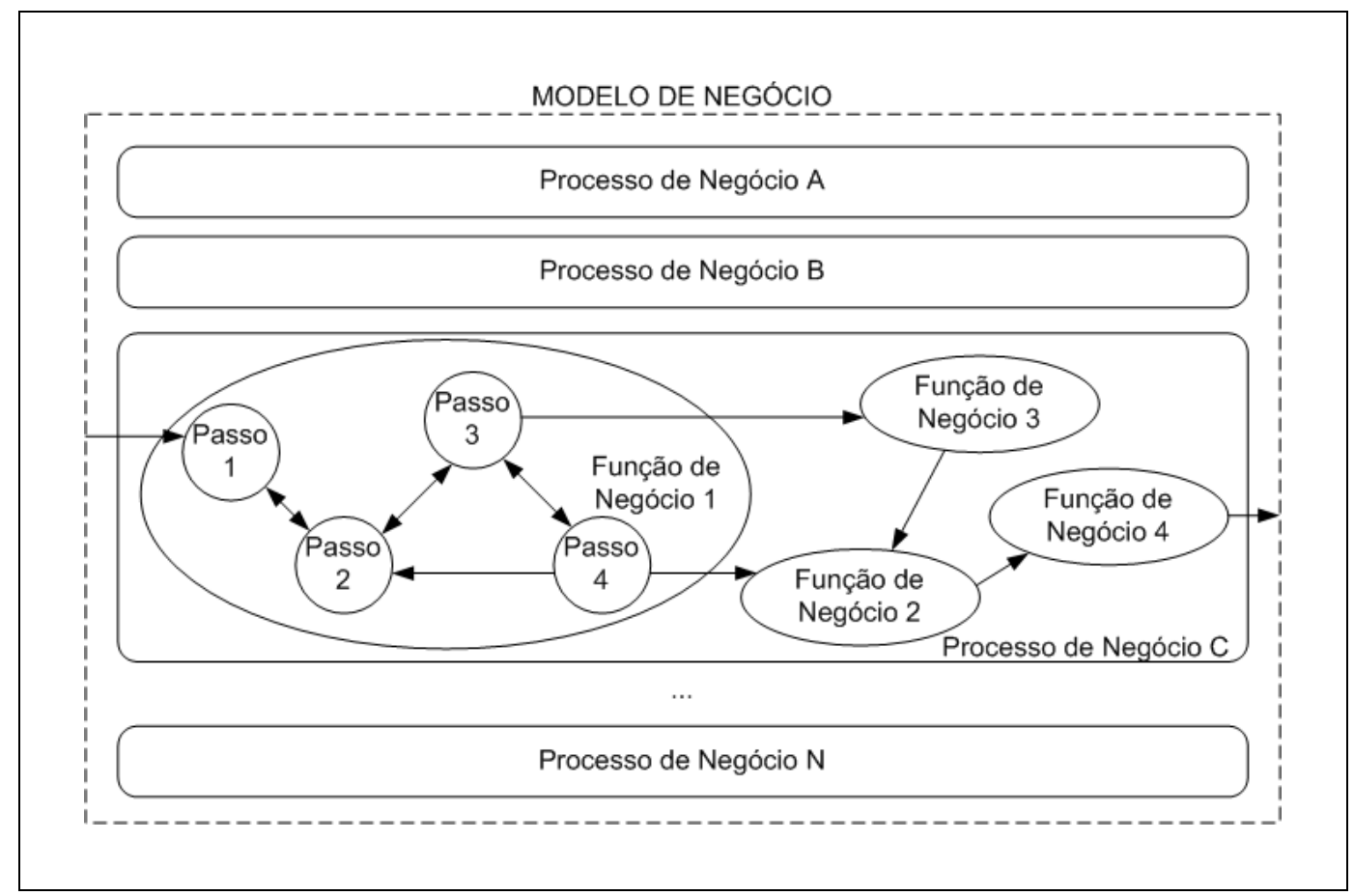

Figura 7 - Relacionamento entre Modelo, Processo, Função e Passo de Negócio

A forma de implementação de um passo de negócio varia de acordo com a tecnologia adotada para a implementação, porém, independente da tecnologia adotada, cada passo de negócio, gera evidências de sua execução no $\log$ do servidor WWW. Dependendo da implementação, o estado final atingido também pode ser estimado através das informações contidas $\log$ do servidor WWW. Por exemplo: Em um determinado web-site, quando o usuário atinge uma página de confirmação de transação e ocorre um erro, o tamanho da página é menor que o tamanho da página quando o usuário atinge uma página de confirmação de transação e não ocorrem problemas. Desta forma, o campo "sc-bytes" do log pode ser utilizado para inferir se o resultado foi positivo ou negativo e associar passos de negócio diferentes para diferentes resultados mesmo quando um mesmo módulo é acessado.

Por exemplo, para executar uma função de negócio "pagamento" para uma loja virtual "hipotética", seria necessário à implementação dos seguintes passos: 
1. Exibir a lista de produtos selecionados com os seus respectivos preços, um botão para confirmação da compra, um botão para cancelar a compra e outro botão para continuar comprando.

2. Exibir uma lista com as formas de pagamentos disponíveis para o consumidor, um botão para confirmação da compra e outro botão para voltar ao passo anterior.

3. No caso de confirmação da compra, o cliente deve ser direcionado ao site processador do meio de pagamento selecionado. Este passo por ser externo pode ser composto de diversos passos

4. No último passo deve ser exibida uma mensagem indicando o sucesso ou o fracasso da transação através do meio de pagamento.

\subsubsection{Análise do comportamento dos consumidores}

Em uma aplicação de negócio eletrônico, cada passo de negócio seguido por um consumidor é realizado através do envio de informações pelo consumidor, do processamento das informações enviadas e, por último, através da montagem de uma página HTML contendo orientações para o consumidor ou contendo uma nova requisição de informações complementares através de um formulário.

O comportamento do consumidor é estudado através da análise de quais passos de negócio foram seguidos, em qual seqüência e qual o passo final de negócio atingido. Como cada passo de negócio é implementado através de uma página HTML gerada dinamicamente, é possível analisar o comportamento do consumidor através do conhecimento de quais páginas foram acessadas e em qual momento cada uma dessas páginas foi acessada. Esta informação pode ser obtida através da monitoração ativa da aplicação ou através do processamento das informações armazenadas nos logs dos servidores WWW. 
As mesmas informações que permitem analisar o comportamento do consumidor, também permitem medir o consumo de recursos de cada requisição através da análise da quantidade de informação transmitida e através do tempo necessário para o processamento da requisição do consumidor. 


\section{Modelagem do Comportamento de Consumidores}

Desde a criação da WWW diversas pesquisas buscam extrair de forma coerente informações sobre o comportamento de consumidores, pois, da mesma forma que em empresas tradicionais, a experiência de um consumidor ao realizar uma transação de negócio é um fator crítico na probabilidade de efetivação da transação e na possibilidade do mesmo consumidor realizar outras transações no futuro.

A modelagem do comportamento de consumidores consiste em estudar a forma que os consumidores interagem com aplicações de negócio eletrônico. Como todas as interações através da WWW são feitas através de servidores WWW, a melhor forma de se estudar estas interações é através da análise das informações trocadas entre o consumidor e o servidor WWW. Esta análise pode ser feita através da adaptação da aplicação de negócio eletrônico para armazenar as informações necessárias ou através da análise das informações contidas nos $\log s$ de servidores WWW.

Diversos trabalhos propuseram formas e ferramentas distintas para a análise destas informações. Esta distinção é devida ao fato de cada um dos trabalhos pretender analisar um determinado fator do comportamento dos consumidores e por isso apenas as informações pertinentes à análise são extraídas e armazenadas. Outro fator foi que a maioria dos trabalhos utilizou informações contidas em logs de servidores WWW, devido à facilidade de obtenção dos mesmos.

Para entender a modelagem do comportamento de consumidores, é necessário entender como o comportamento dos consumidores é capturado, filtrado, identificado e por último analisado. 


\subsection{Trabalhos Relacionados}

A análise de desempenho e a caracterização de cargas de servidores WWW são tópicos amplamente estudados desde a popularização da WWW.

O conceito de se obter informações de comportamento de consumidores e informações de desempenho através de $\log s$ de servidores WWW é comumente utilizado devido à sua simplicidade e ao fato da analise de $\log s$ não afetar o desempenho dos servidores nem requerer a preparação dos servidores antes da analise.

Alguns trabalhos na área de caracterização de carga e analise de comportamento de usuário serviram como inspiração e referência para o presente trabalho.

\subsubsection{Uma metodologia para Caracterização de Carga para Sites de Comércio Eletrônico}

O artigo "A Methodology for Workload Characterization of E-commerce Sites" Apresentado em Menasce et al. (1999), é a principal fonte de referências deste trabalho e descreve uma metodologia de caracterização da carga gerada em um web-site de negócio eletrônico para um conjunto de consumidores. Esta caracterização é feita através da elaboração de uma matriz de probabilidade de transição entre cada página web-site montada a partir do processamento das informações contidas em logs de servidores WWW.

A solução é baseada na construção de uma matriz de probabilidades de transição entre as diversas páginas de um web-site e é estudada em maior profundidade no capítulo 4 deste trabalho.

O foco deste artigo é a caracterização da carga de ambientes transacionais para o correto dimensionamento destes ambientes. Por este motivo, a metodologia proposta neste artigo despreza muita informação que é necessária para a correta medição do consumo de recursos e 
não se preocupa em definir formalmente a metodologia de agrupamento de consumidores em classes de consumidores para a realização da análise.

\subsubsection{Na Busca por Invariantes em Cargas de Negócios Eletrônicos}

O artigo "In Search of Invariants for E-Business Workloads" escrito por Menasce et al. (2000), parte da pesquisa feita por Arlitt e Williamson (1996) e verifica se após cinco anos de crescimento exponencial e mudança de paradigmas na WWW, as 10 invariantes encontradas pelos autores continuam válidas.

O artigo propõe a existência de sete invariantes de carga que se aplicam a web-sites de comércio eletrônico. $\mathrm{O}$ artigo calcula diversas medidas de carga para dois sites: um de venda de livros e outro de leilões. Outra proposição do artigo é uma hierarquia de carga baseadas nas camadas: HTTP Request, Function e Session para caracterizar os logs.

O principal tema do artigo é a verificação da validade das invariantes após cinco anos da pesquisa de referência e também despreza informações importantes para a medição do consumo de recursos. Porém, o artigo é importante para o presente trabalho, pois, introduz uma hierarquia de caracterização de requisição em 3 níveis, que serve de inspiração para este trabalho, estabelece uma técnica para a detecção de robôs em logs WWW e calcula a influência de robôs na carga de web-sites.

\subsubsection{Controle de Sobrecarga Baseado em Sessões para Servidores com Suporte à Qualidade de Serviço.}

Chen e Mohapatra (2002) propõem no artigo "Session-Based Overload Control in QoSAware Web Servers" uma metodologia para a garantia do QoS (qualidade de serviço) em servidores WWW através da substituição do algoritmo de enfileiramento de requisições do servidor WWW por um outro algoritmo que, dado que uma sessão é caracterizada, o algoritmo cria uma fila no servidor para cada função da aplicação. Estas filas são penalizadas 
ou bonificadas baseado na quantidade de requisições existentes na próxima fila para a qual um usuário tende a ir após a requisição que está na fila ser processada.

O artigo não aborda nenhuma das técnicas ou tecnologias utilizadas para a elaboração deste trabalho, porém, a técnica de substituição do algoritmo de enfileiramento do servidor WWW proposta pelo artigo pode ser utilizada junto com dados obtidos pelo presente trabalho para que o servidor WWW garanta a priorização das requisições de acordo com o retorno esperado do consumidor de cada requisição.

\subsubsection{Caracterização Fractal de Cargas em Aplicações para a Web}

O artigo "Fractal Characterization of Web Workloads" escrito por Menasce et al. (2002) utiliza um algoritmo fractal de agrupamento de sessões aplicado sobre a metodologia de analise de carga CVM (Customer Visit Model) para agrupar as sessões em grupos. Após o agrupamento, a analise das navegações contidas dentro do grupo, permite aos autores extrair a o comportamento e a intenção da navegação e desta forma classificar os grupos.

$\mathrm{O}$ artigo, assim como outros artigos do mesmo grupo de pesquisadores, também despreza informações importantes para a medição do consumo de recursos, porém o algoritmo fractal de agrupamento de sessões proposto neste artigo pode ser utilizado para realizar o agrupamento de consumidores ou sessões em classes, que é um dos passos anteriores à aplicação da metodologia proposta neste trabalho.

\subsubsection{Descoberta e Análise Inteligente da Composição do Tráfego de Usuários Web}

O trabalho "Lumberjack: Intelligent Discovery and Analysis of Web User Traffic Composition" compara diversas metodologias e técnicas de agrupamento (clustering) de sessões apresentado por Chi et al. (2002). A comparação das técnicas de agrupamento é feita através de uma experiência onde são dados diferentes objetivos a diferentes grupos de 
usuários e estes usuários navegam em um web-site para cumprir o objetivo dado. Depois, são aplicadas diversas técnicas de agrupamento para comparar e avaliar as técnicas de agrupamento já que os grupos que devem ser formados já são conhecidos. Por último é proposta uma metodologia de agrupamento chamada Lumberjack que se caracteriza por utilizar apenas o conjunto mínimo de fatores necessários para um agrupamento eficiente.

As metodologias analisadas por este trabalho, são principalmente metodologias de agrupamento de sessões utilizadas para web-sites estáticos. Porém, a metodologia Lumberjack proposta, realiza o agrupamento de consumidores ou sessões em classes, que é um dos passos anteriores à aplicação da metodologia proposta neste trabalho.

\subsection{Captura do Comportamento de Consumidores}

Existem três formas de se obter as informações necessárias para a análise: através da compilação de dados existentes nos $\log s$ dos servidores WWW, através do monitoramento ativo da navegação dos consumidores no servidor WWW ou através do monitoramento dinâmico da navegação do consumidor através de extensões ou scripts executados pelo cliente WWW. Cada forma de análise possui suas vantagens e desvantagens.

A obtenção dos dados através do processamento dos dados existentes nos $\log s$ dos servidores WWW é mais vantajosa quando o período para o qual se deseja fazer a analise de comportamento dos usuários é anterior à decisão de análise. Outra vantagem de se utilizar à obtenção dos dados através do processamento dos dados existentes nos logs é a garantia que a execução da análise não interfere no comportamento do consumidor nem no desempenho do sistema. A maior restrição desta forma de obtenção de dados é que a qualidade da análise será proporcional à qualidade das informações armazenadas nos $\log s$, pois diversas informações que são tratadas como opcionais pela maioria dos servidores WWW são extremamente importantes para a correta caracterização da sessão no passo seguinte da análise. Outra restrição é que os dados de comportamento de consumidor só ficam disponíveis após o 
processamento dos logs, tarefas que costuma ser lenta devido ao tamanho que os mesmos costumam atingir.

A monitoração ativa da navegação dos consumidores no servidor WWW consiste na alteração do servidor WWW ou da aplicação de negócio eletrônico para armazenar em banco de dados as sessões e requisições dos consumidores no mesmo instante que as requisições são feitas. Através desta forma de obtenção de navegação garante-se a identificação inequívoca das sessões e também a disponibilidade imediata dos dados para as outras fases da análise. A desvantagem é que a monitoração interfere diretamente no desempenho do sistema.

Outra restrição compartilhada pelas duas formas descritas anteriormente é a incapacidade de detecção de alguns elementos de uma navegação. Algumas navegações não são detectadas por não gerarem requisições, como por exemplo, a navegação através do botão voltar do browser, ou que não são detectadas, pois são respondidas diretamente por proxies sem que esta requisição chegue ao servidor WWW.

Para resolver estas restrições foi proposta por Fenstermacher e Ginsburg (2002) a monitoração dinâmica do comportamento do consumidor através da utilização de um componente de monitoração no browser já que o browser é o elemento mais próximo ao consumidor e desta forma é menos sujeito à perda de informações devido a proxies e etc. $\mathrm{O}$ grande problema desta limitação é a questão da privacidade do consumidor já que eventos que ocorrem no equipamento do consumidor são monitorados e transmitidos para o negócio.

Quando se utiliza monitoração dinâmica ou ativa, é fácil identificar o consumidor através de sua sessão. Porém, quando é utilizada informação armazenada em logs, a identificação é mais trabalhosa e imprecisa, pois, a qualidade da informação extraída dos logs depende da quantidade de informações opcionais armazenadas. Para determinar a seqüência de acessos de um determinado usuário, as seguintes informações do log são necessárias ou úteis:

- Ordem da requisição dentro da seqüência: date e time. 
- Sessão: c-ip, cs-uri-query, cs(Cookie) ou cs(Referrer)

- Usuário: cs-username. cs-uri-query, cs(Cookie) ou obtido de fonte externa a partir da Sessão.

Através dos campos "cs-uri-query", "cs(Cookie)", "cs(Referrer)" é possível identificar a sessão quando a aplicação dinâmica utilizada armazena ou transmite informações de identificação da sessão neste campo. Caso o arquivo de log não armazene estes campos ou a informação armazenada não seja suficiente para identificar a sessão, a sessão pode ser identificada através do endereço IP de origem da requisição "c-ip" desde que a diferença entre o momento da requisição e o momento da última requisição para o mesmo endereço de origem seja menor que um tempo mínimo pré-determinado (time-out).

Através dos campos "cs-uri-query”, "cs(Cookie)", "cs(Referrer)” é possível identificar a sessão quando a aplicação dinâmica utilizada armazena ou transmite informações de identificação da sessão neste campo.

\subsection{Filtragem de Comportamentos}

Após a obtenção da navegação dos consumidores, a filtragem dos elementos desnecessários à análise deve ser feita. Neste passo, todas as requisições feitas ao servidor WWW que não interessam à análise, são descartadas para que não afetem o resultado da análise.

Um exemplo de filtragem é a remoção de requisições que apresentaram erros ou também a remoção de requisições efetuadas por robôs de pesquisa de preços ou indexação de websites. O conjunto de elementos de navegação que sobram após a filtragem pode ser chamado de lista de acessos. 


\subsection{Identificação de Sessões}

Após a filtragem, as requisições devem ser individualizadas por usuários e agrupadas seqüencialmente em sessões. O agrupamento em sessões serve para permitir a identificação de qual módulo um consumidor estava acessando antes de acessar um segundo módulo. Existem três formas de se identificar sessões:

\subsubsection{Sessão Explicita}

Uma requisição possui uma sessão explicita quando algum dos elementos contidos nas requisições da lista de acessos permite identificar univocamente uma sessão. Este elemento geralmente é um código identificador de sessão armazenado em um cookie ou passado como parâmetro.

Quando é utilizado monitoramento dinâmico ou ativo, a identificação é sempre através de sessão explicita. Quando é utilizado monitoramento através de análise de log, só é possível identificar explicitamente a sessão quando algum identificador da sessão está presente nos campos “cs-uri-query”, “cs(Cookie)", "cs(Referrer)” da requisição HTTP e quando estes campos estão presentes no arquivo de log

\subsubsection{Sessão Seqüencial}

Quando não é possível identificar uma sessão de forma explicita, e o campo "cs(Referrer)" esta presente no arquivo de log, É possível identificar as sessões de forma seqüencial, pois o referrer é um dos campos obrigatórios do cabeçalho do protocolo HTTP e transmite a URI do objeto que gerou a requisição. Ou seja, quando é requisitada uma imagem Y para que uma página HTML X seja exibida, a URI da página HTML X é enviada no campo referrer da requisição de Y. Quando uma página HTML Y é requisitada após o usuário ter clicado em um link existente na página HTML X, a URI da página HTML X também é 
enviada no campo referrer. O campo referrer é transmitido por todos os clientes HTTP, porém, só é armazenado quando o servidor WWW está configurado para armazená-lo.

Desta forma, quando o campo referrer de uma requisição não é vazio, é possível localizar qual foi a página anterior através da URI enviado no campo referrer. Caso seja necessário saber o tempo decorrido entre uma requisição e a requisição anterior, pode-se localizar a requisição anterior na lista de acessos através de outros elementos de identificação existentes no URI do referrer, como por exemplo, os parâmetros passados ou localizando a última requisição à página anterior para o mesmo endereço IP da requisição.

\subsubsection{Sessão Implícita}

Quando não é possível identificar uma sessão de forma explicita ou seqüencial, sempre é possível identificar a sessão de forma implícita. Esta deve ser a última técnica de agrupamento de sessão a ser utilizada quando nenhum outro método possa ser utilizado já que é extremamente susceptível a erros de identificação causados pela utilização de proxies. A sessão implícita é obtida através do agrupamento das requisições por IP e o estabelecimento de um tempo máximo entre requisições (Time-out). Desta forma duas requisições existentes na lista de acesso pertencem a uma mesma sessão caso ambas tenha sido feitas a partir de um mesmo endereço IP e o tempo entre elas seja menor que um limite de tempo pré-estabelecido (Time-out).

Banerjee e Ghosh (2000) desenvolveram um método de se diminuir os erros causados pelos proxies através do uso de um crawler para catalogar todas as transições possíveis dentro um web-site antes de fazer o agrupamento de sessões. Desta forma, duas requisições pertencem a uma mesma sessão apenas se a transição entre as duas for viável. O grande problema do método proposto é que além de não conseguir impedir $100 \%$ dos erros causados por proxies, os crawlers costumam ter seu funcionamento limitado em web-sites ativos ou dinâmicos. Crawlers são aplicações que visitam uma a uma as páginas de um web-site 
seguindo os links entre as páginas e armazenam todas as páginas visitadas para posterior extração de informações

No artigo de Menasce et al. (1999), as sessões foram agrupadas através do método implícito.

\subsection{Análise de Comportamento de Consumidores}

Após a captura do comportamento dos consumidores, a filtragem e a identificação de sessões através de um dos métodos descritos anteriormente é possível fazer a análise do comportamento dos consumidores. As pesquisas sobre análise de comportamento de consumidores podem ser divididas em três grandes grupos: As análises baseadas em seqüências, as análises baseadas em páginas visitadas e as análises baseadas no caminho percorrido.

O primeiro grupo, representado principalmente pelos trabalhos de Paliouras et al. (1999), Zhang et al. (2000), Zhang e Chang (2002), Xing e Shen (2002), caracteriza o comportamento do consumidor através da sessão do mesmo. Na maioria das análises, também é preservado o horário em que a página foi requisitada.

Supondo que a sessão extraída para o acesso de um consumidor em um web-site composto pelas páginas $\mathrm{A}, \mathrm{B}, \mathrm{C}, \mathrm{D}, \mathrm{E}$ e F seja representada pela sessão $\mathrm{S} 1$ contendo a sequiência $\{\mathrm{A}, \mathrm{B}, \mathrm{C}, \mathrm{D}, \mathrm{C}, \mathrm{E}, \mathrm{C}, \mathrm{D}, \mathrm{F}\}$, a análise de comportamento utilizará como entrada a própria sessão S1, conforme figura abaixo: 


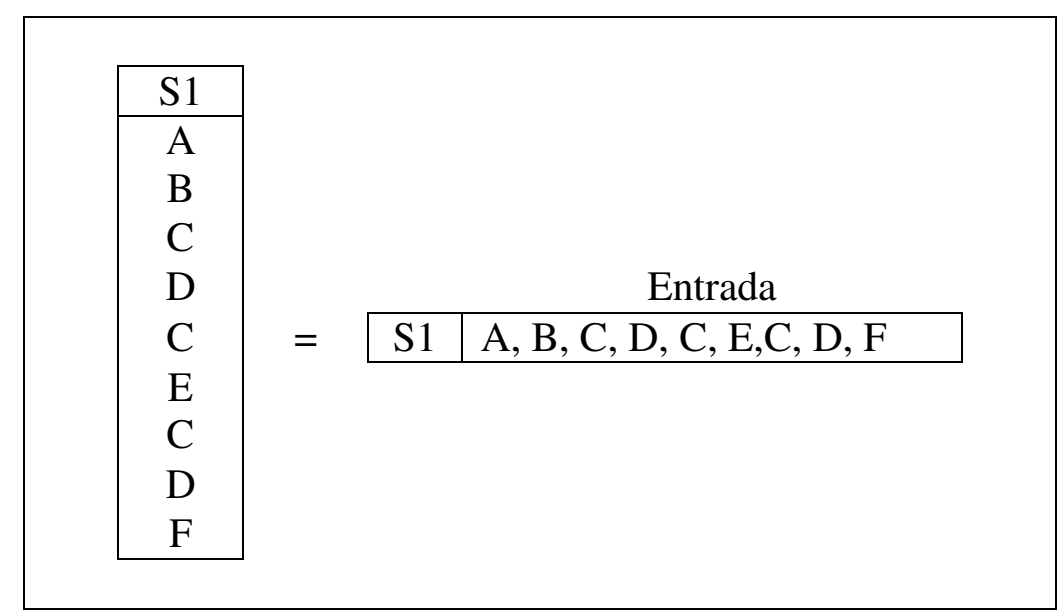

Figura 8 - Modelagem através de seqüência de requisições

O segundo grupo, representado principalmente pelos trabalhos de Toolan e Kusmerick (2002), Woon et al. (2002), Mah e Li (2002) e Chen et al. (2003), agrupa na forma de caminhos percorridos (traversal paths) a seqüência de páginas que precisam ser requisitadas pelos consumidores para se atingir uma determinada página. A grande diferença com relação ao primeiro grupo, é que em uma única sessão, um consumidor pode percorrer diversos caminhos percorridos para chegar a diversas informações. Desta forma, caso o consumidor após requisitar uma página, volte para a página anterior e depois navegue para uma terceira página, o caminho percorrido até a terceira página é dado pelo caminho percorrido até a página anterior somado à requisição da terceira página conforme figura abaixo.

Supondo que a sessão extraída para o acesso de um consumidor em um web-site composto pelas páginas $\mathrm{A}, \mathrm{B}, \mathrm{C}, \mathrm{D}, \mathrm{E}$ e F seja representada pela sessão S1 contendo a sequiência $\{\mathrm{A}, \mathrm{B}, \mathrm{C}, \mathrm{D}, \mathrm{C}, \mathrm{E}, \mathrm{C}, \mathrm{D}, \mathrm{F}\}$, a análise de comportamento utilizará como entrada os caminhos $\mathrm{C} 1, \mathrm{C} 2$ e C3 conforme figura abaixo: 


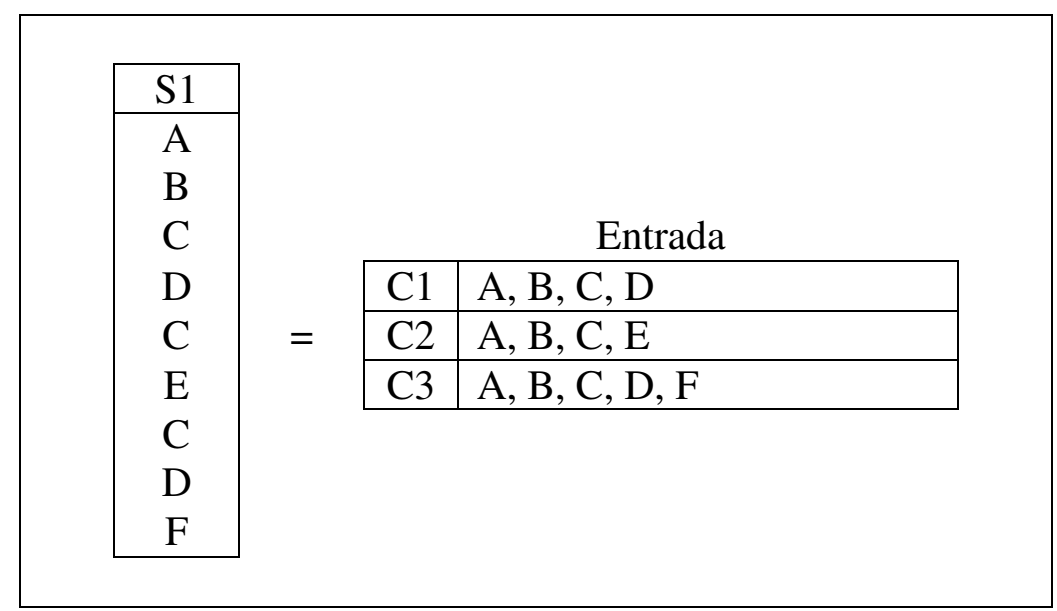

Figura 9 - Modelagem através do caminho percorrido

O terceiro grupo, representado principalmente pelos trabalhos de Menasce et al. (1999), Borges e Levene (2000), Theusinger e Huber (2000), Ohmori et al. (2002), consiste na extração apenas do conjunto de páginas visitadas por um consumidor, independente da seqüência em que foram requisitadas. No caso do trabalho de Menasce et al. (1999) também é armazenada a probabilidade de transição entre cada duas páginas. Apesar da informação sobre a ordem em que as requisições foram feitas existirem na sessão, esta informação é descartada pela análise, pois, apenas informações sobre o número de usuários que visitaram uma página Y após visitar uma página $\mathrm{X}$ são contabilizadas.

\begin{tabular}{|c|c|c|c|c|c|c|c|c|c|}
\hline S1 & \multirow{10}{*}{$=$} & \multicolumn{8}{|c|}{ Entrada } \\
\hline $\mathrm{A}$ & & $\mathrm{P}$ & $\mathrm{A}$ & $\mathrm{B}$ & $\mathrm{C}$ & $\mathrm{D}$ & $\mathrm{E}$ & $\mathrm{F}$ & $\mathrm{O}$ \\
\hline $\mathrm{B}$ & & $\mathrm{A}$ & 0 & 1 & 0 & 0 & 0 & 0 & 0 \\
\hline $\mathrm{C}$ & & B & 0 & 0 & 1 & 0 & 0 & 0 & 0 \\
\hline $\mathrm{D}$ & & $\mathrm{C}$ & 0 & 0 & 0 & $2 / 3$ & $1 / 3$ & 0 & 0 \\
\hline $\mathrm{C}$ & & $\mathrm{D}$ & 0 & 0 & $1 / 2$ & 0 & 0 & $1 / 2$ & 0 \\
\hline $\mathrm{E}$ & & $\mathrm{E}$ & 0 & 0 & 1 & 0 & 0 & 0 & 0 \\
\hline $\mathrm{C}$ & & $\mathrm{F}$ & 0 & 0 & 0 & 0 & 0 & 0 & 1 \\
\hline $\mathrm{D}$ & & & & & & & & & \\
\hline $\mathrm{F}$ & & & & & & & & & \\
\hline
\end{tabular}

Figura 10 - Modelagem através da probabilidade de transição 
O primeiro grupo de modelagens é comumente utilizado para a previsão da próxima página a ser requisitada em uma sessão, tal previsão costuma ser muito utilizada para a melhoria de desempenho de proxies e de servidores WWW através do pré-requisição (prefetch) da próxima página a ser requisitada por um usuário.

O segundo grupo de modelagens, além de ser utilizado para a melhoria de desempenho através de pré-requisição de páginas, também costuma ser utilizado para elaboração de mapas de navegação (site maps) personalizados e para otimizar a estrutura de navegação de websites. Estes dois grupos de modelagens são aplicados principalmente a web-sites estáticos de divulgação.

O terceiro grupo de modelagens, apesar de ser mais simples, também costuma ser utilizado para melhoria de desempenho através de pré-requisição de páginas, porém, conforme notado por Chi et al. (2002) as previsões geradas através deste grupo de modelagens costumam ter seu desempenho abaixo das previsões geradas através da utilização das outras modelagens. Devido a esta limitação, o terceiro grupo de modelagens costuma ser utilizado principalmente para a analise de desempenho de sistemas de aplicações de negócio eletrônico, já que em aplicações de negócio eletrônico, geralmente só é possível atingir uma determinada página, quando um determinado estado de um negócio eletrônico é atingido, e desta forma, a seqüência de páginas que foi percorrida para se atingir uma determinada página não é importante.

Para este trabalho, é importante entender a modelagem Customer Behavior Model Graph (CBMG) proposta por Menasce e Outros (1999) que é classificada no terceiro grupo.

\subsection{Análise de Comportamento CBMG}

A análise de comportamento CBMG consiste em levantar o perfil médio de navegação de um grupo de consumidores do sistema alvo através do cálculo de uma matriz que contém a 
probabilidade de um usuário navegar de uma página a uma outra página do sistema. No artigo de Menasce et al. (1999), os dados são obtidos através do processamento de logs.

Cada célula da matriz contém a probabilidade de um usuário navegar do módulo identificado na linha da matriz para o módulo identificado na coluna. Desta forma a soma das probabilidades em cada uma das linhas deve ser sempre 1.

Para uma navegação em um Web-Site conforme a figura abaixo, teríamos uma matriz de probabilidade de acordo com a tabela após a figura:

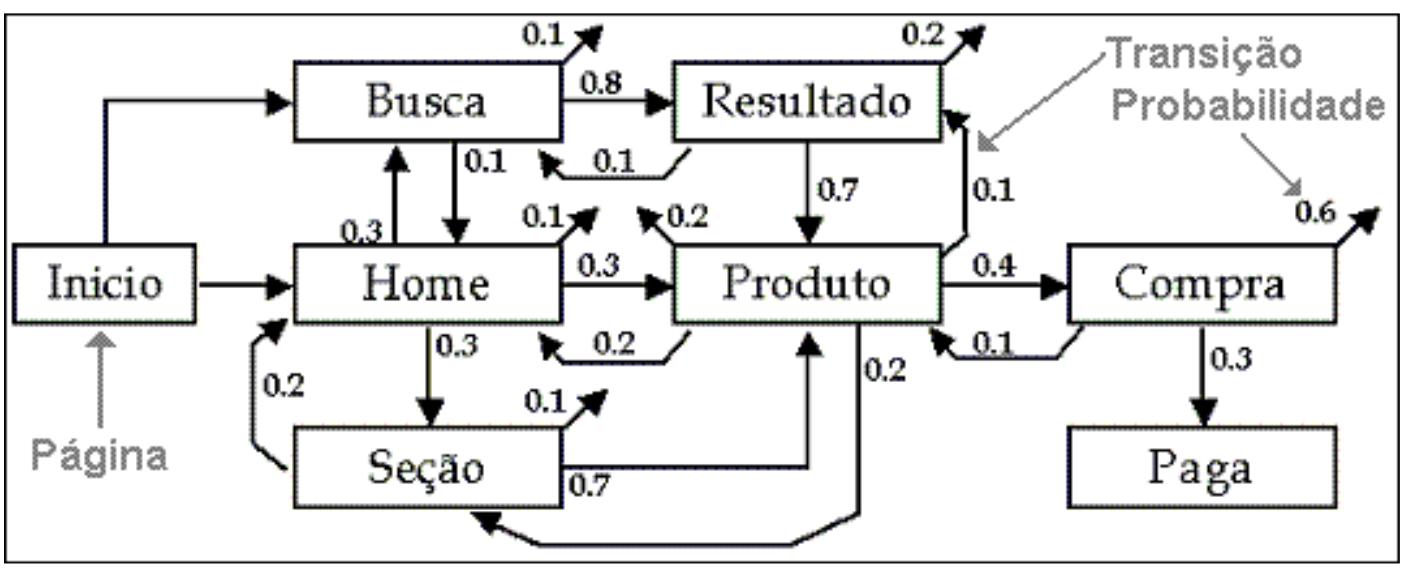

Figura 11 - Diagrama CBMG de um site de comércio eletrônico hipotético

\begin{tabular}{|l|c|c|c|c|c|c|c|c|} 
& Home & Busca & Seção & Resultado & Produto & Compra & Paga & Sair \\
\hline Home & 0.00 & 0.30 & 0.30 & 0.00 & 0.30 & 0.00 & 0.00 & 0.1 \\
\hline Busca & 0.10 & 0.00 & 0.00 & 0.80 & 0.00 & 0.00 & 0.00 & 0.1 \\
\hline Seção & 0.20 & 0.00 & 0.00 & 0.00 & 0.70 & 0.00 & 0.00 & 0.1 \\
\hline Resultado & 0.00 & 0.10 & 0.00 & 0.00 & 0.70 & 0.00 & 0.00 & 0.2 \\
\hline Produto & 0.20 & 0.00 & 0.20 & 0.10 & 0.00 & 0.40 & 0.00 & 0.1 \\
\hline Compra & 0.00 & 0.00 & 0.00 & 0.00 & 0.10 & 0.00 & 0.30 & 0.6 \\
\hline Paga & 0.00 & 0.00 & 0.30 & 0.00 & 0.00 & 0.00 & 0.00 & 1.0 \\
\hline
\end{tabular}

Tabela 6 - Tabela de Probabilidades

A utilização da matriz de probabilidades é importante, pois, a partir da matriz de probabilidades, é possível obter: 
- Quais páginas são utilizadas pelos usuários para iniciar a navegação pelo site,

- O número médio de vezes que cada página é visitada por sessão,

- O tamanho médio (Ou seja, o número médio de páginas visitadas por sessão),

- A probabilidade de um usuário ir de uma página a uma outra página independente do caminho escolhido e do número de passos necessários,

- A probabilidade de um usuário deixar o site a partir de cada página

Caso seja definida uma forma de faturamento associada a uma ou mais páginas (ou transições) do sistema é possível estimar a média de faturamento para cada sessão. Um exemplo seria utilizar a análise descrita na figura 5, e definir que associado à função "Paga" existe um faturamento de acordo com o preço do conjunto de produtos selecionados. Desta forma pode ser calculado qual o retorno médio de cada classe de usuário do sistema multiplicando-se a probabilidade de um usuário efetuar uma compra pelo valor médio da compra.

O valor pago em uma transação de negócio pode ser extraído diretamente do log caso esta informação esteja contida nos campos "cs-uri-query", "cs(Cookie)" ou "cs(Referrer)". Uma outra forma de se extrair o valor da transação é a obtenção do valor da transação do banco de dados da aplicação através do identificador da transação ou do identificador da sessão quando um destes dados esteja contido nos campos "cs-uri-query", "cs(Cookie)" ou "cs(Referrer)".

Para fazer uma analise de comportamento CBMG é necessário seguir um conjunto de passos para transformar informações indiretas sobre a navegação do usuário em uma matriz de probabilidade de transição. 


\subsubsection{Filtragem}

No artigo de Menasce et al. (1999), a lista de acessos é obtida após a filtragem de todas as requisições que apresentaram erros e de todas as requisições a elementos estáticos, como imagens, scripts e outros objetos.

\subsubsection{Identificação de Sessões}

No artigo de Menasce et al. (1999), a sessão é identificada de forma implícita, pois a informação foi extraída de arquivos de logs com informações insuficientes para identificar as sessões de forma mais efetiva.

\subsubsection{Processamento dos Dados}

O processamento de dados é feito em duas partes. Primeiro, são selecionadas as lista de acessos apenas das sessões que forem pertinentes para a análise. Depois são contabilizadas todas as transições existentes na lista de acessos independente das sessões a que pertencem assim como também são marcados quais as últimas páginas de cada sessão para poder se calcular o total de saídas a partir da página.

Por último, a partir do total de transições entre as páginas, é calculada a probabilidade de navegação a partir da divisão do número total de navegações entre duas páginas pelo número total de navegações a partir da página de origem, somado ao número total de saídas a partir da página de origem da transição. A seqüência de operações realizadas no processamento de dados está ilustrada na figura abaixo. 


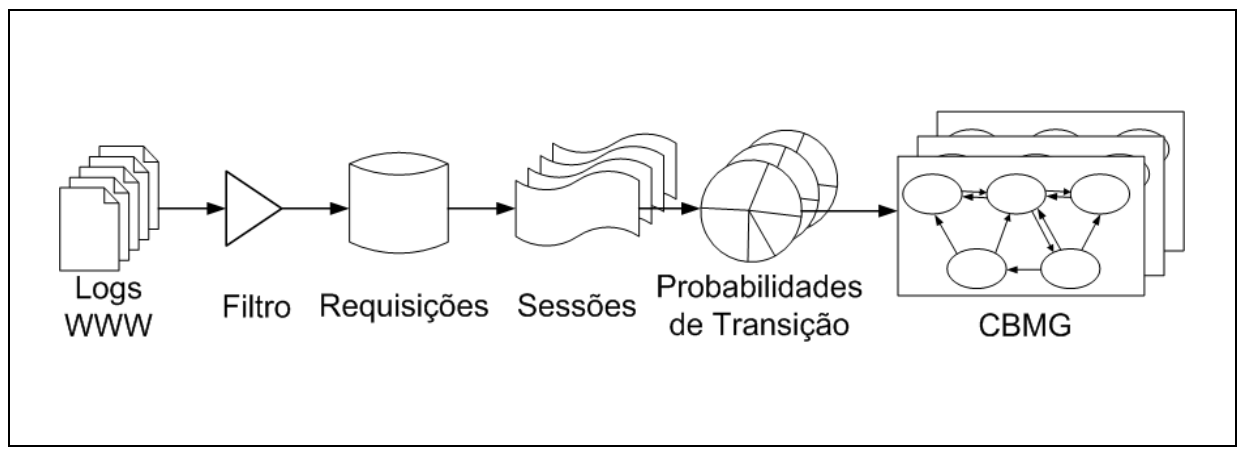

Figura 12 - Processamento dos dados para a obtenção do CBMG

\subsection{Restrições da análise}

A grande restrição de análise de comportamento é sempre condensar os resultados na forma de médias como, por exemplo, a sessão média, o usuário médio e o retorno médio por classe de usuário. Resultados condensados desta forma somente podem ser utilizados para análises de desempenho.

Tais análises são insatisfatórias para as necessidades modernas dos administradores de web-sites que demandam informações mais específicas sobre os usuários dos seus sistemas para poder utilizar técnicas de Business Intelligence (BI) e Customer Relationship Management (CRM) com o intuito de maximizar o retorno monetário dos sistemas.

Além destas restrições da própria análise, outros fatores internos e externos à análise influenciam os seus resultados:

\subsubsection{Filtragem indevida}

A filtragem de imagens, arquivos de estilo e arquivos dinâmicos, mascara dois dados importantes: o tamanho total de uma página e o tempo total para o carregamento da página. Tais informações podem ser vitais para explicar a desistência de um consumidor ou mesmo permite calcular qual é a taxa de transmissão média de dados para um consumidor já que o número de conexões que um cliente WWW abre com o servidor WWW é limitado e por isso, 
alguma forma de enfileiramento deve ser feita para que os arquivos complementares sejam requisitados.

\subsubsection{Identificação de sessão sujeita a erros devido a proxies}

$\mathrm{O}$ acesso a web-sites através de proxies faz com que as requisições recebidas pelos servidores WWW aparentem ter como endereço IP de origem, o endereço IP do proxy. Desta forma, quando dois ou mais usuários acessam um servidor WWW através de um proxy, suas sessões serão indistinguíveis caso a técnica de sessão implícita seja utilizada para identificar as sessões.

Outro efeito colateral causado por proxies é a criação de falsas transições em logs de servidor WWW, já que quando o consumidor solicita uma página que já foi armazenada em cache por um proxy, o proxy retorna a página requisitada que se encontra armazenada e não solicita a página ao servidor WWW. Este efeito não costuma ser importante em web-sites de comércio eletrônico, pois, devido à natureza ativa das páginas, as próprias páginas são construídas especificamente para cada usuário e desta forma não são reutilizadas pelos proxies. Outro fator que diminui o impacto deste efeito é que páginas que eventualmente não sejam requisitadas não afetam o desempenho dos web-sites de comércio eletrônico.

\subsubsection{Sessões irregulares geradas por crawlers e robôs de vendas}

Os crawlers são softwares que navegam em todas as páginas de um ou mais web-sites e armazenam os textos e os links de todas as páginas visitadas para serem utilizadas por ferramentas de buscas. Robôs de vendas são softwares que são executados em web-sites especializados em comparação de preços de produtos e visitam os web-sites de negócios eletrônicos como se fosse um consumidor comum para obter o preço de um determinado produto que está sendo pesquisado pelo consumidor "real" no web-sites de comparação de preços. 
Conforme notado por Menasce et al. (2000), crawlers e robôs algumas vezes são responsáveis por $16 \%$ das requisições de um web-site de negócio eletrônico. Por isso, as requisições feitas por robôs devem ser analisadas do ponto de vista de consumo de recurso, porém as requisições feitas por robôs devem ser filtradas de todas as análises de negócio que envolvam grupos de consumidores reais.

\subsubsection{Identificação errada devido a estruturas complexas de web-sites}

Conforme notado por Pabarskaite (2002), Estruturas complexas de web-site que utilizam, por exemplo: frames, iframes e AJAX geram múltiplas requisições a páginas HTML e módulos de negócio de um servidor WWW mesmo quando apenas uma página é requisitada.

Estas estruturas complexas complicam a análise já que para a montagem de uma única página, diversos arquivos HTML podem ser requisitados, mesmo quando o usuário não realizou nenhuma ação.

A utilização de frames, a primeira solução encontrada para o reaproveitamento de elementos de layout, consiste em carregar um documento HTML principal, o frameset, contendo a organização dos diversos frames que constituem o layout. Cada frame também é um documento HTML e, após o frameset ser processado pelo browser, cada um dos frames constituintes também é requisitado ao servidor WWW.

Os iframes apareceram para suprir a principal limitação dos frames, que é a necessidade da existência do frameset. Os iframes podem ser inseridos em qualquer documento HTML, pois uma vez definido o espaço ocupado por um iframe, um outro documento HTML é requisitado pelo browser e seu conteúdo é exibido no espaço reservado ao iframe.

As aplicações AJAX para a WWW são diferentes das aplicações tradicionais para a WWW no que tange as requisições de documentos. Em uma aplicação tradicional, cada ação de um usuário que implique em uma alteração dos dados a serem exibidos gera uma requisição de um novo documento HTML ao servidor WWW. No caso de uma aplicação 
AJAX as ações do usuário são sempre processadas por uma aplicação dinâmica em Javascript. Quando a ação do usuário implica em uma alteração dos dados a serem exibidos, apenas as informações alteradas são requisitadas ao servidor WWW através da utilização do formato XML e do protocolo HTTP. Ao receber a resposta, a aplicação dinâmica reconstrói a página HTML exibida pelo browser sem que a página inteira seja requisitada novamente ao servidor. A utilização da técnica AJAX reduz a quantidade de informação trafegada entre o browser e o servidor WWW e dessa forma reduz o tempo de carregamento das páginas de uma aplicação ativa. 


\section{Extração de Informações de Negócio através da Modelagem de Comportamento de Consumidores}

O objetivo deste capitulo é:

- Definir a metodologia a ser utilizada para a análise de negócio através de comportamento de classes de consumidores,

- Definir quais os dados de entrada necessários, como eles devem ser processados e as saídas desejadas,

- Especificar uma ferramenta para análise do consumo de recursos de classes de consumidores

O objetivo da metodologia é garantir a viabilidade econômica de aplicações de negócio eletrônico para a WWW cujo valor do faturamento é próximo do custo da transação. O objetivo da ferramenta é permitir a correta contabilização dos custos associados às transações de negócio.

\subsection{Metodologia para Análise de negócio através da Modelagem de Comportamento de Classes de consumidores}

O objetivo da análise proposta é permitir uma comparação mais refinada entre o faturamento do negócio eletrônico e o consumo de recursos pela aplicação para a WWW. Esta análise será feita através da adaptação de uma metodologia de análise de desempenho para que o consumo de recursos possa ser medido de forma mais precisa em relação às análises existentes atualmente.

Assim como nos modelos de negócio tradicionais, o objetivo de um negócio eletrônico é o lucro(L), e este é calculado através da subtração dos custos(C) do faturamento obtido (F): 


$$
\mathrm{L}=\mathrm{F}-\mathrm{C}
$$

O faturamento é feito através da cobrança de valores dos consumidores ou de patrocinadores. A cobrança pode ser feita a cada navegação, toda vez que ocorre uma transação ou feita periodicamente independente do número de transações.

Nos modelos de negócio tradicionais, o custo de uma transação(t) é divido em duas parcelas, o custo fixo $\left(\mathrm{C}_{\text {fixo }}\right)$ e o custo marginal $\left(\mathrm{C}_{\text {marginal }}\right)$.

$$
\mathrm{C}(\mathrm{t})=\mathrm{C}_{\text {fixo }}(\mathrm{t})+\mathrm{C}_{\text {marginal }}(\mathrm{t})
$$

O custo fixo é definido como o custo que ocorre mesmo que não aconteça nenhuma transação. Em modelos de negócio tradicionais, os custos relacionados à utilização do espaço físico e os custos relacionados à mão de obra são considerados custos fixos. Desta forma, em um modelo de negócio tradicional, o custo fixo de uma transação é calculado através da divisão do custo total de operação do negócio dividido pelo número total de transações realizadas $(\mathrm{T})$.

$$
\mathrm{C}_{\text {fixo }}(\mathrm{t})=\mathrm{C}_{\text {total }} / \mathrm{T}
$$

Já os custos marginais de um negócio são custos que só ocorrem quando uma transação é realizada. Em modelos de negócio tradicionais, custos relacionados a impostos e a comissões de vendas são considerados custos marginais. Desta forma o lucro de uma transação é dado pelo faturamento relacionado à transação subtraído do custo da transação:

$$
\mathrm{L}(\mathrm{t})=\mathrm{F}(\mathrm{t})-\mathrm{C}(\mathrm{t})=\mathrm{F}(\mathrm{t})-\mathrm{C}_{\text {total }} / \mathrm{T}-\mathrm{C}_{\text {marginal }}(\mathrm{t})
$$


As análises de negócio existentes atualmente, por terem sido adaptadas de análises aplicadas em modelos de negócios tradicionais, consideram todos os custos não marginais como custos fixos. Ou seja, não levam em consideração que parte dos custos de uma transação de negócio eletrônico é composta pelo consumo de recursos computacionais, e é possível medir ou estimar este consumo para cada transação realizada. Desta forma os custos que até então eram chamados de custos fixos, podem ser divididos em dois componentes: os custos operacionais $\left(\mathrm{C}_{\text {operacional }}\right)$, que são os custos relacionados ao consumo de recursos computacionais e os custos não operacionais $\left(\mathrm{C}_{\text {não-operacional }}\right)$ que são os custos que não estão relacionados ao consumo de recursos, como por exemplo, o valor pago à equipe de operação de um negócio eletrônico.

$$
\mathrm{C}_{\text {fixo }}=\mathrm{C}_{\text {operacional }}+\mathrm{C}_{\text {não-operacional }}
$$

Desta forma, o custo de cada transação é dado pelo seu custo operacional somado ao custo não operacional total dividido pelo número total de transações:

$$
\mathrm{C}_{\text {fixo }}(\mathrm{t})=\mathrm{C}_{\text {operacional }}(\mathrm{t})+\mathrm{C}_{\text {não-operacional }} / \mathrm{T}
$$

O lucro de uma transação de negócio eletrônico pode ser calculado da seguinte forma:

$$
\mathrm{L}(\mathrm{t})=\mathrm{F}(\mathrm{t})-\mathrm{C}_{\text {não-operacional }} / \mathrm{T}-\mathrm{C}_{\text {operacional }}(\mathrm{t})-\mathrm{C}_{\text {marginal }}(\mathrm{t})
$$

Por simplificação, deve-se considerar como faturamento líquido (FL(t)) de uma transação o faturamento real subtraído do custo marginal. Desta forma: 


$$
\mathrm{L}(\mathrm{t})=\mathrm{FL}(\mathrm{t})-\mathrm{C}_{\text {não-operacional }} / \mathrm{T}-\mathrm{C}_{\text {operacional }}(\mathrm{t})
$$

A analise isolada do lucro individual de cada transação realizada em uma aplicação de negócio eletrônico não produz informações de negócios úteis, pois, gera uma quantidade muito grande de dados sem muita correlação. Porém a análise do lucro gerado por um conjunto de transações feitas por um grupo de consumidores pode ser utilizada para extrair informações de negócio úteis. Para isso, devem ser analisados parâmetros de negócio, como o lucro, para classes de usuários de forma que as classes e o comportamento característico dos usuários da classe possam ser comparados. O lucro proporcionado por um grupo de usuários pode ser calculado como a soma do lucro de todas as transações realizadas pelos usuários de uma determinada classe(c):

$$
\mathrm{L}(\mathrm{c})=\Sigma_{\mathrm{c}} \mathrm{L}(\mathrm{t})=\Sigma_{\mathrm{c}}\left(\mathrm{FL}(\mathrm{t})-\left(\mathrm{C}_{\text {não-operacional }} / \mathrm{T}\right)-\mathrm{C}_{\text {operacional }}(\mathrm{t})\right)
$$

Denominando a soma dos faturamentos gerados por todas as transações de usuários de um determinado grupo como $\mathrm{F}(\mathrm{c})$ e o número de transações realizadas pelo grupo como $\mathrm{N}(\mathrm{c})$ :

$$
\mathrm{L}(\mathrm{c})=\mathrm{FL}(\mathrm{c})-\mathrm{C}_{\text {não-operacional }} *(\mathrm{~N}(\mathrm{c}) / \mathrm{T})-\mathrm{C}_{\text {operacional }}(\mathrm{c})
$$

Partindo do pressuposto que a importância de um grupo de consumidores para um negócio eletrônico é dado principalmente pelo lucro gerado por este grupo, é viável afirmar que o cálculo do lucro obtido para cada grupo de usuários é de extrema importância para uma analise de negócio e, por isso, a análise deve realizar os seguintes passos: 
- Calcular o custo não operacional de um negócio eletrônico

- Segmentar os consumidores em classes,

- Aferir o faturamento para cada uma das classes,

- Calcular o número total de transações realizadas por classe,

- Medir o consumo de recursos de cada classe.

Seguindo estes passos é possível observar quais classes são mais rentáveis e quais classes são menos rentáveis e assim, direcionar esforços de adaptação da aplicação, de ajustes no modelo de negócio e de marketing.

\subsubsection{Cálculo do Custo não Operacional de um Negócio Eletrônico}

O cálculo do custo não operacional de um negócio eletrônico consiste na contabilização de todos os custos não passíveis de vinculação a uma transação de negócio. Devido ao fato de o custo não operacional ser independente do número de transações e do usuário que realizou a transação, para efeitos de cálculo, neste trabalho este custo será considerado zero e não será mais discutido neste trabalho.

\subsubsection{Agrupamento de consumidores em classes}

Potencialmente, o agrupamento de consumidores em classes pode ser feito por critérios sócio-econômicos, pela receita gerada, pelo consumo de recursos, pelo horário de utilização ou feita através de algoritmos de agrupamento de sessões através do comportamento.

Para este trabalho, será utilizado como critério de agrupamento em classes a receita gerada por sessão. Esta informação, ao contrário dos critérios sócio-econômicos, pode ser obtida a partir das informações contidas nas requisições feitas pelo consumidor à aplicação 
quando a arquitetura da aplicação assim o permitir. Uma forma certa de se obter esta informação é através da extração da mesma dos dados sobre receitas armazenados pela própria aplicação. O armazenamento de dados sobre receitas é feito por todas as aplicações de negócio devido à necessidade que todo negócio possui de permitir o rastreamento de informações sobre transações financeiras por motivos de segurança.

Outro critério que pode ser utilizado é o critério sócio-econômico que pode ser utilizado como fator de agrupamento quando existirem dentro do repositório de dados do negócio informações suficientes sobre os parâmetros sócio-econômicos dos usuários. Um exemplo da utilização de tal critério para o agrupamento de consumidores seria a classificação de consumidores em grupos formados de acordo com informações quanto ao sexo, idade e cidade onde residem os consumidores. Estas informações podem ser coletadas dos consumidores através da obrigação de preenchimento de um cadastro com informações pessoais do consumidor para permitir a realização de transações na aplicação de negócio eletrônico. O principal fator limitante na utilização do critério sócio-econômico para o agrupamento de sessões é a necessidade de um passo adicional na análise para identificar qual consumidor gerou cada uma das sessões obtidas nas fases seguintes. O critério sócioeconômico não será utilizado neste trabalho devido à dificuldade de coleta das informações de Web-Sites devido a políticas de privacidade e estratégias de negócio dos mesmos.

Outros critérios que poderiam ter sido utilizados são: o consumo de recursos, o horário de utilização e os algoritmos de agrupamento de sessões pela navegação. A grande vantagem na utilização destas informações é o fato de essas informações sempre poderem ser extraídas a partir da mesma fonte de dados utilizada para a extração do consumo de recursos sem a necessidade de se utilizar informações externas. 


\subsubsection{Aferição do faturamento por classes}

A aferição do faturamento por classes de consumidores consiste na contabilização de todos os faturamentos referentes a consumidores pertencentes a uma determinada classe. Esta informação pode ser obtida das mesmas fontes de dados utilizadas para a medição do consumo de recursos quando a arquitetura da aplicação assim o permitir, ou pode ser extraída do repositório de informações de negócios. Para se realizar esta aferição é necessário que a aplicação de negócio eletrônico mantenha um histórico com os valores de transações realizadas e uma forma de associar estes valores à sessão que gerou a transação monetária. Existem duas formas de se fazer esta associação: A forma direta e a forma indireta.

A forma direta de associação é manter armazenado na aplicação o valor faturado para cada um dos consumidores(u). Desta forma é possível extrair o faturamento $F(u)$ de uma classe $(\mathrm{C})$ de consumidores através da soma de do faturamento de todos os consumidores de uma determinada classes $\mathrm{U}(\mathrm{C})$ :

$$
\mathrm{F}(\mathrm{c})=\Sigma_{\mathrm{u}} \mathrm{F}(\mathrm{u}), \text { onde } \mathrm{u} \in \mathrm{U}(\mathrm{C})
$$

A forma indireta de associação é manter armazenado na aplicação o valor faturado para cada sessão $\mathrm{F}(\mathrm{s})$ e também manter armazenada a identificação do usuário de cada sessão U(s). Desta forma é possível extrair o faturamento por classe através da seguinte fórmula:

$$
\mathrm{F}(\mathrm{c})=\Sigma_{\mathrm{s}} \mathrm{F}(\mathrm{s}) \text {, onde } \mathrm{U}(\mathrm{s}) \in \mathrm{U}(\mathrm{C})
$$

Devido ao fato de o agrupamento em classes ter sido realizado utilizando-se como critério o faturamento por sessão, vamos assumir que cada sessão possui um usuário diferente e será utilizada neste trabalho a forma indireta de associação. 


\subsubsection{Calculo do número total de transações realizadas por classes}

O número total de transações que uma determinada classe de consumidores realizou pode ser obtido das mesmas fontes de dados utilizadas para a medição do consumo de recursos quando a arquitetura da aplicação assim o permitir, ou pode ser extraído do repositório de informações de negócios.

Devido ao fato de o agrupamento em classes ter sido realizado utilizando-se como critério o faturamento por sessão, o número total de transações de cada classe T(c) pode ser calculado através da contabilização de todas as sessões que tivera faturamento $F(s)$ maior que zero:

$$
\mathrm{T}(\mathrm{c})=\Sigma_{\mathrm{s}} 1 \text {, onde } \mathrm{F}(\mathrm{s})>0
$$

Se outros métodos de agrupamento de sessão tivessem sido escolhidos, outras formas de cálculo do número total de transações por classe devem ser utilizadas.

\subsubsection{Medição do Consumo de Recursos por Classe}

Para permitir a extração de informações mais completas quanto ao consumo de recursos de cada uma das classes de consumidores, além da obtenção da matriz de probabilidade como é feito na análise CBMG, é necessário também contabilizar informações referentes ao tamanho da informação recebida, o tamanho da informação transmitida e o tempo de processamento de cada transação. Por este motivo, boa parte das informações desprezadas pela análise CBMG devem ser contabilizadas e, para cada nó do gráfico CMBG, as seguintes informações também precisam ser extraídas:

- O tamanho total do documento HTML principal que implementa o passo de negócio (I),

- O tempo de transmissão do documento HTML (T)

- A quantidade média de elementos extras carregados $(\mathrm{N})$, 
- O tempo médio para se carregar os elementos extras (TN),

- O tamanho médio dos elementos extras (IN).

Desta forma, o consumo de recursos em tempo CT e o consumo de recurso em informação CI podem ser calculados através das formulas:

$$
\begin{gathered}
\mathrm{CT}=\mathrm{T}+\mathrm{N} * \mathrm{TN} \mathrm{e} \\
\mathrm{CI}=\mathrm{I}+\mathrm{N} * \mathrm{IN}
\end{gathered}
$$

Devido ao fato do consumo de recursos em tempo e o consumo de recursos em informação possuírem duas unidades diferentes, para se calcular o consumo total de recursos, utilizaremos um fator de correção $\alpha$, que expressa a relação entre o custo de uma unidade de informação em relação ao custo de uma unidade tempo. Cada negócio eletrônico possui uma característica diferente e por isso o fator de correção deve ser calculado de acordo com as características de cada negócio. Neste trabalho, o fator de correção $\alpha$, vai ser calculado como a relação entre o consumo total de recursos em informação da aplicação $(\Sigma C I)$ e o consumo total de recursos em informação da aplicação $(\Sigma C T)$ :

$$
\alpha=\Sigma \mathrm{CI} / \Sigma \mathrm{CT}
$$

Com isso temos o consumo total de recursos $\mathrm{C}$ :

$$
\mathrm{C}=\mathrm{CI}+\mathrm{CT}=\mathrm{I}+\mathrm{N} * \mathrm{IN}+\alpha *(\mathrm{~T}+\mathrm{N} * \mathrm{TN})
$$

Devido à necessidade de armazenamento destas novas informações, a análise CBMG precisa ser alterada de forma que cada nó do grafo passe a armazenar, além do nome do 
módulo, os atributos descritos acima. Medidas que caracterizem a variação de cada uma das novas informações extraídas também são importantes.

Para obter as informações necessárias, após as sessões terem sido identificadas, o passo seguinte deve ser identificar à qual grupo pertence cada uma das sessões encontradas. $\mathrm{O}$ processo de identificação do grupo, ao qual uma sessão pertence, está intimamente ligado ao processo de agrupamento de consumidores em classes.

Neste trabalho, o processo de agrupamento de consumidores em classes utiliza somente informações extraídas da mesma fonte de dados de onde são extraídas as sessões, como logs de servidores WWW. Por isso, é possível identificar o grupo ao qual uma sessão pertence no mesmo passo em que as sessões são extraídas.

Caso o processo de agrupamento de consumidores em classes selecionado utilize outras informações além das informações contidas na mesma fonte de dados de onde são extraídas as sessões, como por exemplo, quando os consumidores são agrupados por critérios sócioeconômicos, é necessário incluir um passo extra após o agrupamento dos consumidores em classes e antes da medição do consumo de recursos, responsável por identificar o consumidor que realizou cada sessão, obter de um repositório externo de dados o grupo ao qual este consumidor pertence e identificar a sessão como pertencente ao grupo.

\subsubsection{Resultados esperados da análise}

O resultado da análise deve ser uma tabela comparativa entre diversos grupos contendo as seguintes informações:

- $\operatorname{Grupo}(\mathrm{G})$

- Número de Sessões $\mathrm{S}(\mathrm{G})$

- Faturamento Líquido F(G)

- Custo Operacional $\mathrm{C}(\mathrm{G})$ 
- Lucro L(G)

- Faturamento Líquido por Sessão F(S)

- Custo Operacional por Sessão C(S)

- Lucro por Sessão L(S)

Desta tabela é possível extrair quais grupos são mais rentáveis e quais grupos são menos rentáveis.

Outro resultado da análise deve ser um diagrama CBMG por grupo avaliado. Este diagrama é importante, pois permite um segundo nível de análise quando dois ou mais grupos apresentam diferenças muito grande no fator "Custo Operacional por Sessão". Quando isso ocorre, os diagramas CBMG destes grupos devem ser comparados para ver se a diferença é causada por diferenças na quantidade de recursos acessados por sessão, causada pelo acesso a um diferente conjunto de módulos da aplicação ou causado pela utilização da aplicação de forma diferente por diferentes grupos.

\subsection{Ferramenta para Análise do Consumo de Recursos de Classes de consumidores}

A ferramenta proposta serve para medir o consumo de recursos através da realização de uma análise CBMG modificada. Nesta análise, as seguintes informações também devem ser extraídas:

- O tamanho total do documento HTML principal que implementa o passo de negócio,

- A quantidade média de elementos extras carregados,

- O tempo médio para se carregar os elementos extras,

- O tamanho médio dos elementos extras. 
Além da extração destas informações, a ferramenta deve também calcular a variância destes valores.

Além de medir do consumo de recursos de acordo com a metodologia de análise proposta, a ferramenta também deve possuir as seguintes características:

- Capacidade de utilização dos três métodos descritos de identificação de sessão

- Capacidade de fazer análises limitadas no tempo

- Capacidade de armazenamento de análises e resultados

Para especificar, projetar e implementar a ferramenta, os seguintes passos foram seguidos:

\subsubsection{Análise de requisitos para implementação da ferramenta}

A ferramenta pode extrair dos logs dos servidores WWW da aplicação analisada a navegação dos usuários ou a aplicação analisada deve ser adaptada para inserir as informações de navegação dos usuários diretamente no banco de dados da ferramenta.

O sistema deve conseguir agrupar as navegações em sessões e identificar a qual grupo cada uma das sessões encontradas pertence. A partir deste ponto, para cada grupo, deve ser calculado a matriz de probabilidade de transições e o consumo de recursos associado a cada um dos nós do grafo.

Para modelar a solução foi escolhida a técnica de modelagem orientada a objeto, pois essa técnica permite transportar elementos do domínio problema diretamente para o domínio da solução e após este passo selecionar quais características (atributos) dos objetos são necessários para o correto entendimento do problema e para a solução do problema. Esta técnica também permite que sejam facilmente encontrados as classes e os métodos de cada 
classe, para a resolver de forma atômica os diversos passos necessários para a solução do problema.

A especificação da solução foi feita utilizando a notação UML devido à sua larga utilização em meios profissionais e acadêmicos, e também devido à capacidade de síntese de seus diversos modelos. Para este projeto, foram documentados os diagramas de classes, casos de uso e diagramas de seqüência.

O banco de dados necessário para o armazenamento dos logs pré-analisados, das análises e das sessões foi modelado utilizando-se modelos entidade-relacionamento obtidos a partir do diagrama de classes.

\subsubsection{Projeto da ferramenta}

Para modelar corretamente o sistema em classes de objetos, é necessário iniciar o projeto pela principal informação de entrada do sistema: os arquivos que contém logs de servidores web, modelados na forma da classe "LogFile". Sobre estes objetos são efetuadas as principais operações de análise através dos seus métodos de análise e de extração de sessão. Os objetos da classe "LogFile" são persistentes

Cada arquivo de log é formado por diversas entradas, modeladas pela classe "EntradaDeLog". A classe "Entrada de Log" é utilizada somente na fase de análise dos arquivos de Log e por isso esta classe não é persistente.

As informações importantes de uma entrada de log, que são necessárias para diversas fases da análise, foram modeladas através da classe "Chamada". Esta classe é persistente e contém todas as informações da Entrada de Log referentes à requisição do usuário que podem ser usadas para identificar o seu comportamento

Para poder modelar corretamente o comportamento de navegação de um usuário, foi criada a classe transição, que modela um passo da navegação de um usuário no sistema. As informações do destino da transição sempre são conhecidas e modeladas através de objetos da 
classe "Chamada". Já as informações da página de origem dependem das informações armazenadas em cada entrada do log e também da fase e passo atual da análise. Por isso a origem é modelada através da classe "Página" que pode ser uma chamada, uma página do sistema, um elemento externo ou ser desconhecida.

Cada um dos objetos da classe transição pode ou não ter sua sessão identificada. Esta sessão é modelada através da classe "Sessão". Esta classe é a responsável por identificar a relação entre os usuários e as transições e através das transições identificar as relações entre os usuários e as chamadas.

Uma análise é efetuada sobre um conjunto de arquivos de logs e apenas as chamadas pertencentes a determinadas sessões são consideradas para análise. Estas análises são modeladas através da classe "Análise". Cada análise gera como resultado uma matriz de probabilidades.

A probabilidade de navegação entre duas páginas quaisquer do sistema para uma determinada análise é modelada através da classe "Probabilidade". Desta forma, a matriz de probabilidades de uma determinada análise é formada pelo conjunto de objetos da classe "Probabilidade" relacionados a uma determinada análise. 


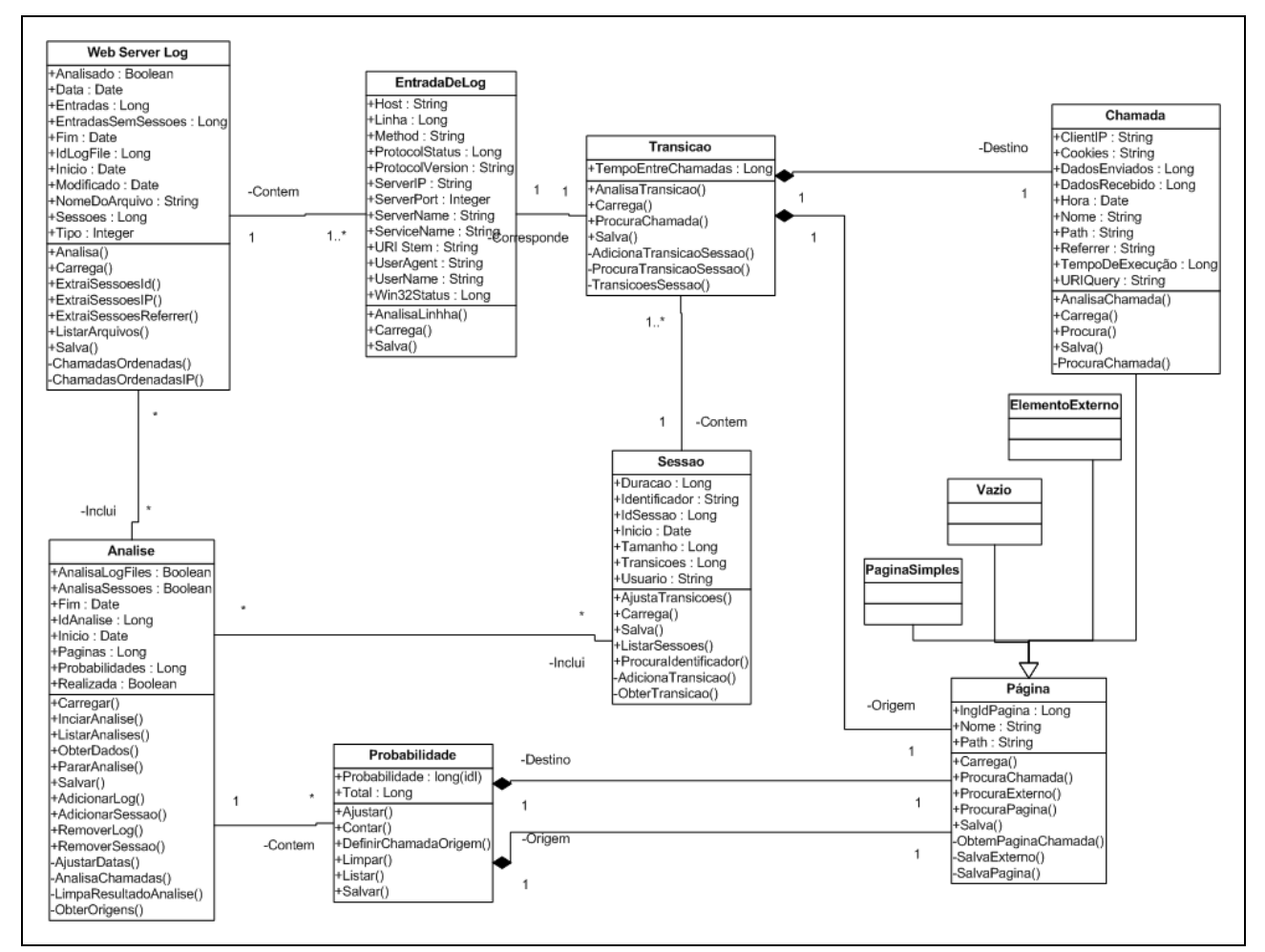

Figura 13 - Diagrama de Classe de Implementação da Ferramenta Proposta

\subsubsection{Implementação da ferramenta}

A ferramenta será implementada utilizando a linguagem de programação Visual Basic e as classes de implementação serão encapsuladas em componentes para serem acessíveis através da interface $\mathrm{COM}+$.

Para melhor utilização do sistema, suas funcionalidades foram agrupadas em três componentes: "CBMGLog", "CBMGSessao" e "CBMGAnalise”. Cada componente responsável por uma fase distinta da análise.

O componente "CBMGLog" é responsável por analisar e gerenciar os arquivos de logs. Na tabela abaixo estão listadas as interfaces deste componente 


\begin{tabular}{|l|l|}
\hline Interface & Descrição \\
\hline CarregaArquivosFisicos() & $\begin{array}{l}\text { Interface utilizada para que os novos arquivos de } \\
\text { log gerados após a ultima utilização do sistema } \\
\text { sejam reconhecidos. }\end{array}$ \\
\hline Listar() & $\begin{array}{l}\text { Interface utilizada para listar todo os arquivos de } \\
\text { log conhecidos pelo sistema. }\end{array}$ \\
\hline AnalisarArquivo (Nome) & $\begin{array}{l}\text { Interface utilizada para que um arquivo de log seja } \\
\text { analisado e as informações importantes sejam } \\
\text { armazenadas no banco de dados }\end{array}$ \\
\hline $\begin{array}{l}\text { ExtrairSessoes (Nome, Método, } \\
\text { LimpaSessoes) }\end{array}$ & $\begin{array}{l}\text { Interface utilizada para extrair as sessões de um } \\
\text { determinado arquivo de log. O método de extração } \\
\text { deve ser passado como parâmetro }\end{array}$ \\
\hline
\end{tabular}

Tabela 7 - Interfaces do componente CBMGLog

O componente "CBMGSessoes" é responsável por gerenciar as sessões existentes. Na tabela abaixo estão listadas as interfaces deste componente:

\begin{tabular}{|l|l|}
\hline Interface & Descrição \\
\hline ListarSessoes() & $\begin{array}{l}\text { Interface utilizada para listar todas as sessões } \\
\text { localizadas em todos os logs analisados no sistema. }\end{array}$ \\
\hline $\begin{array}{l}\text { Localizar (Identificador, Ip, } \\
\text { Inicio, Fim) }\end{array}$ & $\begin{array}{l}\text { Interface utilizada para localizar sessões em função } \\
\text { dos seus dados }\end{array}$ \\
\hline Adicionar (Identificador) & $\begin{array}{l}\text { Interface utilizada para que seja criada uma nova } \\
\text { sessão no sistema identificada por "Identificador". }\end{array}$ \\
\hline
\end{tabular}

Tabela 8 - Interfaces do componente CBMGSessao

O componente "CBMGAnalise" é o principal componente do sistema já que é o responsável pela analise de comportamento. Na tabela abaixo estão listadas as interfaces deste componente: 


\begin{tabular}{|l|l|}
\hline Interface & Descrição \\
\hline ListarAnalises() & $\begin{array}{l}\text { Interface utilizada para listar todas as análises } \\
\text { conhecidas pelo sistema. }\end{array}$ \\
\hline CriaAnalises() & $\begin{array}{l}\text { Interface utilizada para criar uma nova análise em } \\
\text { branco. }\end{array}$ \\
\hline RealizarAnalise (IdAnalise) & $\begin{array}{l}\text { Interface utilizada para iniciar uma analise } \\
\text { identificada por "IdAnalise" }\end{array}$ \\
\hline InterromperAnalise (IdAnalise) & $\begin{array}{l}\text { Interface utilizada para interromper a analise } \\
\text { identificada por: "IdAnalise" }\end{array}$ \\
\hline $\begin{array}{l}\text { IncluirSessoes (IdAnalise, } \\
\text { IdSessao) }\end{array}$ & $\begin{array}{l}\text { Interface utilizada para incluir a sessão identificada } \\
\text { por "IdSessao" na análise identificada por } \\
\text { "IdAnalise" }\end{array}$ \\
\hline $\begin{array}{l}\text { IncluirLogFile (IdAnalise, } \\
\text { IdLogFile) }\end{array}$ & $\begin{array}{l}\text { Interface utilizada para incluir o LogFile } \\
\text { identificado por "IdLogFile" na análise } \\
\text { identificada por "IdAnalise" }\end{array}$ \\
\hline $\begin{array}{l}\text { ExcluirSessao (IdAnalise, } \\
\text { IdSessao) }\end{array}$ & $\begin{array}{l}\text { Interface utilizada para remover a sessão } \\
\text { identificada por "IdSessao" da análise identificada } \\
\text { por "IdAnalise" }\end{array}$ \\
\hline $\begin{array}{l}\text { ExcluirLogFile (IdAnalise, } \\
\text { IdSessao) }\end{array}$ & $\begin{array}{l}\text { Interface utilizada para remover o LogFile } \\
\text { identificado por "IdLogFile" da análise } \\
\text { identificada por "IdAnalise" }\end{array}$ \\
\hline ListarSessoes (IdAnalise) & $\begin{array}{l}\text { Interface utilizada para listar as sessões incluídas } \\
\text { na análise identificada por "IdAnalise" }\end{array}$ \\
\hline ListarLogFile (IdAnalise) & $\begin{array}{l}\text { Interface utilizada para listar os "LogFile"s } \\
\text { incluídos na análise identificada por "IdAnalise" }\end{array}$ \\
\hline $\begin{array}{l}\text { Interface utilizada para obter os dados gerados pela } \\
\text { análise identificada por "IdAnalise" }\end{array}$ \\
$\begin{array}{l}\text { Interface utilizada para gerar o gráfico da análise } \\
\text { identificada por "IdAnalise". Este foi o único } \\
\text { método que não foi implementado }\end{array}$ \\
\hline IdAnalise)
\end{tabular}

Tabela 9 - Interfaces do componente CBMGAnalise 


\section{Aplicação da análise e da ferramenta propostas}

Para validar a ferramenta e a análise propostas foi realizado um teste sobre dados simulados. O primeiro objetivo deste teste foi verificar a eficácia da ferramenta em identificar corretamente a sessão ao qual pertence cada requisição e, uma vez identificada à qual grupo pertence cada uma das sessões localizadas, analisar corretamente o consumo de recursos para cada grupo.

Uma vez validada a ferramenta, as informações por ela produzidas foram analisadas e a sua interpretação foi comparada ao comportamento esperado para cumprir o segundo objetivo do teste que era a validação do processo de análise proposto.

A utilização de dados simulados ao invés de dados reais foi devido a dificuldade de obtenção dos dados reais. Porém, para permitir a validação tanto da análise quanto da ferramenta, a navegação simulada foi inspirada no comportamento normalmente associado á alguns grupos de consumidores que, tipicamente, utilizam aplicações de negócio eletrônico.

\subsection{Aplicação da Ferramenta sobre Dados Simulados}

O objetivo deste teste foi validar a ferramenta. Esta validação foi constatada ao se observar que as análises de navegação obtidas para cada grupo diferiam dentro do esperado dos dados de comportamento utilizados para alimentar a ferramenta que gerou a simulação.

\subsubsection{Preparação da massa de testes}

Para preparar a massa de testes, foram seguidos os seguintes passos:

Primeiro, foi especificada uma aplicação simulada de negócio eletrônico inspirada no estudo de caso do capítulo 2. Por isso, para o número de módulos $(\mathrm{Na})$ foi escolhido o valor 6 , pois este valor representa as seis primeiras funções de negócio listadas naquele capitulo, 
excluindo-se a função de personalização, pois esta função raramente é acessada por uma sessão típica.

Foi então escolhido o valor 3 como a quantidade $(\mathrm{Ng})$ de grupos de usuários inspirado pelo seguinte agrupamento típico de consumidores por comportamento:

\begin{tabular}{|l|l|l|}
\hline Grupo & Descrição & Comportamento \\
\hline A & $\begin{array}{l}\text { Consumidores } \\
\text { Eventuais }\end{array}$ & $\begin{array}{l}\text { Chegam ao site através de propagandas, geralmente atraídos } \\
\text { por um produto específico. Por este motivo costumam ter } \\
\text { uma navegação curta, baixa probabilidade de realização de } \\
\text { transação e baixo valor médio de transação. }\end{array}$ \\
\hline B & $\begin{array}{l}\text { Consumidores } \\
\text { Focados }\end{array}$ & $\begin{array}{l}\text { Estão decididos a realizar uma compra e costumam } \\
\text { comparar um ou mais produtos semelhantes antes de } \\
\text { realizar a escolha e efetivar a transação. Por isso costumam } \\
\text { ter navegações longas. }\end{array}$ \\
\hline C & $\begin{array}{l}\text { Consumidores } \\
\text { Fiéis }\end{array}$ & $\begin{array}{l}\text { Geralmente, visitam a loja virtual de tempos em tempos } \\
\text { atrás de produtos que os interessem ou atrás de promoções. } \\
\text { Nem todas as sessões costumam realizar compras, porém, } \\
\text { quando efetivam a transação, o valor faturado costuma ser } \\
\text { acima da média dos valores aferidos para os demais grupos. }\end{array}$ \\
\hline
\end{tabular}

Tabela 10 - Agrupamento de Consumidores

Em seguida, para os 3 grupos projetados, foi escolhido arbitrariamente um número de sessões (Ns(g)) por grupo: Foi escolhido 900 para o grupo A, 1000 para o grupo B e 800 para o grupo C.

Inspirado no comportamento de cada grupo foi especificado um diagrama de probabilidade de transição entre cada um dos $(\mathrm{Na})$ módulos da aplicação.

\begin{tabular}{|c|c|c|c|c|c|c|c|}
\hline $\mathrm{P}$ & $\mathrm{A}$ & $\mathrm{B}$ & $\mathrm{C}$ & $\mathrm{D}$ & $\mathrm{E}$ & $\mathrm{F}$ & $\mathrm{O}$ \\
\hline $\mathrm{A}$ & 0 & 1 & 0 & 0 & 0 & 0 & 0 \\
\hline $\mathrm{B}$ & $1 / 2$ & 0 & $1 / 2$ & 0 & 0 & 0 & 0 \\
\hline $\mathrm{C}$ & 0 & $1 / 3$ & 0 & $1 / 3$ & $1 / 3$ & 0 & 0 \\
\hline $\mathrm{D}$ & 0 & 0 & $1 / 3$ & 0 & 0 & $1 / 3$ & $1 / 3$ \\
\hline $\mathrm{E}$ & 0 & 0 & $1 / 3$ & 0 & 0 & $1 / 3$ & $1 / 3$ \\
\hline $\mathrm{F}$ & 0 & 0 & 0 & 0 & 0 & 0 & 1 \\
\hline
\end{tabular}

Tabela 11 - Probabilidade de transição do grupo A 


\begin{tabular}{|c|cc|c|c|c|c|c|c|}
\hline $\mathrm{P}$ & $\mathrm{A}$ & $\mathrm{B}$ & $\mathrm{C}$ & $\mathrm{D}$ & $\mathrm{E}$ & $\mathrm{F}$ & $\mathrm{O}$ \\
\hline $\mathrm{A}$ & 0 & 1 & 0 & 0 & 0 & 0 & 0 \\
\hline $\mathrm{B}$ & $1 / 2$ & 0 & $1 / 2$ & 0 & 0 & 0 & 0 \\
\hline $\mathrm{C}$ & 0 & $1 / 2$ & 0 & $1 / 2$ & 0 & 0 & 0 \\
\hline $\mathrm{D}$ & 0 & 0 & $1 / 2$ & 0 & 0 & $1 / 2$ & 0 \\
\hline $\mathrm{E}$ & 0 & 0 & $1 / 3$ & 0 & 0 & $1 / 3$ & $1 / 3$ \\
\hline $\mathrm{F}$ & 0 & 0 & 0 & 0 & 0 & 0 & 1 \\
\hline
\end{tabular}

Tabela 12 - Probabilidade de transição do grupo B

\begin{tabular}{|c|cc|c|c|c|c|c|c|}
\hline $\mathrm{P}$ & $\mathrm{A}$ & $\mathrm{B}$ & $\mathrm{C}$ & $\mathrm{D}$ & $\mathrm{E}$ & $\mathrm{F}$ & $\mathrm{O}$ \\
\hline $\mathrm{A}$ & 0 & 1 & 0 & 0 & 0 & 0 & 0 \\
\hline $\mathrm{B}$ & 0 & 0 & 1 & 0 & 0 & 0 & 0 \\
\hline $\mathrm{C}$ & 0 & 0 & 0 & $1 / 3$ & $2 / 3$ & 0 & 0 \\
\hline $\mathrm{D}$ & 0 & 0 & $1 / 3$ & 0 & 0 & $2 / 3$ & 0 \\
\hline $\mathrm{E}$ & 0 & 0 & $2 / 3$ & 0 & 0 & 0 & $1 / 3$ \\
\hline $\mathrm{F}$ & 0 & 0 & 0 & 0 & 0 & 0 & 1 \\
\hline
\end{tabular}

Tabela 13 - Probabilidade de transição do grupo C

Para garantir que cada grupo apresentasse um consumo diferenciado de recursos, foi definida a seguinte quantidade média de dados transmitidos e recebidos por grupo:

\begin{tabular}{|c|c|c|}
\hline Grupo & Dados Enviados & Dados Recebidos \\
\hline A & 1.000 bytes & 10.000 bytes \\
\hline B & 2.000 bytes & 20.000 bytes \\
\hline C & 4.000 bytes & 40.000 bytes \\
\hline
\end{tabular}

Tabela 14 - Quantidade de Dados por Grupo

No cálculo do tempo médio de requisição, foi considerado que todos os grupos apresentam a mesma velocidade de transmissão de dados e por isso os tempos de requisição são sempre proporcionais aos valores sorteados para a quantidade de dados enviados e recebidos.

Para o valor médio de cada transação $\operatorname{Vm}(G)$ foram selecionados os valores: $\operatorname{Vm}(A)=$ $100, \operatorname{Vm}(B)=200$ e $\operatorname{Vm}(C)=300$

Por último, para determinar se uma a realização ou não de uma transação, deve-se verificar se a sessão passa pela página $\mathrm{F}$ já que pelo modelo utilizado, a página $\mathrm{F}$ é a página de confirmação de pagamento. 


\subsubsection{Realização da simulação}

A partir da massa de testes definida anteriormente, uma aplicação computacional desenvolvida em Visual Basic simulou o comportamento dos consumidores dentro da aplicação conforme definido na massa de testes. Para aproximar a simulação da realidade, foi utilizada uma variação de $10 \%$ sobre a média pretendida em todos os casos de sorteio de valores.

O resultado da simulação foi um conjunto de requisições de páginas HTML que por sua vez foi inserido diretamente no repositório da ferramenta desenvolvida como aconteceria nos casos onde o sistema analisado estivesse sendo monitorado através de formas de monitoração dinâmicas ou ativas.

Para evitar que erros na identificação das sessões afetassem a validação da ferramenta ou a validação da análise, foi definido que todas as requisições teriam o identificador da sessão explicito nos parâmetros passados pelo cliente durante a requisição (uri-query) assim como acontece em diversas aplicações existentes atualmente. Além disso, para simplificar a identificação de qual grupo contém cada uma das sessões, um identificador de grupo também foi adicionado aos parâmetros transmitidos do cliente para a aplicação. Desta forma, toda requisição possui no campo uri-query a seguinte informação: "?NumGrupo=<Identificacão do Grupo $>\&$ Sessao=<Número da Sessão $>”$.

Para a realização da simulação foi utilizado um microcomputador Athlon 1533 Mhz com $512 \mathrm{Mb}$ de Memória e para a simulação foram gastos 1 minuto e 28 segundos durantes os quais a quantidade média de memória utilizada pelo processo foi de 17 Megabytes e a utilização de CPU pelo processo ficou em 98\%. Foram gerados no total 34360 registros correspondentes a 34360 requisições. 


\subsubsection{Aplicação da ferramenta sobre os dados simulados}

Sobre a massa de testes criada foram feitas 4 análises: Uma análise contemplando todas as sessões existentes na massa de testes utilizada e uma análise individualizada para cada uma das sessões. Estas análises foram realizadas em duas etapas.

\subsubsection{Identificação e agrupamento de sessões}

A primeira etapa, comum a todas as análises, consistia na identificação e agrupamento de sessões. Esta etapa, feita através da interface "ExtrairSessões" do componente CBMGLog teve a duração de 2 horas e 38 segundos, extraiu um total de 2700 sessões, valor já esperado por se tratar da soma da quantidade de sessões de cada um dos grupos. Devido a um numero explicito de sessão estar presente em cada chamada conforme definido na simulação, foi utilizado método de identificação de sessões explícitas.

\subsubsection{Analise independente de grupo}

Depois de realizada a primeira etapa foi então realizada a primeira análise de probabilidade de transição utilizando como entrada todas as requisições simuladas. O resultado obtido foi:

\begin{tabular}{|c|c|c|c|c|c|c|c|}
\hline P & A & B & C & D & E & F & O \\
\hline A & 0 & 1 & 0 & 0 & 0 & 0 & 0 \\
\hline B & 0.46 & 0 & 0.54 & 0 & 0 & 0 & 0 \\
\hline C & 0 & 0.34 & 0 & 0.41 & 0.25 & 0 & 0 \\
\hline D & 0 & 0 & 0.43 & 0 & 0 & 0.50 & 0.07 \\
\hline E & 0 & 0 & 0.53 & 0 & 0 & 0.12 & 0.35 \\
\hline F & 0 & 0 & 0 & 0 & 0 & 0 & 1 \\
\hline
\end{tabular}

Tabela 15 - Probabilidade de transição combinada 
A probabilidade de transição esperada $\operatorname{Pxy}(A+B+C)$ pode ser calculada da seguinte forma:

$$
\frac{=\operatorname{Pxy}(\mathrm{A}) * \mathrm{Na}+\operatorname{Pxy}(\mathrm{B}) * \mathrm{Nb}+\operatorname{Pxy}(\mathrm{C}) * \mathrm{Nc}}{\mathrm{Na}+\mathrm{Nb}+\mathrm{Nc}}=\frac{\operatorname{Pxy}(\mathrm{A}) * 900+\operatorname{Pxy}(\mathrm{B}) * 1000+\operatorname{Pxy}(\mathrm{C}) * 800}{2700}
$$

Logo. A tabela esperada seria:

\begin{tabular}{|c|c|c|c|c|c|c|c|}
\hline P & A & B & C & D & E & F & O \\
\hline A & 0 & 1 & 0 & 0 & 0 & 0 & 0 \\
\hline B & 0.35 & 0 & 0.65 & 0 & 0 & 0 & 0 \\
\hline C & 0 & 0.30 & 0 & 0.39 & 0.31 & 0 & 0 \\
\hline D & 0 & 0 & 0.39 & 0 & 0 & 0.50 & 0.11 \\
\hline E & 0 & 0 & 0.43 & 0 & 0 & 0.23 & 0.34 \\
\hline F & 0 & 0 & 0 & 0 & 0 & 0 & 1 \\
\hline
\end{tabular}

Tabela 16 - Probabilidade de transição combinada esperada

Temos como erro:

$$
\text { Erro }=\frac{\sqrt{\sum(R x y-P x y)^{2}}}{\sqrt{\sum(P x y)^{2}}}=12,29 \%
$$

Como resultado da análise também foi produzida a seguinte tabela com o consumo de recursos:

\begin{tabular}{|c|c|c|c|}
\hline Página & Enviados $(\mathrm{Kb})$ & Recebidos(Kb) & Tempo(ms) \\
\hline A & $1868 \pm 791$ & $18701 \pm 7898$ & $564 \pm 306$ \\
\hline B & $1840 \pm 798$ & $18416 \pm 8047$ & $556 \pm 313$ \\
\hline C & $2217 \pm 1005$ & $22122 \pm 10001$ & $665 \pm 379$ \\
\hline D & $2168 \pm 992$ & $21660 \pm 9809$ & $653 \pm 369$ \\
\hline E & $2928 \pm 1502$ & $29286 \pm 14996$ & $879 \pm 546$ \\
\hline F & $2191 \pm 901$ & $22013 \pm 9073$ & $676 \pm 370$ \\
\hline Média & $2056 \pm 914$ & $20568 \pm 9142$ & $621 \pm 351$ \\
\hline
\end{tabular}

Tabela 17 - Consumo combinado de recursos 
Para calcular o consumo esperado para o conjunto de sessões foi utilizada a seguinte formula:

Consumo $=\underline{\mathrm{NMR}(\mathrm{A}) * \mathrm{NS}(\mathrm{A}) * \mathrm{~T}(\mathrm{~A})+\mathrm{NMR}(\mathrm{B}) * \mathrm{NS}(\mathrm{B}) * \mathrm{~T}(\mathrm{~B})+\mathrm{NMR}(\mathrm{C}) * \mathrm{NS}(\mathrm{C}) * \mathrm{~T}(\mathrm{C})}$

$$
\mathrm{NMR}(\mathrm{A}) * \mathrm{NS}(\mathrm{A})+\mathrm{NMR}(\mathrm{A}) * \mathrm{NS}(\mathrm{B})+\mathrm{NMR}(\mathrm{A}) * \mathrm{NS}(\mathrm{C})
$$

Onde: $\operatorname{NMR}(G)=$ Numero médio de Requisições por Sessão do Grupo G

$$
\begin{aligned}
\text { NS }(G) & =\text { Numero de Sessões para analisadas do grupo } G \\
T(G) & =\text { Tamanho médio da requisição enviada ou recebida do grupo } G
\end{aligned}
$$

NS $(G)$ e $T(G)$ foram parâmetros utilizados para gerar a simulação e valem:

$$
\begin{aligned}
& \text { NS }(A)=900, \operatorname{Tenviado}(A)=1000, \operatorname{Trecebido}(A)=10000 \\
& \text { NS }(B)=1000, \operatorname{Tenviado}(B)=2000, \operatorname{Trecebido}(B)=20000 \\
& N S(C)=800, \operatorname{Tenviado}(C)=4000, \operatorname{Trecebido}(C)=40000
\end{aligned}
$$

Para calcular a $\operatorname{NMR}(G)$ foi utilizado o algoritmo de cálculo do tamanho médio da sessão proposto no artigo de Menasce et al. (1999):

$$
\mathrm{S}=\Sigma \mathrm{Vk}
$$

Onde Vk é o número médio de vistas a página $\mathrm{K}$ e pode ser resolvido através da transformação da matriz de probabilidade em um sistema de equações lineares onde:

$$
\begin{gathered}
\mathrm{V}_{1}=1 \mathrm{e} \\
\mathrm{Vn}=\sum_{k=1}^{p} V_{k} * p_{k, n}
\end{gathered}
$$


Onde p é o número total de páginas e $\mathrm{p}_{\mathrm{k}, \mathrm{n}}$ é a probabilidade de transição da página $\mathrm{k}$ para a página $n$. Assim temos:

\begin{tabular}{|c|c|}
\hline Grupo & Número Médio de Requisições por Sessão \\
\hline A & 10,34 \\
\hline B & 17,00 \\
\hline C & 7,02 \\
\hline
\end{tabular}

Tabela 18 - Número de médio de requisições por sessão para cada grupo NMR

O número médio esperado de requisições por sessão pode ser calculado através da média ponderada do número médio de requisições por grupo:

$$
\mathrm{NMR}=\frac{\mathrm{NS}(\mathrm{A}) * \mathrm{NMR}(\mathrm{A})+\mathrm{NS}(\mathrm{B}) * \mathrm{NMR}(\mathrm{B})+\mathrm{NS}(\mathrm{C}) * \mathrm{NMR}(\mathrm{C})}{\mathrm{NS}(\mathrm{A})+\mathrm{NS}(\mathrm{B})+\mathrm{NS}(\mathrm{C})}=11,82
$$

Desta forma:

Consumo Esperado de Dados Enviados $=2.056$

Consumo Esperado de Dados Recebidos $=20.568$

Calculando-se o erro temos:

\begin{tabular}{|c|c|c|}
\hline & Dados Enviados & Dados Recebidos \\
\hline Esperado & 2.060 bytes & 20.604 bytes \\
\hline Medido & 2.056 bytes & 20.568 bytes \\
\hline Erro & $0,19 \%$ & $0,17 \%$ \\
\hline
\end{tabular}

O Número médio de requisições por sessão NMR pode ser calculado dividindo-se o número total de requisições que foi 31660, pelo total de sessões medidas em 2700.

$$
\mathrm{NMR}=\frac{\mathrm{NR}}{\mathrm{NS}}=\frac{31660}{2700}=11,73 \quad \text { Erro }=\frac{11,73-11,82}{11,82}=0,76 \%
$$




\subsubsection{Analise para o grupo A}

Depois de realizada a analise completa, foi criada uma nova analise e nela inseridas todas as sessões cujo identificador indicasse pertencer ao grupo A. No total foram inclusas 900 sessões conforme esperado. Foi então realizada a análise de probabilidade de transição e o resultado obtido foi:

\begin{tabular}{|c|c|c|c|c|c|c|c|}
\hline P & A & B & C & D & E & F & O \\
\hline A & 0 & 1 & 0 & 0 & 0 & 0 & 0 \\
\hline B & 0.52 & 0 & 0.48 & 0 & 0 & 0 & 0 \\
\hline C & 0 & 0.32 & 0 & 0.32 & 0.36 & 0 & 0 \\
\hline D & 0 & 0 & 0.35 & 0 & 0 & 0.31 & 0.34 \\
\hline E & 0 & 0 & 0.30 & 0 & 0 & 0.33 & 0.37 \\
\hline F & 0 & 0 & 0 & 0 & 0 & 0 & 1 \\
\hline
\end{tabular}

Tabela 19 - Probabilidade de transição para o grupo A

Comparando com a tabela de transição esperada, temos como erro:

$$
\text { Erro }=\frac{\sqrt{\sum(R x y-P x y)^{2}}}{\sqrt{\sum(P x y)^{2}}}=3,90 \%
$$

Como resultado da análise também foi produzida a seguinte tabela com o consumo de recursos:

\begin{tabular}{|c|c|c|c|}
\hline Página & Enviados $(\mathrm{Kb})$ & Recebidos $(\mathrm{Kb})$ & Tempo(ms) \\
\hline A & $997 \pm 114$ & $9975 \pm 1148$ & $303 \pm 104$ \\
\hline B & $1002 \pm 116$ & $9994 \pm 1153$ & $299 \pm 104$ \\
\hline C & $1002 \pm 116$ & $9997 \pm 1143$ & $300 \pm 102$ \\
\hline D & $1005 \pm 111$ & $10001 \pm 1156$ & $304 \pm 105$ \\
\hline E & $1000 \pm 119$ & $10055 \pm 1149$ & $305 \pm 100$ \\
\hline F & $989 \pm 116$ & $1002 \pm 1163$ & $304 \pm 108$ \\
\hline Média & $999 \pm 115$ & $9995 \pm 1150$ & $302 \pm 103$ \\
\hline \multicolumn{4}{|c|}{ Tabela 20 - Consumo de recursos do grupo A }
\end{tabular}


Quanto ao consumo de recursos, é possível calcular o seguinte erro:

\begin{tabular}{|c|c|c|}
\hline & Dados Enviados & Dados Recebidos \\
\hline Esperado & 1.000 bytes & 10.000 bytes \\
\hline Medido & 999 bytes & 9.995 bytes \\
\hline Erro & $0,1 \%$ & $0,05 \%$ \\
\hline
\end{tabular}

Tabela 21 - Erro no Consumo de Recursos do Grupo A

O Número médio de requisições por sessão NMR pode ser calculado dividindo-se o número total de requisições classificadas como sendo do grupo A, que foram 9461, pelo total de sessões do grupo A medidas em 900.

$$
\begin{aligned}
& \mathrm{NMR}(\mathrm{A})=\underline{\mathrm{NR}(\mathrm{A})}=\underline{9641}=10,51 \quad \text { Erro }=\underline{10,51-10,34}=1,66 \% \\
& \text { NS(A) } \quad 900 \quad 10,34
\end{aligned}
$$

\subsubsection{Analise para o grupo B}

A mesma analise realizada para o grupo A foi realizada para o grupo B através da criação de uma nova analise e da inserção todas as sessões cujo identificador indicasse pertencer ao grupo B. No total foram inclusas 1000 sessões conforme esperado. Foi então realizada a análise de probabilidade de transição e o resultado obtido foi:

\begin{tabular}{|c|c|c|c|c|c|c|c|}
\hline $\mathrm{P}$ & $\mathrm{A}$ & $\mathrm{B}$ & $\mathrm{C}$ & $\mathrm{D}$ & $\mathrm{E}$ & $\mathrm{F}$ & $\mathrm{O}$ \\
\hline $\mathrm{A}$ & 0 & 1 & 0 & 0 & 0 & 0 & 0 \\
\hline $\mathrm{B}$ & 0.50 & 0 & 0.50 & 0 & 0 & 0 & 0 \\
\hline $\mathrm{C}$ & 0 & 0.50 & 0 & 0.50 & 0 & 0 & 0 \\
\hline $\mathrm{D}$ & 0 & 0 & 0.48 & 0 & 0 & 0.52 & 0 \\
\hline $\mathrm{E}$ & 0 & 0 & 0 & 0 & 0 & 0 & 0 \\
\hline $\mathrm{F}$ & 0 & 0 & 0 & 0 & 0 & 0 & 1 \\
\hline
\end{tabular}

Tabela 22 - Probabilidade de transição para o grupo A

Como não havia possibilidade de transição para a página $\mathrm{E}$, não foi possível medir nenhuma possibilidade de transição a partir da mesma e por este motivo todos os valores para 
a linha E na tabela estão zerados. Por este motivo, no calculo do Erro esta coluna foi omitida.

Comparando com a tabela de transição esperada, temos como erro:

$$
\text { Erro }=\frac{\sqrt{\sum(R x y-P x y)^{2}}}{\sqrt{\sum(P x y)^{2}}}=0,93 \%
$$

Como resultado da análise também foi produzida a seguinte tabela com o consumo de recursos:

\begin{tabular}{|c|c|c|c|}
\hline Página & Enviados $(\mathrm{Kb})$ & Recebidos(Kb) & Tempo(ms) \\
\hline A & $1998 \pm 228$ & $20038 \pm 2304$ & $607 \pm 211$ \\
\hline B & $2001 \pm 230$ & $20007 \pm 2298$ & $605 \pm 206$ \\
\hline C & $1998 \pm 231$ & $19972 \pm 2323$ & $603 \pm 206$ \\
\hline D & $1997 \pm 232$ & $20058 \pm 2327$ & $606 \pm 204$ \\
\hline E & - & - & - \\
\hline F & $2009 \pm 227$ & $20137 \pm 2286$ & $619 \pm 215$ \\
\hline Média & $2000 \pm 230$ & $20020 \pm 2308$ & $606 \pm 207$ \\
\hline \multicolumn{4}{|c}{ Tabela 23 - Consumo de Recursos do Grupo B }
\end{tabular}

Quanto ao consumo de recursos, é possível calcular o seguinte erro:

\begin{tabular}{|c|c|c|}
\hline & Dados Enviados & Dados Recebidos \\
\hline Esperado & 2.000 bytes & 20.000 bytes \\
\hline Medido & 2.000 bytes & 20.020 bytes \\
\hline Erro & $0,00 \%$ & $0,10 \%$ \\
\hline
\end{tabular}

Tabela 24 - Erro no Consumo de Recursos do Grupo B

O Número médio de requisições por sessão NMR pode ser calculado dividindo-se o número total de requisições classificadas como sendo do grupo B, que foram 16592, pelo total de sessões do grupo B medidas em 1000.

$$
\operatorname{NMR}(\mathrm{A})=\frac{\mathrm{NR}(\mathrm{A})}{\mathrm{NS}(\mathrm{A})}=\frac{16592}{1000}=16,59 \quad \text { Erro }=\frac{16,59-17,00}{17,00}=2,41 \%
$$




\subsubsection{Analise para o grupo C}

Para o grupo $\mathrm{C}$ foram analisadas 800 sessões conforme esperado. Foi então realizada a análise de probabilidade de transição e o resultado obtido foi:

\begin{tabular}{|c|c|c|c|c|c|c|c|}
\hline P & A & B & C & D & E & F & O \\
\hline A & 0 & 1 & 0 & 0 & 0 & 0 & 0 \\
\hline B & 0 & 0 & 1 & 0 & 0 & 0 & 0 \\
\hline C & 0 & 0 & 0 & 0.32 & 0.68 & 0 & 0 \\
\hline D & 0 & 0 & 0.32 & 0 & 0 & 0.68 & 0 \\
\hline E & 0 & 0 & 0.67 & 0 & 0 & 0 & 0.33 \\
\hline F & 0 & 0 & 0 & 0 & 0 & 0 & 1 \\
\hline
\end{tabular}

Tabela 25 - Probabilidade de transição para o grupo C

$$
\text { Erro }=\frac{\sqrt{\sum(R x y-P x y)^{2}}}{\sqrt{\sum(P x y)^{2}}}=1,51 \%
$$

Como resultado da análise também foi produzida a seguinte tabela com o consumo de recursos:

\begin{tabular}{|c|c|c|c|}
\hline Página & Enviados $(\mathrm{Kb})$ & Recebidos(Kb) & Tempo(ms) \\
\hline A & $4013 \pm 473$ & $39983 \pm 4593$ & $1181 \pm 399$ \\
\hline B & $4000 \pm 471$ & $40304 \pm 4707$ & $1126 \pm 403$ \\
\hline C & $4012 \pm 461$ & $39942 \pm 4607$ & $1196 \pm 405$ \\
\hline D & $4002 \pm 453$ & $39677 \pm 4551$ & $1190 \pm 399$ \\
\hline E & $4025 \pm 456$ & $40236 \pm 4639$ & $1206 \pm 409$ \\
\hline F & $3965 \pm 460$ & $39896 \pm 4554$ & $1232 \pm 418$ \\
\hline Média & $4009 \pm 462$ & $40033 \pm 4616$ & $1202 \pm 405$ \\
\hline \multicolumn{4}{|c}{ Tabela 26 - Consumo de Recursos do Grupo C } \\
\hline
\end{tabular}

Quanto ao consumo de recursos, é possível calcular o seguinte erro:

\begin{tabular}{|c|c|c|}
\hline & Dados Enviados & Dados Recebidos \\
\hline Esperado & 4.000 bytes & 40.000 bytes \\
\hline Medido & 4.009 bytes & 40.033 bytes \\
\hline Erro & $0,22 \%$ & $0,08 \%$ \\
\hline
\end{tabular}

Tabela 27 - Erro no Consumo de Recursos do Grupo C 
O Número médio de requisições por sessão NMR pode ser calculado dividindo-se o número total de requisições classificadas como sendo do grupo C, que foram 5607, pelo total de sessões do grupo C medidas em 800.

$$
\begin{aligned}
& \mathrm{NMR}(\mathrm{A})=\underline{\mathrm{NR}(\mathrm{A})}=\underline{5607}=7,01 \quad \text { Erro }=\underline{7,01-7,02}=0,14 \% \\
& \begin{array}{lll}
\mathrm{NS}(\mathrm{A}) & 800 & 7,02
\end{array}
\end{aligned}
$$

\subsubsection{Aplicação da metodologia de análise sobre os dados simulados}

Segundo a metodologia proposta no capitulo 4, são necessários 5 passos.

- Calcular o custo não operacional de um negócio eletrônico

- Segmentar os consumidores em classes,

- Aferir o faturamento para cada uma das classes,

- Calcular o número total de transações realizadas por classe,

- Medir o consumo de recursos de uma das classes.

O primeiro passo, não é aplicável já que a análise é feita sobre uma simulação e não um negócio eletrônico real.

O segundo passo, a segmentação dos consumidores em classes, foi feito no momento da definição da massa de testes. Os consumidores foram divididos em 3 grupos e a identificação do grupo ao qual cada sessão pertence pode ser feito através da análise dos dados passados a cada requisição de cada sessão do grupo.

Para podermos aferir o faturamento médio para cada grupo temos que levar em conta dois fatores: A probabilidade de realização de uma transação, que conforme a definição da massa 
de testes é igual à probabilidade de uma sessão passar pela página $\mathrm{F}$ e o valor médio da transação que também é dado pela definição da massa de testes.

Para calcular a probabilidade de uma sessão passar pela página $F$ foi utilizada a fórmula para o cálculo do número médio de vistas a página proposta no artigo de Menasce et al. (1999). Para calcular Vn deve-se resolver sistema de equações lineares obtido através da transformação da matriz de probabilidade $\left(p_{k, n}\right)$, onde:

$$
\begin{gathered}
\mathrm{V}_{1}=1 \mathrm{e} \\
\mathrm{Vn}=\sum_{k=1}^{p} V_{k} * p_{k, n}
\end{gathered}
$$

Calculando-se $\mathrm{V}_{\mathrm{f}}=\mathrm{V}_{5}$ para todos os grupos temos:

\begin{tabular}{|c|c|}
\hline Grupo & Probabilidade de Transação \\
\hline A & $48,16 \%$ \\
\hline B & $100,00 \%$ \\
\hline C & $50,00 \%$ \\
\hline A+B+C & $66,91 \%$ \\
\hline
\end{tabular}

Tabela 28 - Probabilidade de Realização de Trasação por Grupo

Multiplicando-se a probabilidade de realização de transação $\operatorname{Pt}(\mathrm{G})$ de cada grupo pelo valor definido na massa de testes como valor médio de cada transação do grupo $\operatorname{Vm}(G)$, podemos aferir o valor médio de transação por sessão para cada grupo $\mathrm{Vs}(\mathrm{G})$ :

$$
\mathrm{Vs}(\mathrm{G})=\mathrm{Pt}(\mathrm{G}) * \mathrm{Vm}(\mathrm{G})
$$


Obtendo como Resultado:

\begin{tabular}{|c|c|}
\hline Grupo & Valor Médio \\
\hline A & 48,16 \\
\hline B & 200,00 \\
\hline C & 150,00 \\
\hline A+B+C & 198,18 \\
\hline
\end{tabular}

Tabela 29 - Valor Médio de Transação por Sessão do Grupo

Sendo que para calcular $\mathrm{Vs}(\mathrm{A}+\mathrm{B}+\mathrm{C})$ foi utilizada a formula:

$$
\mathrm{Vs}(\mathrm{A}+\mathrm{B}+\mathrm{C})=\frac{\mathrm{Vs}(\mathrm{A}) * \mathrm{NS}(\mathrm{A})+\mathrm{VS}(\mathrm{B}) * \mathrm{NS}(\mathrm{B})+\mathrm{VS}(\mathrm{C}) * \mathrm{NS}(\mathrm{C})}{\mathrm{Pt}(\mathrm{A}) * \mathrm{NS}(\mathrm{A})+\mathrm{Pt}(\mathrm{B}) * \mathrm{NS}(\mathrm{B})+\mathrm{Pt}(\mathrm{C}) * \mathrm{NS}(\mathrm{C})}
$$

O último passo é medir o consumo de recursos por sessão de cada grupo. Para isso será necessário extrair o consumo médio de recursos por página para cada grupo das tabelas 15 , 19, 22 e 25 e multiplicar pelo número de requisições por sessão medida para cada grupo:

\begin{tabular}{|c|c|c|c|c|}
\hline Grupo & NMR & Dados Enviados & Dados Recebidos & Tempo \\
\hline A & 10,51 & $999 \pm 115$ & $9995 \pm 1150$ & $302 \pm 103$ \\
\hline B & 16,59 & $2000 \pm 230$ & $20020 \pm 2308$ & $606 \pm 207$ \\
\hline C & 7,01 & $4009 \pm 462$ & $40033 \pm 4616$ & $1202 \pm 405$ \\
\hline A+B+C & 11,73 & $2056 \pm 914$ & $20568 \pm 9142$ & $621 \pm 351$ \\
\hline
\end{tabular}

Tabela 30 - Consumo de Recursos por Requisição por Grupo

Para calcular o consumo de recursos por sessão deve-se multiplicar o número de requisições por sessão pela quantidade de recursos consumidos por requisição. A quantidade de dados recebidos e a quantidade de dados enviados podem ser combinadas em uma única medida chamada de dados trafegados: 


\begin{tabular}{|c|c|c|}
\hline Grupo & Dados Trafegados & Tempo \\
\hline A & $115547 \pm 18806$ & $3174 \pm 1082$ \\
\hline B & $365312 \pm 59486$ & $10054 \pm 3434$ \\
\hline C & $308734 \pm 50323$ & $8426 \pm 2859$ \\
\hline A+B+C & $265380 \pm 166828$ & $7284 \pm 4117$ \\
\hline
\end{tabular}

Tabela 30 - Consumo de Recursos por Sessão por Grupo

Para medir a importância do grupo em relação ao total, deve-se calcular o total de dados trafegados, tempo consumido e faturamento de um grupo em relação ao total de dados trafegados, tempo consumido e faturamento de todos os grupos juntos.

\begin{tabular}{|c|c|c|c|c|}
\hline Grupo & Sessões & Dados Trafegados & Tempo & Faturamento \\
\hline A & $33,33 \%$ & $14,52 \%$ & $14,54 \%$ & $11,93 \%$ \\
\hline $\mathrm{B}$ & $37,04 \%$ & $51,00 \%$ & $51,16 \%$ & $55,04 \%$ \\
\hline $\mathrm{C}$ & $29,63 \%$ & $34,48 \%$ & $34,30 \%$ & $33,03 \%$ \\
\hline
\end{tabular}

Tabela 31 - Faturamento e Consumo de Rercursos por Grupo

Por último, para poder comparar os grupos, deve-se obter uma tabela de consumo de recursos e faturamento relativo de cada sessão do grupo em relação ao consumo e faturamento médio para cada sessão independente de grupo:

\begin{tabular}{|c|c|c|c|}
\hline Grupo & Dados Trafegados & Tempo & Faturamento \\
\hline A & $-56,46 \%$ & $-56,43 \%$ & $-75,70 \%$ \\
\hline B & $+37,66 \%$ & $+38,02 \%$ & $+0,92 \%$ \\
\hline C & $+16,37 \%$ & $+15,67 \%$ & $-24,31 \%$ \\
\hline
\end{tabular}

Tabela 32 - Comparação da Sessão média de cada grupo com a Sessão média

Os dados obtidos confirmaram a validade da metodologia de análise, pois permitiram identificar que o grupo B era o mais rentável apesar do tamanho médio de suas sessões ser maior que o tamanho das sessões dos outros grupos. Também permitiu identificar que o grupo 
A era o menos rentável de todos devido a uma baixa probabilidade de realização de transação. O grupo C conforme esperado foi caracterizado pelo consumo e faturamento intermediários.

\subsubsection{Exemplo de interpretação do resultado da análise de negócios}

Caso assumamos que a análise esteja sendo realizada para identificar qual grupo de consumidores é mais rentável para uma loja virtual e sugerir ações para melhorar o desempenho do negócio, as seguintes conclusões seriam válidas:

A partir das tabelas 30 e 31 é possível identificar que o grupo de consumidores mais rentável é o grupo B, pois é responsável por 55,04 \% do faturamento e apenas $51,08 \%$ do consumo de recursos. Porém, ao se comparar uma sessão do grupo B com uma sessão média, é possível identificar um consumo de recursos por sessão 37,84\% acima do consumo médio.

Outra conclusão possível é que o grupo de consumidores menos rentável é o grupo A, pois é responsável por $14,53 \%$ do consumo e por apenas $11,93 \%$ do faturamento. A análise da tabela de probabilidade de transições para este grupo permite afirmar que este grupo possui a menor probabilidade de realização de transição que os outros grupos devido a uma alta probabilidade de navegação de usuários das páginas D e E para a saída (Página O) sem passar pela página de realização de transação (Página F).

Baseado na interpretação dos resultados e no conhecimento das características de comportamento de cada um dos grupos, a seguintes ações poderiam ser sugeridas para melhorar o desempenho dos aspectos de negócio:

- Focar melhor as estratégias de marketing para aumentar a porcentagem de sessões do grupo A que realizam transações.

- Diminuir o consumo de recursos das páginas mais visitadas pelas sessões do grupo B ou melhorar a navegação da loja virtual como um todo para diminuir o consumo de recursos pelo grupo B e dessa forma aumentar a rentabilidade do grupo. 


\section{Conclusões}

Este trabalho propôs uma nova metodologia para a avaliação do comportamento de classes de consumidores e avaliação da importância relativa de cada classe para sistemas de negócios eletrônicos.

Para permitir a avaliação do consumo de recursos de cada uma das classes de consumidores, este trabalho também propôs e implementou uma ferramenta para fazer análises de desempenho voltadas ao consumo de recursos computacionais.

A ferramenta foi validada, pois todos os valores intermediários produzidos pela análise foram próximos aos valores esperados que constavam da massa de testes projetada, visto que a discrepância encontrada na validação dos dados analisados foi sempre pequena.

A analise dos resultados produzidos pela ferramenta permitiu também validar a metodologia de análise proposta. Isto foi possível, pois o resultado da análise coincide com o comportamento esperado de cada uma das classes e também os resultados da análise permitiram sugerir alterações no modelo de negócio e na aplicação de negócio eletrônico para melhorar o desempenho da aplicação.

\subsection{Contribuições}

Uma contribuição deste trabalho é a criação de uma analise intermediária que permite a convergência de duas formas de análises, a de negócio e a de desempenho, que atualmente são realizadas por equipes distintas e em momentos distintos, para otimizar o funcionamento de aplicações de negócio eletrônico. Ao combinar a análise de negócio e de comportamento de consumidores com a quantificação do consumo de recursos por classes de consumidores, esta nova análise permite uma visão mais holística do funcionamento de uma aplicação de negócio eletrônico. 
Outra contribuição deste trabalho é a ferramenta utilizada para medir o consumo de recursos de cada classe de consumidores. Além do produto da aplicação desta ferramenta ser condição sine-qua-non para a realização da análise, o diferencial desta ferramenta em relação às ferramentas implementadas nos trabalhos que serviram de base para esta dissertação é o fato de a ferramenta permitir a identificação de sessões três diferentes formas: explicita, seqüencial e implícita. Tal funcionalidade é resultado da necessidade de uma maior precisão na identificação das sessões, pois a quantificação incorreta do consumo de recursos pode acarretar grandes erros na análise proposta. Enquanto nos demais trabalhos, o erro na identificação da sessão não influencia muito nos resultados.

\subsection{Trabalhos Futuros}

Uma lacuna deixada por este trabalho foi a ausência de testes dobre dados reais. Este ponto foi deixado em aberto, pois os mesmo problemas para obtenção de dados reais descritos por Menasce et al. (1999) também foi encontrado durante a elaboração deste trabalho.

Outra possibilidade de expansão deste trabalho é a realização de análises utilizando as outras formas de identificação de sessões de forma seqüencial e implícita que não foram cobertas pelo presente trabalho. Assim como a comparação do resultado de análises executadas com diferentes formas de identificação sobre os mesmos dados. 


\section{LISTA DE REFERÊNCIAS}

ARLITT, M., WILLIAMSON, C. Web Server Workload Characterization. Proceedings of the 1996 SIGMETRICS Conference on Measurement of Computer Systems, 1996.

BANERJEE, A., GHOSH, J. Concept Based Clustering of Clickstream Data. Proceedings of the 3rd International Conference on Information Technology, p.145-150, 2000.

BERNERS-LEE, T. Information Management: A Proposal, Mar 1989, disponível em: <http://www.w3.org/History/1989/proposal.html>. Acesso em: Jul.2005.

BORGES, J., LEVENE, M. Data mining of user navigation patterns. Lecture Notes in Artificial Intelligence, p.92-111, 2000.

CHANG, H., ZHANG, F. Research and development in Web usage mining system-key issues and proposed solutions: a survey. Proceedings of the International Conference on Machine Learning and Cybernetics, v.02, p.986-990, 2002.

CHEN, Z., FOWLER, R., FU, A., WANG, C. Linear and Sublinear Time Algorithms for Mining Frequent Traversal Path Patterns From Very Large Web Logs. Proceedings of the Seventh International Database Engineering and Applications Symposium, 2003.

CHEN, H., MOHAPATRA, P., Session-Based Overload Control in QoS-Aware Web Servers. Proceedings of IEEE INFOCOM ,2002.

CHI, E., ROSIEN, A., HEER, J. LumberJack: Intelligent Discovery and Analysis of Web User Traffic Composition. The Proceedings of the ACMSIGKDD Workshop on Web Mining for Usage Patterns and User Profiles, 2002.

FENSTERMACHER, K., GINSBURG, M. Mining Client-Side Activity for

Personalization. The Proceedings of the 4th IEEE Int'l Workshop on Advanced Issues of ECommerce and Web-Based Information Systems, 2002.

MAH, T., LI, W. Visually Mining Web User Click Paths. IEEE International Conference on Data Mining, p.771-774, 2002. 
MENASCÉ, D., ALMEIDA, V., FONSECA, R., MENDES, M. A Methodology for

Workload Characterization of E-commerce Sites. Proceedings of the ACM Conference in Eletronic Commerce, p.119-129, 1999.

MENASCÉ, D., ALMEIDA, V., FONSECA, R., RIEDI, R., RIBEIRO, F., MEIRA JR., W. In Search of Invariants for E-Business Workloads. Proceedings of the ACM Conference in Eletronic Commerce, 2000.

MENASCÉ, D., A Reference Model for Designing an E-Commerce Curriculum. IEEE Concurrency, v.8, n.1, p.82-85, 2000.

MENASCÉ, D., ALMEIDA, V., ABRAHAO, B., RIBEIRO, F., BARBARA, D., Fractal Characterization of Web Workloads. Web Engineering track of the Eleventh International World Wide Web Conference, 2002

OHMORI, T., TSUTATANI, Y., HOSHI, M. A novel datacube model supporting interactive web-log mining. Proceedings of the First International Symposium on Cyber Worlds, p.419-427, 2002.

PABARSKAITE, Z. Implementing Advanced Cleaning and End-User interpretability Technologies in Web Log Mining. International Conference of Information Technologies Interfaces, p.109-113, 2002.

PALIOURAS, G., PAPATHEODOROU, C., KARKALETSIS, V., SPYROPOULOS, C.D., TZITZIRAS, P. From Web Usage Statistics to Web Usage Analysis. Proceedings of the IEEE Conference on Systems Man and Cybernetics, p.159-164, 1999.

PETEROVIC, O., KITTL, C., TEKSTEN, R.D., L. Developing Business Models for eBusiness. International Conference on Electronic Commerce, Viena, 2001.

THEUSINGER, C., HUBER, K. Analyzing the footsteps of your customers - A case study by ASK net and SAS Institute GmbH. ACM Workshop on Web Mining for E-Commerce Challenges and Opportunities, 2000.

THE INTENET ENGINEERING TASK FORCE (IETF), RCF 1 - Host Sofwtare, Abr 1969, disponível em: <http://www.ietf.org/rfc/rfc1.txt>. Acesso em: Jul.2005. 
THE INTENET ENGINEERING TASK FORCE (IETF), RCF 114 - A File Transfer

Protocol, Abr 1971, disponível em: <http://www.ietf.org/rfc/rfc114.txt>. Acesso em: Jul.2005.

THE INTENET ENGINEERING TASK FORCE (IETF), RCF 137 - Telnet Protocol, Abr 1971, disponível em: <http://www.ietf.org/rfc/rfc97.txt>. Acesso em: Jul. 2005.

THE INTENET ENGINEERING TASK FORCE (IETF), RCF 196 - A Mailbox Protocol, Jul 1971, disponível em: <http://www.ietf.org/rfc/rfc114.txt>. Acesso em: Jul. 2005.

THE INTENET ENGINEERING TASK FORCE (IETF), RCF 760 - Internet Protocol, Jan 1980, disponível em: <http://www.ietf.org/rfc/rfc760.txt>. Acesso em: Jul. 2005.

THE INTENET ENGINEERING TASK FORCE (IETF), RCF 761 - Transmission Control Protocol, Jan 1980, disponível em: <http://www.ietf.org/rfc/rfc761.txt>. Acesso em: Jul. 2005 .

THE INTENET ENGINEERING TASK FORCE (IETF), RCF 1866 - Hypertext Markup Language - 2.0, Nov 1995, disponível em: <http://www.ietf.org/rfc/rfc1866.txt>. Acesso em: Jul. 2005.

THE INTENET ENGINEERING TASK FORCE (IETF), RCF 1945 - Hypertext Transfer Protocol -- HTTP/1.0, Mai 1996, disponível em: <http://www.ietf.org/rfc/rfc1945.txt>. Acesso em: Jul. 2005.

THE INTENET ENGINEERING TASK FORCE (IETF), RCF 2109 - HTTP State Management Mechanism, Fev 1997, disponível em: <http://www.ietf.org/rfc/rfc2109.txt>. Acesso em: Jul. 2005.

THE INTENET ENGINEERING TASK FORCE (IETF), RCF 2616 - Hypertext Transfer Protocol -- HTTP/1.1, Jun 1999, disponível em: <http://www.ietf.org/rfc/rfc2616.txt>. Acesso em: Jul. 2005.

THE INTENET ENGINEERING TASK FORCE (IETF), RCF 2818 - HTTP over TLS, Mai 2000, disponível em: <http://www.ietf.org/rfc/rfc2818.txt>. Acesso em: Jul. 2005. 
THE INTENET ENGINEERING TASK FORCE (IETF), Extended Log File Format W3C -- Working Draft, Mar 1996, disponível em: <http://www.w3.org/TR/WD-logfile>. Acesso em: Out. 2006.

TIMMERS, P. Models for Electronic Markets. Electronic Markets, n.08, p.03-08, 1998.

TOOLAN, F., KUSMERICK, N. Mining Web Logs for Personalized Site Maps.

Proceedings of the Third International Conference on Web Information Systems Engineering, 2002.

WOON, Y., NG, W., LIM, E. Online and Incremental Mining of Separately-Grouped Web Access Logs. Proceedings of the 3rd International Conference on Web Information Systems Engineering, 2002.

WORLD WIDE WEB CONSORTIUM (W3C), The Platform for Privacy Preferences 1.0 (P3P1.0) Specification, Abr 2002, disponível em: < http://www.w3.org/TR/2002/REC-P3P20020416/>. Acesso em: Jul. 2005.

XING, D., SHEN, J. Low state-space complexity and high coverage Markov browsing forecast. Proceedings of the International Conference on Machine Learning and Cybernetics, v.02, p.1093-1097, 2002.

ZHANG, H., YANG, Q., SU, Z. WhatNext: A Prediction System for Web Requests using N-gram Sequence Models. International Conference on Web Information Systems Engineering, p.214-221, 2000. 